Pontifícia Universidade C Católica

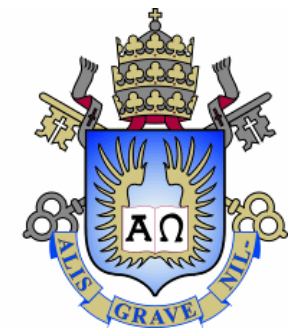

David Eduardo López Pantoja

O valor da flexibilidade de produção: uma aplicação regional no setor Sucro-alcooleiro Brasileiro

Dissertação de Mestrado

Dissertação apresentada como requisito parcial para obtenção do grau de Mestre pelo Programa de PósGraduação em Engenharia de Produção do Departamento de Engenharia Industrial da PUC-Rio.

Orientador: Prof. Carlos Patrício Samanez

Rio de Janeiro

Setembro de 2014 


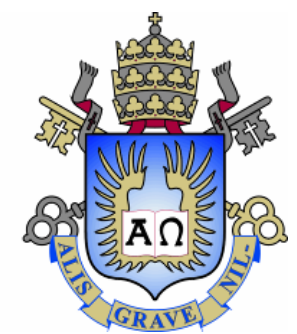

David Eduardo López Pantoja

\section{O valor da flexibilidade de produção: uma aplicação regional no setor Sucro-alcooleiro Brasileiro}

Dissertação apresentada como requisito parcial para obtenção do grau de Mestre pelo Programa de PósGraduação em Engenharia de Produção do Departamento de Engenharia Industrial da PUC-Rio. Aprovada pela Comissão Examinadora abaixo assinada.

Prof. Carlos Patrício Samanez

Orientador

Departamento de Engenharia Industrial - PUC-Rio

Prof. Fernando Antônio Lucena Aiube Departamento de Engenharia Industrial - PUC-Rio

Prof. Calos Alberto Gonçalves da Silva Departamento de Economia - UERJ

Prof. José Eugenio Leal Coordenador Setorial do Centro Técnico Científico - PUC-Rio 
Todos os direitos reservados. É proibida a reprodução total ou parcial do trabalho sem autorização da universidade, do autor e do orientador.

David Eduardo López Pantoja

Graduou-se em Engenharia Eletrônica pela Universidade de Narino (Pasto - Colômbia) no ano 2011.

Ficha Catalográfica

López Pantoja, David Eduardo

O valor da flexibilidade de produção: uma aplicação regional no setor Sucro-alcooleiro Brasileiro / David Eduardo López Pantoja ; orientador: Carlos Patrício Samanez. - 2014.

90 f. : il. (color.) ; $30 \mathrm{~cm}$

Dissertação (mestrado)-Pontifícia Universidade Católica do Rio de Janeiro, Departamento de Engenharia Industrial, 2014.

Inclui bibliografia

1. Engenharia Industrial - Teses. 2. Commodities. 3. Opções reais (OR). 4. Flexibilidade. 5. Árvore bivariável. 6. Árvore recombinante. 7. Matlab. I. Samanez, Carlos Patrício. II. Pontifícia Universidade Católica do Rio de Janeiro. Departamento de Engenharia Industrial. III. Título. 
Para mis padres. 


\section{Agradecimentos}

Primeiramente, a Deus por me amparar nos momentos difíceis, me dar força interior para superar os obstáculos, mostrar os caminhos nas horas incertas e me suprir em todas as minhas necessidades.

Ao meu orientador Professor Carlos Patrício Samanez pela colaboração, paciência e seus conhecimentos repassados durante todo o desenvolvimento deste trabalho.

A todos os professores e funcionários do Departamento de Engenharia Industrial da PUC-Rio pelos ensinamentos e pela ajuda.

Aos meus amigos e familiares, em especial as minhas mães, que sempre têm estado orando a Deus por mim, também a Angélica pela sua ajuda.

Especial agradecimento, ao meu presente do céu, minha filhota Valentina Lopez, por me acordar sempre com um beijo para ir à PUC.

Por fim, meu agradecimento ao CNPq, CAPES e à PUC-Rio, pelos auxílios concedidos, sem os quais esta dissertação não seria realizada. 


\section{Resumo}

Pantoja, David Eduardo Lopez; Samanez, Carlos Patrício. O valor da flexibilidade de produção: uma aplicação regional no setor Sucroalcooleiro Brasileiro. Rio de Janeiro, 2014. 90p. Dissertação de Mestrado Departamento de Engenharia Industrial, Pontifícia Universidade Católica do Rio de Janeiro.

As novas tecnologias no setor sucroalcooleiro permitem flexibilidade no que diz respeito a produzir etanol ou açúcar, podendo em qualquer momento concentrar a produção na commodity que gere maior rentabilidade. Ao longo da pesquisa foi identificado que o Imposto sobre Operações relativas à Circulação de Mercadorias e Prestação de Serviços de Transporte Interestadual e Intermunicipal e de Comunicação (ICMS), gera uma variação importante no preço destas duas commodities nas diferentes regiões do Brasil. Como exemplo, podemos citar o fato de São Paulo em 2013 ter um ICMS de 12\%, enquanto no estado do Pará foi observada uma taxa de $30 \%$ para a mesma data. Neste estudo trabalha-se com duas regiões do Brasil, a sudeste representada pelo estado de São Paulo e a região Nordeste representada pelos estados de Alagoas e Pernambuco. Para conseguir avaliar a flexibilidade gerencial, nesta dissertação é utilizada a teoria das Opções Reais $(O R)$ que enfatiza o valor da flexibilidade que o tomador de decisões possui ao possibilitar a alteração dos rumos de um projeto especialmente em condições de incerteza. Neste estudo foram feitos testes que determinaram que os preços das commodities seguem um Movimento de Reversão à Média Aritmética, com o qual determinou-se os parâmetros que descrevem este tipo de comportamento. Utilizou-se as abordagens de árvores recombinantes de Nelson e Ramaswamy (1990) e de arvores bivariáveis de Hahn e Dyer (2011) é construído para estas teorias um algoritmo programado em Matlab. Esta pesquisa revela que para as duas regiões estudadas a flexibilidade de produção gera rentabilidade maior que nas usinas cuja produção não é flexível, além disso mostra que a capacidade de produção maior e um imposto ICMS menor, proporcionam às empresas flexíveis da região sudeste um maior valor quando comparadas com as usinas da região nordeste. 


\section{Palavras-chave}

Opções Reais; setor sucro-alcooleiro; modelos estocásticos. 


\section{Abstract}

Pantoja, David Eduardo Lopez; Samanez, Carlos Patrício (advisor). The production flexibility value: a regional application in the brasilian ethanol-sugar sector. Rio de Janeiro, 2014.90p. MSc. Dissertation Departamento de Engenheira Industrial, Pontifical Universidade Católica do Rio de Janeiro.

New technologies in the Sugar-Alcohol sector allow flexibility with regard to produce ethanol or sugar, it may at any time concentrate production in the commodity that generates higher benefits. During the research, it was identified that tax over operations related to Circulation of Goods and Supply of Services of Interstate and Intermunicipal Transportation and Communication (ICMS) generates a significant variation in the price of these two commodities in different regions of Brazil. As an example, we can mention the fact that Sao Paulo in 2013 had a ICMS of $12 \%$, while in the state of Pará a rate of $30 \%$ was observed for the same date. In this study we work with two regions of Brazil, the southeast region represented by the state of São Paulo and the Northeast region represented by the states of Alagoas and Pernambuco. To be able to assess the managerial flexibility, this dissertation is to the theory of real options (OR) that emphasizes the value of flexibility that the decision maker has to enable the change of the direction of a project especially under conditions of uncertainty. This study made tests that determined that commodity prices follow a Reversal Movement to the Arithmetic Mean, with which it was determined the parameters that describe this behavior. We used the approach of recombinant tree Nelson and Ramaswamy (1990) and Hahn bivariate trees and Dyer (2011) is constructed for these theories an algorithm programmed in Matlab. This research reveals that for both regions studied the production flexibility generates higher profitability than in plants whose production is not flexible, also shows that the increased production capacity and a smaller ICMS tax, provide flexible companies from the Southeast greater value when compared with the plants in the northeastern 


\section{Keywords}

Real Options; ethanol-sugar sector; stochastic models. 


\section{Sumário}

1. Introdução 15

$\begin{array}{ll}\text { 1.1. Objetivos } & 17\end{array}$

$\begin{array}{ll}\text { 1.2. } & \text { Estrutura do Trabalho } \\ \end{array}$

2. Revisão de Literatura 19

2.1. A industrialização do álcool no Brasil 19

2.2. Brasil e a cana de açúcar 23

2.2.1. Área cultivada no Brasil com Cana de Açúcar 24

2.3. Preços do etanol 26

2.3.1. Análise Tributária do etanol no Brasil 26

2.3.2. Análise da Paridade de preços 30

2.4. Opções Reais 31

2.4.1. Opções Reais e Opções Financeiras 34

2.4.2. Tipo de Opções Reais 35

2.4.2.1. Opção de troca 36

3. Processos Estocásticos 38

3.1. Processo de Markov 38

3.2. Processo de Wiener 39

3.3. Processo de Itô 40

3.4. Lema de Itô 41

3.5. Movimento Browniano com drift 42

3.6. Movimento Geométrico Browniano (MGB) 42

3.6.1. Discretização do MGB 44

3.6.2. Estimativa dos parâmetros 44

3.7. Processo de Reversão à Média 45

3.7.1. Discretização do Modelo de Reversão à Média 47

3.7.2. Estimativa dos parâmetros 47

3.8. Determinação do processo 49 
4. Método Binomial 53

4.1. Árvore Binomial Recombinante 54

4.2. Modelagem bivariavel do processo de Reversão à Média 57

5. Avaliação da opção de flexibilidade no setor sucro-alcooleiro 60

5.1. Determinação dos parâmetros dos processos por meio da regressão lineal 63

5.2. Determinação do processo 65

5.3. Parâmetros estocásticos para o etanol e o açúcar 68

5.4. Metodologia de avaliação 69

5.4.1. Avaliação das árvores recombinantes $\quad 74$

5.4.2. Avaliação das árvores bivariáveis 78

6. Conclusões 81

7. Referências Bibliográficas 83

8. Anexos 86

8.1. Demonstração das propriedades estatísticas do MRM 86

8.2. Probabilidades condicionais $\mathrm{P}_{\mathrm{u} \mid \mathrm{d}}$ e $\mathrm{P}_{\mathrm{d} \mid \mathrm{d}} \quad 87$

8.3. Valor presente dos fluxos de caixa das árvores recombinantes para as commodities na região Nordeste e Sudeste 


\section{Lista de tabelas}

Tabela 1 - Regiões plantadas de cana de açúcar no Brasil para o ano 2012

Tabela 2 - Alíquota ICMS nas regiões do Brasil para o ano $2013 \quad 29$

Tabela 3 - Analogia entre opções reais e financeiras 35

Tabela 4 - Valores críticos para o Teste da Raiz Unitária de Dickey e Fuller $\left(\tau^{*}\right)$

Tabela 5 - Parâmetros de regressão dos preços deflacionados do etanol e do açúcar para a região Nordeste e Sudeste

Tabela 6 - Teste da Raiz Unitária de Dickey e Fuller

Tabela 7 - Parâmetros estocásticos do etanol e do açúcar para as regiões do Nordeste e Sudeste

Tabela 8 - Resumo das equações para determinar os parâmetros num MRM

Tabela 9 - Produção e destinação de cana de açúcar nas regiões Nordeste e Sudeste

Tabela 10 - Número de usinas nas regiões do Nordeste e Sudeste

Tabela 11 - Índices de produção do açúcar e do etanol no Brasil 71

Tabela 12 - Proporção da produção do açúcar e do etanol para a região Nordeste e Sudeste

Tabela 13 - ICMS para a região Nordeste e Sudeste 73

Tabela 14 - Resumo dos parâmetros do trabalho 74

Tabela 15 - Valor presentes (VP) dos fluxos de caixa das árvores recombinantes

Tabela 16 - Resultados dos valores presentes dos fluxos de caixa, das árvores binômias e bivariaveis e o valor da opção de troca 


\section{Lista de figuras}

Figura 1 - Mapa da produção de cana de açúcar no Brasil 25

Figura 2 - Efeito do ICMS sobre o consumo do etanol 28

Figura 3 - Capacidade autorizada por estado (milhões de litros/dia)

Figura 4 - Economia vantajosa do etanol com paridade do $70 \%$

Figura 5 - $\quad$ Paridade do preço do etanol hidratado por capital 31

Figura 6 - Paridade do preço do etanol hidratado por regiões 31

Figura 7 - Incerteza e flexibilidade 33

Figura 8 - Tipo de Opções Reais 35

Figura 9 - Opção troca de insumo input-output, exemplo do carro Flex-Fuel

Figura 10 - Opção troca de produto input-output, exemplo usina Flex

Figura 11 - Àrvore binomial para um intervalo $\Delta t$

Figura 12 - Nó de ramificação binomial para os preços 56 $(X=\operatorname{Ln}(x))$

Figura 13 - Árvore bivariável (quadrinômial) 57

Figura 14 - Divisão, marginal condicional do quadrinômial $\quad 59$

Figura 15 - Preços do etanol e do açúcar para a região 61 Nordeste

Figura 16 - Preços do etanol e do açúcar deflacionados para a região Nordeste pelo IGP-DI, Base: Jul 2014

Figura 17 - Preços do etanol e do açúcar para a região Sudeste 62

Figura 18 - Preços etanol e açúcar deflacionados para a região Sudeste pelo IGP-DI, Base: Jul 2014

Figura 19 - Regressão para o açúcar na região Sudeste 63

Figura 20 - Regressão para o etanol na região Sudeste 64

Figura 21 - Regressão para o açúcar na região Nordeste 64 
Figura 22 - Regressão para o etanol na região Nordeste

Figura 23 - Teste de Razão da Variância dos preços deflacionados do açúcar e do etanol nas regiões do Nordeste e Sudeste

Figura 24 - Teste de Razão da Variância dos In (preços) deflacionados do açúcar e do etanol nas regiões Nordeste e Sudeste

Figura 25 - Árvore recombinante do preço do açucar na região Nordeste 75

Figura 26 - Probabilidades de Martingale censuradas do açúcar na região Nordeste

Figura 27 - Valor presente dos fluxos do açúcar na região Nordeste

Figura 28 - Valor presente dos fluxos (VP) de caixa para a árvore quadrinomial bivariavel para região Nordeste 78

Figura 29 - Valor presente dos fluxos (VP) de caixa para a árvore quadrinomial bivariavel para região Sudeste 79

Figura 30 - Valor presente dos fluxos (VP) do etanol para região Nordeste 88

Figura 31 - Valor presente dos fluxos (VP) do açúcar para região Sudeste 88

Figura 32 - Valor presente dos fluxos (VP) do etanol para região Sudeste 
1.

Introdução

A produção de cana de açúcar no Brasil, que na década passada era quase que exclusivamente destinada somente à produção de açúcar, agora destina-se também à produção de etanol, o que permitiu o desenvolvimento de uma forte indústria bio-combustível no país.

A produção e o uso do etanol no Brasil são o melhor exemplo (no mundo) da introdução de energia renovável com uma grande escala de produção. Esse processo exigiu extenso desenvolvimento tecnológico (geração, importação, adaptação e transferência de tecnologias) na produção (agrícola e industrial), na logística e nos usos finais, nos últimos trinta anos. Também foi importante uma legislação específica, subsídios iniciais e permanente negociação entre os principais setores envolvidos: os produtores de etanol, os fabricantes de veículos, os setores reguladores governamentais e a indústria do petróleo, em um denso processo de aprendizagem. Esses fatos permitiram desenvolver uma indústria forte, que junto com as usinas flexíveis, permitem ao empresário decidir a commodity a produzir, neste caso açúcar ou etanol, mudando assim a forma de decisão do produtor.

Para a avaliação de investimentos a forma clássica é o Fluxo de Caixa Descontado (FCD), no qual se estima o valor esperado dos futuros fluxos de caixa e usa-se uma taxa de desconto ajustada ao risco do projeto para trazer para valor presente esses fluxos de caixa esperados, os indicadores gerados por este método, tais como o Valor Presente Líquido (VPL), não conseguem avaliar a flexibilidade gerencial nem se adaptar às novas informações. No entanto, no mundo real a incerteza faz com que os valores estejam sempre flutuando dependentes de diferentes fatores tais como: demanda, oferta e diferentes tipos de taxas e impostos.

Um dos fatores tributários que geram grandes diferenças nos preços do etanol e do açúcar nas diferentes regiões do Brasil é o Imposto sobre Operações relativas à Circulação de Mercadorias e Prestação de Serviços de Transporte 
Interestadual e Intermunicipal e de Comunicação (ICMS), pois é um imposto estadual, ou seja, somente o governo federal e do Distrito Federal têm competência para instituí-lo. Por exemplo, segundo a ÚNICA ${ }^{1}$, São Paulo, em 2013, tinha um ICMS de $12 \%$, enquanto que o Pará tinha $30 \%$ para a mesma data.

Para a análise de investimentos em ativos reais em condições de incerteza e flexibilidades gerenciais tem-se consolidado uma metodologia relativamente nova, a teoria das Opções Reais (OR). Esta enfatiza o valor da flexibilidade que o tomador de decisão tem em alterar os rumos de um projeto à medida que a incerteza vai se revelando. As Opções Reais são definidas por Dias (2014) como o direito, mas não a obrigação, que um agente possui quando toma decisões sobre um ativo real.

As OR possuem importância principalmente quando a volatilidade dos preços se torna importante na determinação do investimento, sua imprevisibilidade, ou melhor, sua incerteza de mercado. $\mathrm{O}$ fato de o investimento e o timing serem irreversíveis são fatores capturados pelas OR, características essas que não são capturadas pelo método convencional do FCD.

Com esta nova ferramenta o gerente tem a possibilidade de mensurar o valor decorrente da flexibilidade de adiar, contrair, expandir, fazer paradas temporárias ou abandonar o projeto. Permite também analisar o valor implícito na possibilidade de troca de insumos ou produtos, chamada Opção de Troca.

Nesta dissertação será calculado o valor da opção de trocar a produção entre açúcar (com etanol como subproduto) e etanol, assim como identificar quanto essa flexibilidade agrega economicamente ao projeto.

A modelagem discreta por árvore binomial recombinante desenvolvida por Cox, Ross e Rubinstein(1979) para avaliar OR, teve um grande sucesso por generalizar o modelo de Black, Scholes e Merton (1973), modelo aplicado a fatores de risco que seguem um Movimento Geométrico Browniano (MGB). Já Boyle (1988) introduziu o conceito da árvore bivariável, que foi seguido por Nelson e Ramaswamy (1990) que apresentaram um método de sequência binomial em um modelo abrangente que pode ser utilizado para processos estocásticos que seguem tanto um MGB quanto um MRM. Hahn e Dyer(2011) modelaram processos com dois fatores em tempo discreto através de árvores

\footnotetext{
${ }^{1}$ União da Indústria de Cana-de-Açúcar (UNICA) é a maior organização representativa do setor de açúcar e bioetanol do Brasil.
} 
binomiais bivariáveis, utilizando um formato de árvores bidimensional. para os mesmos problemas analisados por Schwartz e Smith (2000).

No presente estudo assume-se que a fonte principal que gera a incerteza sobre o fluxo de caixa é o preço das commodities. Dado este fato, e a partir das series históricas dos preços, os parâmetros do processo estocástico foram determinados. O apreçamento da opção foi realizado seguindo as metodologias desenvolvidas por Nelson e Ramaswamy(1999) e Hahn \& Dyer (2011). Foi assumindo um processo de Reversão à Média Aritmético (MRM) de OrnsteinUhlenbeck (O-U).

\section{1.}

\section{Objetivos}

A presente dissertação tem por finalidade avaliar o valor da opção de troca na indústria sucro-alcooleira. Por tanto, são avaliadas duas usinas que somente produzem açúcar ou etanol, e posteriormente esses valores são comparados aos de uma usina flex que pode trocar sua produção entre as duas commodities (açúcar e etanol). A análise é efetuada para as regiões Sudeste e Nordeste do Brasil.

Após efetuada uma análise comparativa de melhor ajustamento ao comportamento das séries históricas de preços, entre o MGB e o MRM, aplicou-se a abordagem binomial e bivariável para a avaliação das opções e da usina Flex, respectivamente.

\section{2.}

\section{Estrutura do Trabalho}

O presente estudo divide-se em oito capítulos. No capítulo 1 se faz uma breve introdução acerca da contextualização da pesquisa, bem como o objetivo do trabalho. No capítulo 2 é feita uma revisão bibliográfica, onde se trata o tema da indústria do álcool e da cana de açúcar no Brasil, além de uma apresentação das Opções Reais. No capítulo 3 é introduzida a teoria de processos estocásticos, onde se tratam temas tais como, processo de Markov processos de Wiener, lema de Itô, MRM e MGB, além de dois testes para determinação do processo estocástico de melhor ajuste. No capítulo 4, detalha-se os processos binomial, binomial recombinante, e a modelagem bivariável de Processo de Reversão à Média. No capítulo 5, é aplicada a teoria para o cálculo do valor da opção de troca entre o 
etanol e a açúcar. O capitulo 6 apresenta as conclusões mais relevantes da pesquisa. Finalmente, no capitulo 7 e 8 , encontra-se as referências bibliográficas e anexos do estudo. 


\section{2.}

\section{Revisão de literatura}

A produção e o uso do etanol no Brasil são hoje o melhor exemplo (no mundo) da introdução de energia renovável em grande escala de produção. Partindo da produção estabelecida de açúcar, um processo completo de integração das produções de derivados da indústria açucareira foi obtido nas usinas, com grande flexibilidade nas unidades produtoras, as perdas no processo foram reduzidas e houve melhoria na qualidade do açúcar.

Esse processo, no entanto, exigiu extenso desenvolvimento tecnológico (geração, importação, adaptação e transferência de tecnologias) na produção (agrícola e industrial), na logística e nos usos finais, nos últimos trinta anos. Também foi importante uma legislação específica, subsídios iniciais e permanente negociação entre os principais setores envolvidos: os produtores de etanol, os fabricantes de veículos, os setores reguladores governamentais e a indústria do petróleo, em um intenso processo de aprendizagem.

A seguir, serão abordados temas referentes à indústria produtora de cana de açúcar e álcool no Brasil, bem como uma breve abordagem de preços e análise tributária dessas commodities, ao fim, destaca-se a teoria de Opções Reais.

\section{1.}

\section{A industrialização do álcool no Brasil}

Os primeiros usos do etanol como combustível no Brasil ocorreram por volta do final dos anos 20 do século passado, quando a Usina Serra Grande Alagoas - USGA, localizada no município de São José da Laje, produziu o combustível pela primeira vez. Também o Instituto Nacional de Tecnologia produziu álcool para a propulsão de automóveis na década de 20. Em 1931, a mistura de 5\% de álcool à gasolina foi tornada obrigatória por lei, a fim de drenar os excedentes de produção da indústria açucareira, cuja porcentagem foi sendo gradativamente aumentada. Nos anos seguintes, já durante a Segunda Guerra Mundial, milhares de automóveis rodavam com álcool nos Estados de 
Pernambuco e de Minas Gerais, derivado da cana de açúcar e da mandioca, respectivamente. No entanto, a produção foi incipiente e não chegou a fazer concorrência com a gasolina já normalmente utilizada como combustível.

Ademais, na medida em que os problemas gerados pela recessão econômica foram diminuindo, os preços do petróleo e seus derivados começaram também a ceder, o que acabou por inviabilizar a continuidade da produção do etanol à época.

Posteriormente, na década de 1970, com o desencadeamento das duas crises do petróleo e a supervalorização do barril, onde em 1973, o preço barril passou de US\$ 2,90 para US\$11,95, aliaram-se à crise, o aumento do consumo interno de gasolina e da dívida externa, o risco de desabastecimento, a poluição ambiental e a dependência de países produtores do combustível fóssil. O governo Brasileiro priorizou investimentos direcionados à produção de cana de açúcar, de etanol (álcool) e de automóveis movidos a etanol, inclusive com ações que obrigassem todos os postos de gasolina no Brasil a comercializarem etanol, esse fato levou a criação do primeiro veículo movido a etanol.

PROALCOOL. O Programa Nacional do álcool, o Proálcool, foi instituído o 14 de novembro de 1975 através do decreto $\mathrm{n}^{\circ} 76.593$ do governo federal e estendeu-se até 1979, e teve como objetivo centralizar esforços na produção de álcool etílico anidro carburante (AEAC), a partir da cana de açúcar, para ser usado na mistura à gasolina em motores do ciclo $\mathrm{Otto}^{2}$, na proporção de $20 \%$. De acordo com o programa, a produção do álcool oriundo da cana-de-açúcar, da mandioca ou de qualquer outro insumo deveria ser incentivada através da expansão da oferta de matérias-primas, com especial ênfase no aumento da produção agrícola, da modernização e ampliação das destilarias existentes e da instalação de novas unidades produtoras, anexas a usinas ou autônomas, e de unidades armazenadoras.

Lima et. al. (2013) mencionam que o programa Proálcool representa o marco na evolução do etanol no mercado brasileiro, a qual caracterizou o mercado demandante, e foi dividida em três etapas: a primeira se inicia em 1975 e termina em 1979, decorrente da elevação nos preços dos barris de petróleo; a segunda etapa, de 1980 a 1990, registra o auge do Proálcool; a terceira etapa estende-se de 1991 a 2003, e apresenta a estagnação do programa na década de noventa, conjuntamente com outra tentativa de reativação do Proálcool, em 1996, porém

\footnotetext{
${ }^{2}$ Os motores de combustão interna utilizam os ciclos de Diesel e Otto, sendo que no de Otto é possível usar gasolina ou etanol como carburante.
} 
não se sucedendo e encerrando-se então com a desregulamentação do setor sucroenergético.

i) Primeira etapa (1975 a 1979): Esta etapa inicial, segundo Santos (1993) teve dois problemas: o preço pago a os produtores e a questão da estocagem do combustível. Lima et. al. (2013) destaca que o primeiro problema tem como solução o apoio intervencionista por parte do governo (representado pela estatal - Petrobrás), subsidiando os fretes de etanol, o que já não ocorre mais no setor; e com relação a estocagem do etanol, surge outro problema relacionado ao Proálcool: nem os usineiros, nem o Instituto do Açúcar e do Álcool (IAA), nem o conselho Nacional do Petróleo (CNP) assumiram a reponsabilidade de estocar, distribuir e comercializar até o momento em que foi atribuída ás distribuidoras a responsabilidade de adquirir o etanol diretamente das usinas, conforme as cotas fixadas pelo Concelho Nacional do Petróleo e transportá-lo para os centros de mistura e refinarias. Ou seja, nesse instante, constituiu-se a base secundária do mercado de combustível etanol.

ii) Segunda etapa (1980 a 1990): foi instituído pelo decreto-lei de $n^{\circ}$ 83.700 do Governo Federal, em 5 de julho de 1979, com a produção de álcool etílico hidratado combustível, (AEHC), que na atualidade é denominado etanol etílico hidratado carburante (EEHC), o qual foi utilizado para o recém lançado Carro a Álcool. Aqueles automóveis com motores ciclo Otto que foram modificados para receber $100 \%$ de etanol hidratado. Nesta segunda etapa segundo Melo; Fonseca (1981, p. 58) o que se procurava era a aderência ao programa pela indústria automobilística, a qual foi atingida em parte pela guerra entre Irã e Iraque, que em setembro de 1980, cortou 50\% das importações diárias de petróleo do Brasil o que incentivou a venda de carros movidos a álcool ou etanol.

Por outro lado seguindo com os acontecimentos da época Lima et. al. (2013) ressaltam que os veículos daquela época movidos a etanol hidratado foram produzidos a um ritmo acelerado o qual levou a um mau funcionamento nas baixas temperaturas, resultando no desenvolvimento de um novo motor e novos materiais resistentes à corrosão.

Comenta Moraes (2000, p. 42), que o estímulo que o governo teve que oferecer para aumentar a demanda destes carros foi inicialmente fixar o preço do etanol hidratado a uma relação de $65 \%$ do valor da gasolina, além de dar prazos 
mais longos e financiamento para a compra de carros a etanol, e a abertura de fim de semana a postos de abastecimento.

Segundo Scandiffio (2005, p. 39), o uso do combustível AEHC atingiu $37,8 \%$ da frota brasileira de automóveis e comerciais leves, comtemplando assim seu auge por volta de 1989, onde o consumo de etanol hidratado foi de 10,8 bilhões de litros. Destaca Santos (1993, p. 57) que o ano de 1985 foi o momento onde iniciava o declínio da fase de expansão do Proálcool, a deficiência no planejamento levou a um desajuste entre oferta do Etanol, a qual parou de crescer a partir de 1985 e a produção de carros movidos com ele a qual crescia regularmente. Isso pelo fato dos preços internos do combustível começar a cair em razão da queda no preço do barril do petróleo, uma vez que o preço do etanol não podia ser superior aos $65 \%$ do preço da gasolina. Assim a diminuição do preço do petróleo a partir de 1986 refletiu diretamente no preço da gasolina, o qual servia de referência para o preço do etanol hidratado, diminuindo, consequentemente, a competitividade do combustível renovável e a demanda por veículos movidos a etanol acrescendo-se o fato de ser uma tecnologia que ainda empregava dificuldades na partida a frio, o que tornava o veículo a gasolina mais eficiente comparativamente.

Scandiffio (2005, p. 45) destaca que a diminuição na demanda pelo etanol dá-se pelo fato de que o contexto desse mercado se apresentava na sua fase de declínio, isso porque cerca de 28 destilarias autônomas, financiadas pelo Proálcool, teriam encerrado suas atividades na safra 1989/90.

iii) Terceira etapa (1990 a 2003): a qual Lima et. al (2013) define como etapa de estagnação do programa. Nesta etapa, o presidente Fernando Collor de Mello, promoveu a abertura do mercado por meio das importações de veículos, o que levou a indústria segundo Santos e Burity (2012, p. 29) a maior qualidade e níveis de produtividade, o qual motivou as empresas a empregarem a tecnologia Flex Fuel.

A tecnologia dos motores Flex-Fuel veio dar novo fôlego ao consumo interno de álcool. O carro que pode ser movido a gasolina, álcool ou uma mistura dos dois combustíveis foi introduzido no País em março de 2003 e conquistou rapidamente o consumidor. Hoje a opção já é oferecida para quase todos os modelos das indústrias e, os automóveis bicombustíveis ultrapassaram pela primeira vez os movidos a gasolina na corrida do mercado interno. Diante do 
nível elevado das cotações de petróleo no mercado internacional, a expectativa da indústria é que essa participação se amplie ainda mais.

Segundo Lima et. al (2013) esta fase do Proálcool demarca o fim do programa, como primeira medida foi a extinção do instituto do álcool e açúcar IAA em 1990 que havia sido criado em 1933. Nota-se que segundo Moraes (2000) foram transferidas as atribuições do IAA para a secretaria do desenvolvimento regional da presidência da república, até a criação da Comissão Consultiva Nacional de Açúcar e Álcool em 1991, o setor sucro-energético cancelou sua desregulamentação por meio dessa comissão, que encerrou o monopólio público na comercialização do combustível etanol, cujo domínio se fazia tanto do lado da oferta quanto da demanda. Então há um novo cenário de relacionamento entre os produtores, usineiros, refinarias e distribuidoras onde prevaleciam as regras do livre mercado que perduram até hoje. Estes novos cenários admitem que os preços da cana de açúcar pago aos produtores passem a ser fixado a partir de duas variáveis: quantidade de Açúcar Total Recuperável (ATR) e os preços dos derivados (etanol anidro ${ }^{3}$ e hidratado ${ }^{4}$ ) na condição PVU (Posto Veiculo Usina) no estado de são Paulo, para o mercado interno e externo. O qual quer dizer que as usinas compram ATR e vendem ATR modificado, em forma de açúcar e etanol, já no caso do PVU, uma empresa distribuidora de etanol contrata uma transportadora para retirar o produto na usina que lhe vendera. $\mathrm{Na}$ atualidade o etanol hidratado para fins combustíveis é adquirido pelas distribuidoras e direcionado para os postos de revenda no país o qual para o ano 2010 foram 37 mil postos. O autor mostra que atualmente há 508 distribuidoras no mercado nacional, sendo também responsável por $60 \%$ do abastecimento de etanol dentre os 37 mil postos de combustíveis do país.

\footnotetext{
${ }^{3}$ Etanol anidro - usado como aditivo na gasolina para todo o país. A proporção da mistura pode Variar entre 20 e 25\%, sendo que atualmente está em $23 \%$. A mistura é obrigatória por lei federal e O nível da mistura, no intervalo autorizado, é definido pelo governo federal de acordo com a Produção e disponibilidade do produto.

${ }^{4}$ Etanol hidratado - usado como combustível dedicado para mover automóveis leves regulados para seu uso.
} 


\section{2.}

\section{Brasil e a cana de açúcar}

A cana de açúcar é a terceira maior atividade agrícola do Brasil em termos de área de produção e de valor bruto produzido, sendo que soja e milho são as maiores culturas do país. A cana de açúcar no Brasil pode ser produzida em quase todas as regiões do país. Os maiores produtores no Brasil são os estados de São Paulo, Paraná, Triangulo Mineiro e zona da Mata Nordestina com a maior participação na produção.

\subsection{1.}

\section{Área cultivada no Brasil com cana de açúcar}

De acordo com o segundo levantamento da safra 2013/2014 feito pelo Ministério da Agricultura, Pecuária e Abastecimento (MAPA) em cooperação com a Companhia Nacional de Abastecimento (CONAB) ${ }^{5}$ no mês de Agosto do 2013, a área cultivada com cana-de-açúcar que será colhida e destinada à atividade sucroalcooleira, está estimada em 8.799.150 mil hectares, distribuídas em todos estados produtores conforme suas características. O estado de São Paulo permanece como o maior produtor com 51,31\% (4.515.360 hectares) da área plantada, seguido por Minas Gerais com 8,0\% (781.920 hectares), Goiás com 9,3\% (818.390 hectares), Paraná com 7,04\% (620.330 hectares), Mato Grosso do Sul com 7,09\% (624.110 hectares), Alagoas com 5,02\% (442.590 hectares) e Pernambuco com 3,25\% (286.030 hectares). Nos demais estados produtores as áreas são menores, com representações abaixo de 3,0\%. Na Figura 1, pode-se observar o mapa da produção da cana de açúcar, e também uma ilustração da distribuição dela no país.

\footnotetext{
5 A CONAB faz levantamentos de safras, disponíveis no seu site,
} http://www.conab.gov.br/conteudos.php?a=1253\&t=2. 


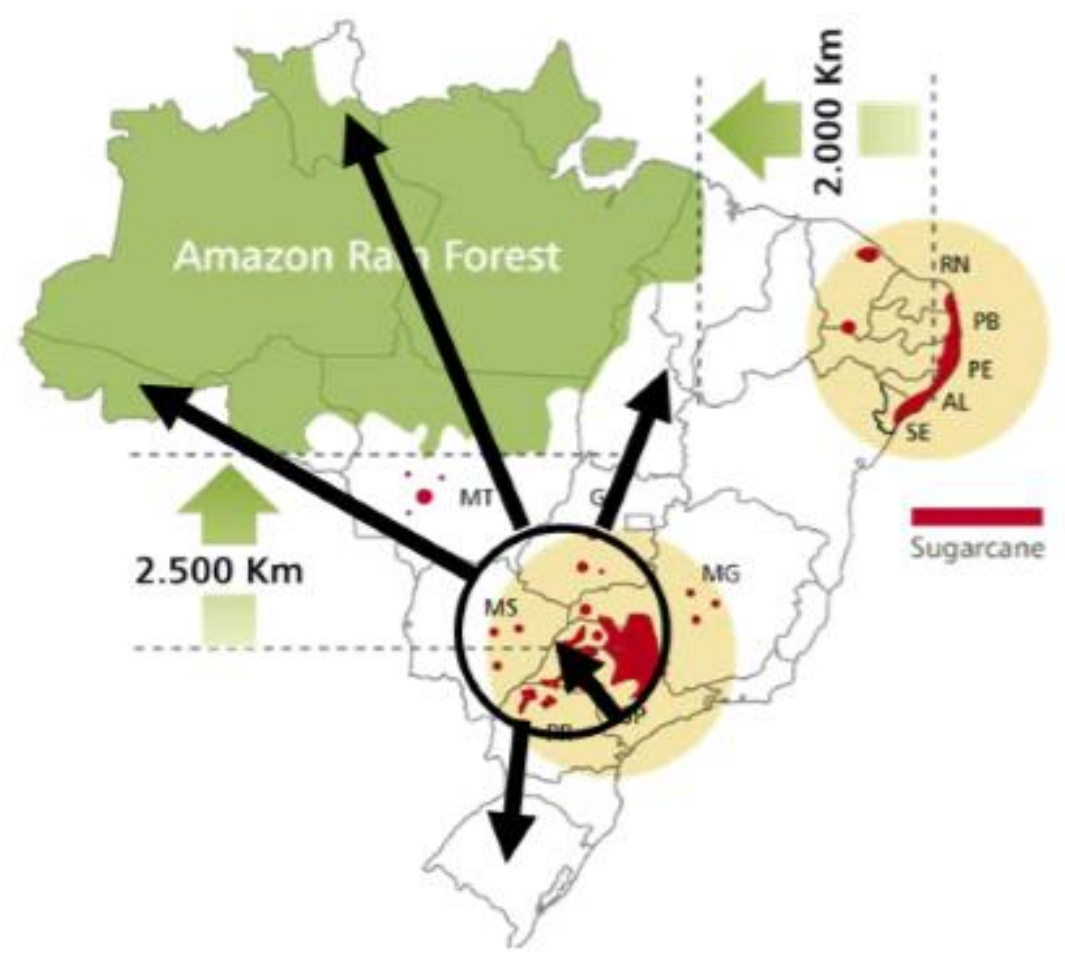

Figura 1- Mapa da produção de cana de açúcar no Brasil

Fonte: NIPE-Unicamp, IBGE e CTC

Os hectares plantados em 2012 com cana de açúcar nas diferentes regiões do Brasil são sintetizados na Tabela 1, observa-se que o sudeste do país tem a maior área com o $64.05 \%$ da plantação em tudo o Brasil.

Tabela 1 - Regiões plantadas de cana de açúcar no Brasil para o ano 2012

\begin{tabular}{l|l|c|c}
\hline \multicolumn{2}{c|}{ Brasil e regiões } & $\begin{array}{c}\text { Região Área plantada de } \\
\text { cana de açúcar } \\
\text { (hectares) }\end{array}$ & $\begin{array}{c}\text { Porcentagem da } \\
\text { plantação no brasil } \\
(\%)\end{array}$ \\
\hline 1 & Brasil & 9.752 .328 & \\
2 & Sudeste & 6.246 .586 & 64,05 \\
3 & Centro-Oeste & 1.538 .549 & 15,77 \\
4 & Nordeste & 1.217 .115 & 12,48 \\
5 & Sul & 697.114 & 7,148 \\
6 & Norte & 52.964 & 0,543 \\
\hline
\end{tabular}

Fonte: Instituto Brasileiro de Geografia e Estadística (IBGE) ${ }^{6}$

\footnotetext{
${ }^{6}$ Instituto Brasileiro de Geografia e Estadística (IBGE), dados pegos do banco de dados agregados, sistema IBGE recuperação automática, http://www.sidra.ibge.gov.br/bda/tabela/listabl1.asp?c=1612\&n=0\&u=0\&z=p\&o=27\&i=P
} 


\section{3.}

\section{Preços do etanol}

No Brasil, desde o ano 2002, de acordo com a Lei $n^{\circ}$ 9.478/1997, alterada pela Lei $\mathrm{n}^{\circ}$ 9.990/2000, existe um regime de liberdade de preços em toda a cadeia de produção e comercialização de combustíveis, produção, distribuição e revenda.

Este fato deixa sem qualquer tipo de tabelamento, valores máximos e mínimos, participação do governo na formação de preços, nem necessidade de autorização prévia para reajustes de preços de combustíveis. O órgão regulador das atividades que integram a indústria do petróleo e gás natural e a dos biocombustíveis no Brasil é a Agência Nacional do Petróleo (ANP) ${ }^{7}$, que acompanha os preços por meio do Levantamento de Preços e de Margens de Comercialização de Combustíveis. A ANP, foi implantada pelo Decreto $\mathrm{n}^{\circ} 2.455$, de 14 de janeiro de 1998, e entre as suas finalidades tem:

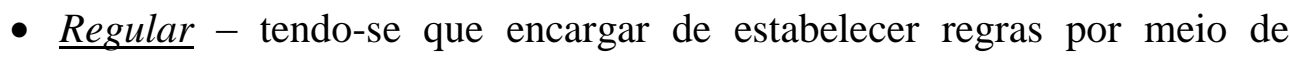
portarias, instruções normativas e resoluções para o funcionamento das indústrias e do comércio de óleo, gás e biocombustíveis.

- Contratar - a ANP procura promover licitações e assinar contratos em nome da União com os concessionários em atividades de exploração, desenvolvimento e produção de petróleo e gás natural, e autorizar as atividades das indústrias reguladas.

- Fiscalizar - uma das finalidades mais importantes é fazer cumprir as normas nas atividades das indústrias reguladas, diretamente ou mediante convênios com outros órgãos públicos.

\subsection{1.}

\section{Analise Tributário do etanol no Brasil}

Segundo Samanez et. al. (2013), o preço final dos combustíveis tem quatro componentes: o primeiro é o Preço de Realização, que é o preço de venda da mercadoria na usina ou refinaria sem impostos nem frete às distribuidoras de combustíveis; o segundo é o Imposto federal, PIS/PASEP ${ }^{8}$ e COFINS $^{9}$, e o

\footnotetext{
${ }^{7}$ Agencia Nacional do Petróleo ANP informação obtida diretamente do site http://www.anp.gov.br

${ }^{8}$ O PIS/PASEP (Programa de integração social) são contribuições sociais de natureza tributária, devidas pelas pessoas jurídicas, com objetivo de financiar o pagamento do seguro-desemprego,
} 
estadual, ICMS ${ }^{10}$, que incide sobre o produtor e a distribuidora, e a $\operatorname{CIDE}^{11}$, de competência exclusiva da União, o qual incide sobre o produtor. A terceira parte é a Logística, que tem como componente o frete das diferentes estancias pelas quais o produto tem que passar até chegar ao ponto final (usina-distribuidor-ponto de revenda). E, como quarta, a Margem, que é formada por uma parcela do distribuidor e outra do revendedor.

Além disso, Samanez et. al. (2013) ressaltam a importância que tem o ICMS, o qual é diferente para cada estado e para cada tipo de combustível. Estas diferentes alíquotas fazem com que o preço do etanol por estado e por região sejam diferentes, tornando o combustível mais ou menos atraente para os consumidores, embora sua utilização seja sempre melhor para o meio ambiente do que gasolina.

Segundo o Boletim mensal dos combustíveis renováveis, feito pelo Ministério de Minas e Energia ${ }^{12}$ (MME), edição $n^{\circ} 68$ correspondente ao mês de setembro do 2013, com a edição da medida provisória nº 613 em 7 de maio de 2013, e sua posterior conversão na lei $\mathrm{n}^{\circ} 12.859$, em 10 de setembro de 2013, foi instituído o credito presumido de PIS/CONFINS ao produtor de etanol, o que na pratica zerou a alíquota de $\mathrm{R} \$ 0,12$ por litro para o etanol. Assim não mais incidem tributos federais no etanol. Sobre o etanol e a gasolina, ainda incidem impostos estaduais (ICMS).

No mapa mostrado na Figura 2, a cor cinza mostra os estados em que o consumidor paga mais impostos sobre o etanol. Os estados em verde são os que proporcionam maiores economias aos consumidores. A Figura 2 permite inferir que as regiões do norte e alguns estados da região nordeste do Brasil são as que

abono e participação na receita dos órgãos e entidades para os trabalhadores públicos e privados, foi instituído em 1970.

${ }_{9}^{9}$ A Contribuição para o Financiamento da Seguridade Social (COFINS) é uma contribuição federal brasileira, de natureza tributária, incidente sobre a receita bruta das empresas em geral, destinada a financiar a seguridade social, a qual abrange a previdência social, a saúde e a assistência social. Foi instituída pela lei complementar no 70/91, sendo regulamentada pela lei no 9.718/98.

${ }^{10} \mathrm{O}$ Imposto sobre Operações relativas à Circulação de Mercadorias e Prestação de Serviços de Transporte Interestadual e Intermunicipal e de Comunicação (ICMS) é um imposto estadual, ou seja, somente os governos dos Estados do Brasil e do Distrito Federal têm competência para instituí-lo (conforme o art. 155, II, da Constituição de 1988).

${ }^{11}$ A Contribuição sobre Intervenção no Domínio Econômico A CIDE é cobrada sobre a importação e a comercialização de petróleo e seus derivados, gás e álcool etílico.

12 Boletim mensal que está disponível para download no site http://www.mme.gov.br/spg/menu/publicacoes.html 
proporcionam menores vantagens e economias aos consumidores de etanol, por quanto nestas regiões é melhor para ou usuário a utilização de outros tipos de combustíveis.

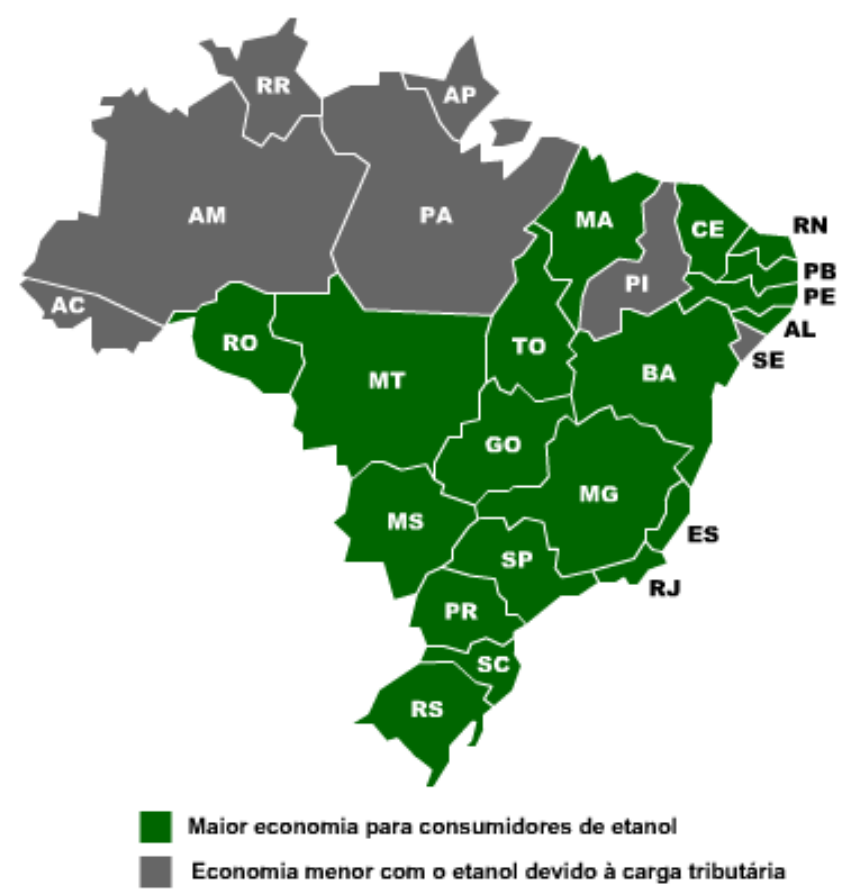

Figura 2 - Efeito do ICMS sobre o consumo do etanol

Fonte: ÚNICA

A Tabela 2 apresenta as alíquotas de ICMS para as diferentes regiões, estes dados foram coletadas do site da ÚNICA, Nela pode-se distinguir que o estado com menor ICMS é São Paulo, que tributa ao etanol em 12\%, e o estado com maior alíquota é o Pará, que tem um índice de $30 \%$.

O Boletim da MME do mês de outubro do 2013, divulga que para o dito mês a ANP autorizou a operação de 365 usinas de etanol, e até o dia 02 de Outubro do mesmo ano, as usinas autorizadas perfaziam uma capacidade total de aproximadamente 194 milhões de litros de etanol hidratado por dia e de 99 milhões de litros de etanol anidro por dia. A esse despeito, a Figura 3 mostra a capacidade autorizada por Estados. 
Tabela 2 - Alíquota ICMS nas regiões do Brasil para o ano 2013

\begin{tabular}{l|c}
\hline \multicolumn{1}{c|}{ Região } & \begin{tabular}{c} 
ICMS (\%) \\
\multicolumn{1}{c}{ Região Norte }
\end{tabular} \\
\hline \multicolumn{1}{c}{ Região Nordeste } & 25 \\
\hline $\begin{array}{l}\text { Rondônia, Acre, Amazonas, } \\
\text { Roraima, Amapá, Tocantins. } \\
\text { Pará }\end{array}$ & $\mathbf{3 0}$ \\
\hline \multicolumn{1}{c}{ Região Sudeste } & 19 \\
\hline Bahia & 25 \\
Maranhão, Piauí, Ceará, Rio Grande & \\
do Norte, Paraíba, Pernambuco. & \\
Alagoas, Sergipe. & 27 \\
\hline \multicolumn{1}{c}{ Região sul } & 25 \\
\hline Minas gerais & 27 \\
Espirito santo & $\mathbf{1 2}$ \\
Rio de janeiro & 18 \\
São Paulo & 25 \\
\hline Paraná & 25 \\
\hline Santa Catarina, Rio Grande do Sul & \\
\hline Golas centro-oeste & \\
Mato grosso do sul, Mato Grosso & \\
\hline
\end{tabular}

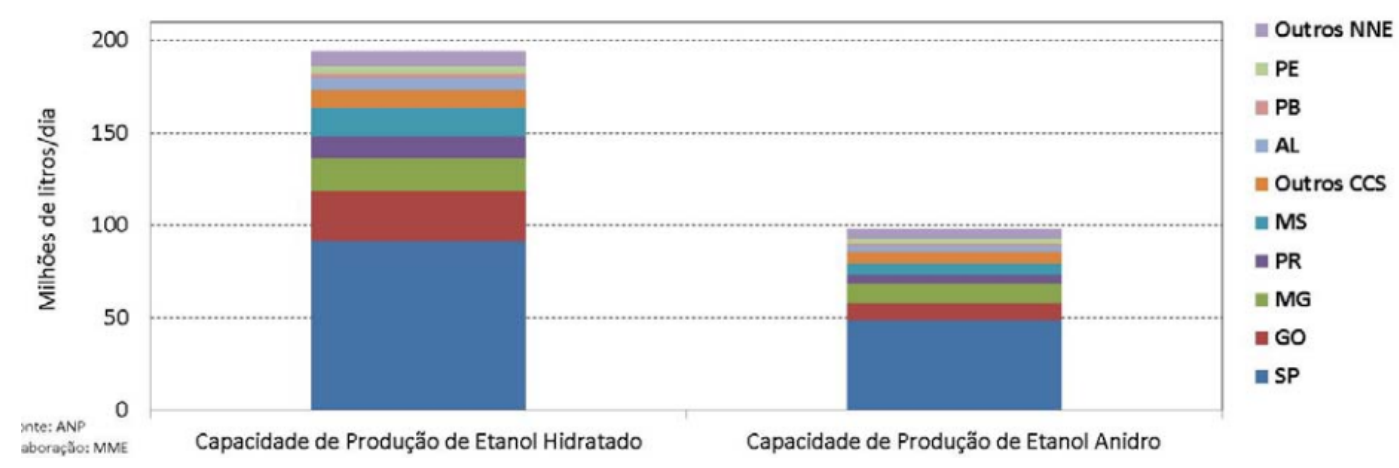

Figura 3 - Capacidade autorizada por estado (milhões de litros/dia)

Fonte: Boletim Mensal dos combustíveis renováveis, edição 68, MME

Da capacidade autorizada de produção de etanol, os estados de São Paulo, Goiás e Minas Gerais representam aproximadamente 70\% tanto de anidro, quanto de hidratado. O estado de São Paulo tem a maior capacidade autorizada, que representa em torno de $50 \%$ da capacidade total, tanto de etanol anidro quanto de etanol hidratado. 


\subsection{2.}

\section{Analise da paridade de preços}

Para que seja vantajoso o uso do etanol sobre a gasolina, a paridade, que é obtida a partir da divisão do preço do etanol hidratado pelo preço da gasolina ao consumidor, deve ter um limite de $70 \%$ para que aconteça um benefício econômico para o comprador. Segundo a União da Indústria de Cana-de-Açúcar (ÚNICA), desde o 3 de novembro de 2013 até o dia 30 do mesmo mês, só em 4 estados o consumo de etanol é economicamente vantajoso segundo a paridade do 70\%. Na Figura 4, marcado em cor verde mostra-se os quatro estados no Brasil que tem benefício econômico para o etanol, Mato Grosso, Goiás, São Paulo e Paraná. Nas Figuras 5 e 6, mostra-se os comportamentos das capitais e das regiões no Brasil para a semana do 6 ao 12 de outubro de 2013, onde pode-se distinguir que Goiânia, Cuiabá, Curitiba e São Paulo tiveram paridade inferior a 70\%. E as cidades de Vitória, Belém, Teresina, Macapá e Boa Vista tiveram as maiores paridades, próximas ao $90 \%$. Destaque-se que para as regiões Centro Oeste e Sudeste os compradores de etanol tem uma vantagem econômica no consumo de etanol, se comparado à gasolina.
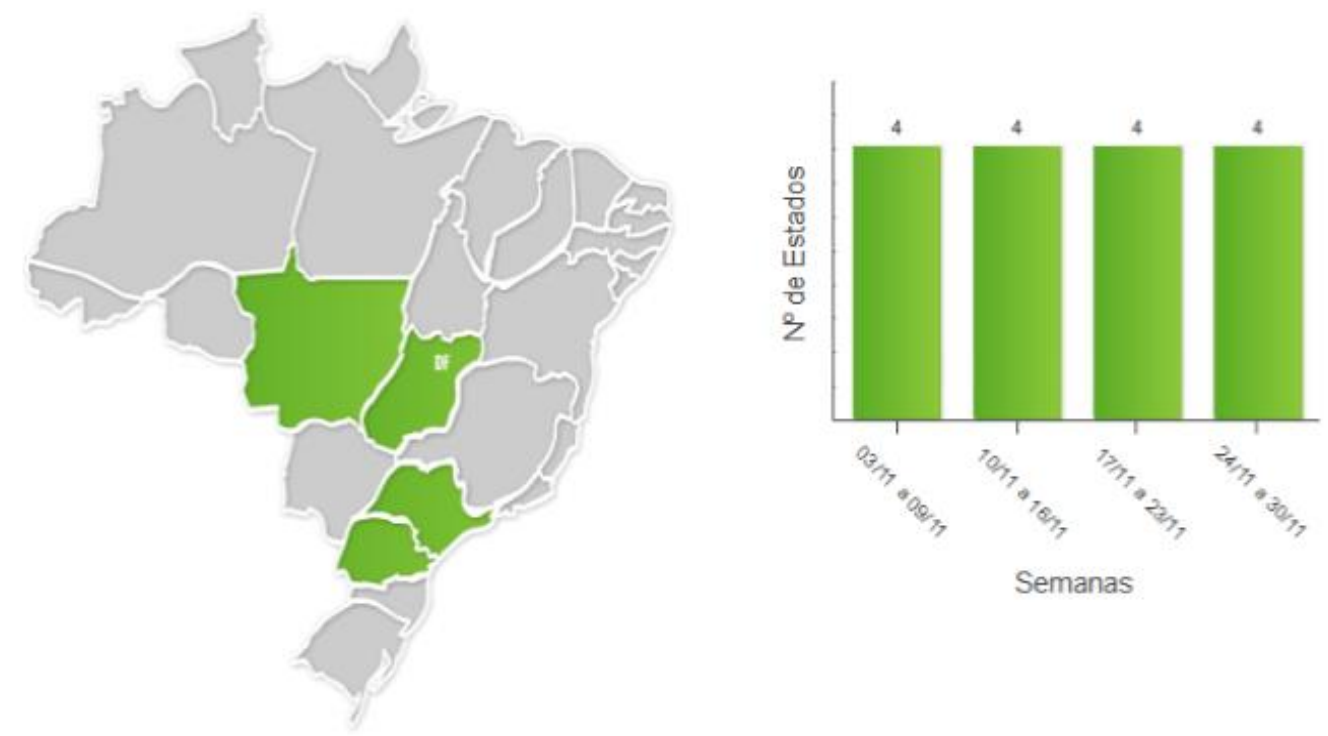

Figura 4 - Economia vantajosa do etanol com paridade do $70 \%$

Fonte: ÚNICA 


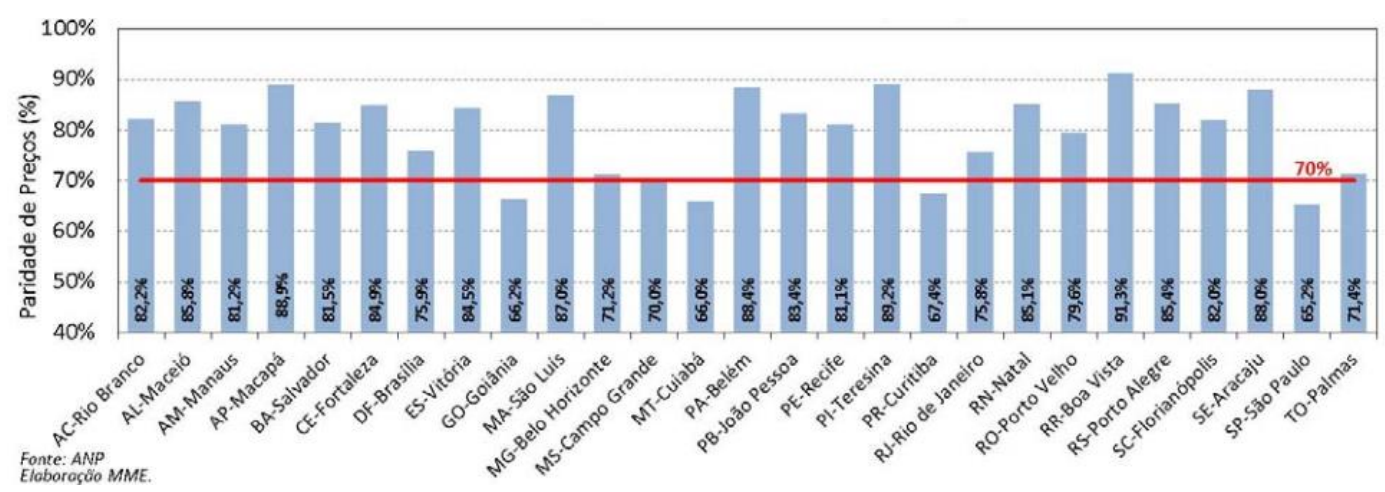

Figura 5 - Paridade do preço do etanol hidratado por capital.

Fonte: MME

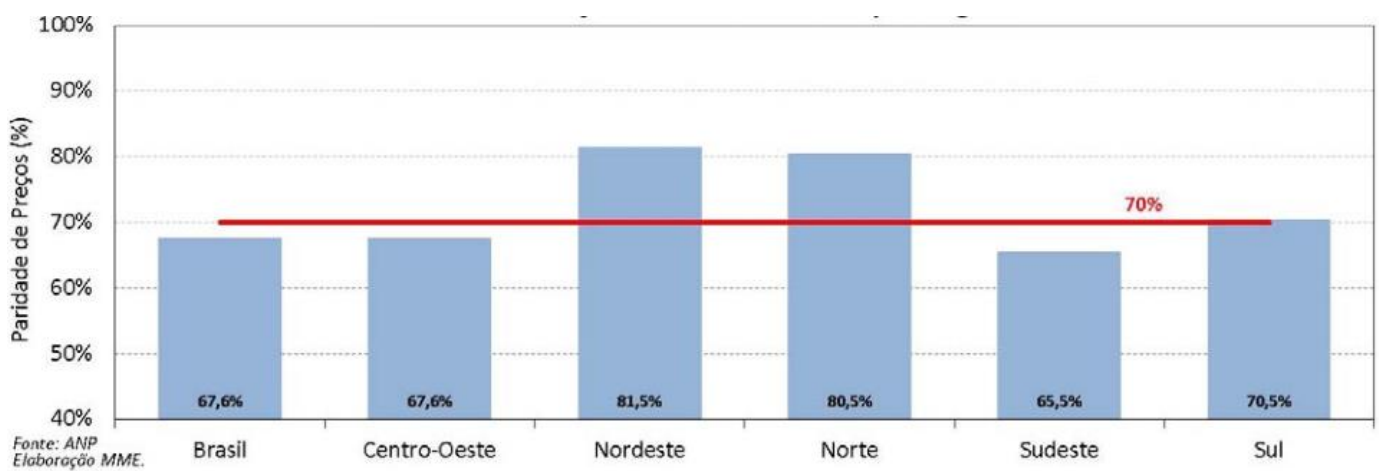

Figura 6 - Paridade do preço do etanol hidratado por regiões.

Fonte MME

\section{4 .}

\section{Opções Reais}

As Opções Reais (OR) é uma abordagem de avaliação de projetos complementar as ferramentas de uso tradicional de desconto de fluxos de caixa no tempo, com a particularidade que dá um valor às flexibilidades que o projeto possa ter.

As OR foram desenvolvidas no cenário acadêmico a partir do modelo de Black e Scholes (1973), que precifica o valor de uma Opção do tipo europeu com base no valor de um ativo subjacente. Cox, Ross e Rubinstein (1979) desenvolveram um modelo para precificar o valor de uma opção, utilizando um modelo binomial que considera um grande número de intervalos discretos e define a direção a ser tomada pelo valor do ativo subjacente, caracterizada por uma probabilidade associada a sua volatilidade. 
A teoria das OR é uma abordagem sólida para a análise de investimentos em condições de incerteza, em que o problema é tratado como um problema de otimização sob incerteza, onde se procura maximizar o valor do ativo através do exercício ótimo das opções relevantes, sujeito às incertezas e às restrições físicas, legais e outras.

Para que uma opção real tenha valor são necessárias três condições com relação ao valor do ativo subjacente: incerteza do seu valor futuro e irreversibilidade, pelo menos parcial em relação ao investimento, e timing, momento ótimo de investir. (DIXIT e PINDYCK, 1994).

Essas condições não são levadas em conta pelas teorias tradicionais de FCD, o que faz com que essa metodologia não consiga capturar a flexibilidade gerencial nem o impacto estratégico dos projetos.

Copeland e Antikarov (2001) identificam as cinco variáveis sobre as quais depende o valor das opções: o valor do ativo subjacente, o preço de exercício, o prazo de vencimento da opção, o desvio-padrão do valor do ativo-subjacente sujeito a risco, taxa de juros livre de risco e uma sexta que seriam os dividendos que podem ser pagos pelo ativo-subjacente. A importância das Opções Reais é maior quando os cenários têm uma alta volatilidade e as tecnologias são flexíveis, o que permite uma intervenção a baixo custo. Na Figura 7 encontra-se esse fato.

As situações de maior valor de OR são aquelas que se encontram no quadrante de alta incerteza e alta capacidade de reagir a ela. Trigeorges (1996) menciona que, sob incerteza, o valor futuro de uma variável é caracterizada por sua distribuição de probabilidades, sendo essa variabilidade uma medida do risco da variável, com impacto nos fluxos de caixa futuros. 


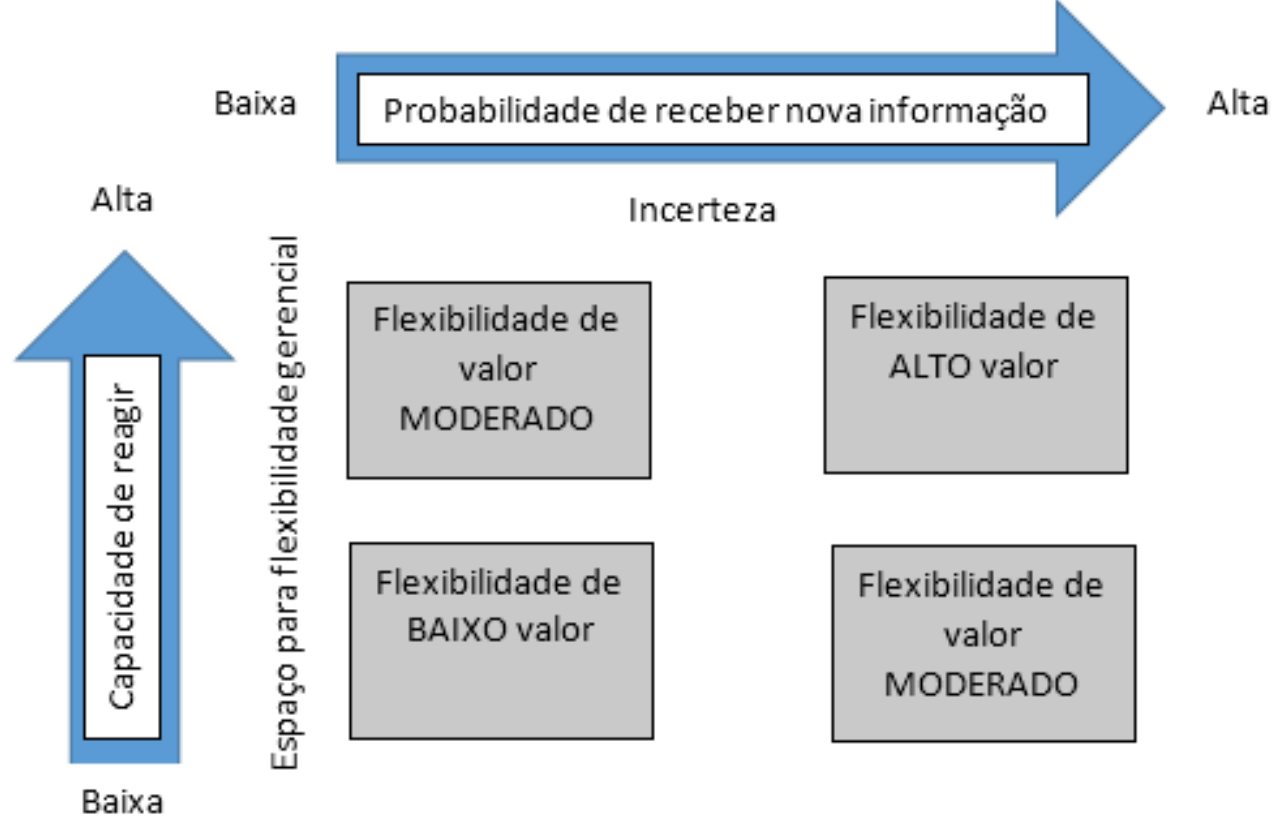

Figura 7 - Incerteza e flexibilidade

Fonte: Copeland e Antikarov (2011)

Dias (2014) enumera três diferentes tipos de incerteza: uma incerteza econômica ou de mercado, uma técnica ou privada e uma última estratégica. A primeira faz referência às incertezas exógenas ao projeto, próprias dos movimentos gerais da economia, os quais tem variações continuas que fazem oscilar os preços das commodities ${ }^{13}$ e as variáveis macroeconômicas. A segunda, em contraposição à primeira, é endógena ao projeto, não é correlacionada aos movimentos da economia, e para mudá-la comumente deve-se inverter em informação. As últimas são também endógenas e modeladas pela teoria dos jogos bayesianas $^{14}$, e a sua incerteza está relacionada com o comportamento de outros agentes que interagem num ambiente econômico.

Dias (2014) define uma Opção Real como o direito, mas não a obrigação, que um agente possui quando toma decisões sobre um ativo real. $\mathrm{O}$ agente pode ser um gerente, um consumidor, um planejador social ou qualquer tomador de decisão. $\mathrm{O}$ ativo real pode ser uma oportunidade de investir num projeto ou num ativo já existente, tal como uma fábrica. A decisão é exercer ou não uma ou mais OR.

\footnotetext{
${ }^{13}$ Uma commodity é um bem fungível, ou seja, é equivalente e trocável por outra igual independentemente de quem a produz, como por exemplo o petróleo, etanol, açúcar.

${ }^{14}$ Teoria dos jogos é basicamente um ramo da matemática aplicada que estuda situações estratégicas onde jogadores escolhem diferentes ações na tentativa de melhorar seu retorno.
} 


\subsection{1.}

\section{Opções Reais e Opções Financeiras}

Uma opção financeira é um direito, e não uma obrigação, de comprar ou vender um ativo (básico) financeiro, o qual tem um preço, chamado preço de exercício, e uma data de expiração. Segundo o que se procure comprar ou vender, define-se: opção de compra (call opção) como a opção que dá o direito de comprar o ativo básico e, para a opção de venda (put opção) como o direito de vender o ativo básico. O preço de exercício pode ser exercido de duas formas: na data de vencimento ou de expiração, e neste caso temos uma opção europeia, ou em qualquer data até a expiração, e neste caso temos uma opção americana.

Pode-se fazer uma analogia entre opções reais e financeiras. As opções reais utilizam em sua análise a estrutura matemática relativa aos ativos financeiros, apesar dos ativos relacionados às OR estarem caraterizados como ativos representativos do lado real da economia, pelos ativos produtivos.

Dias (2014), indica a importância de se levar em conta as diferenças entre os tipos de opções:

- As opções financeiras, que são geralmente de curto prazo, diferem das Opções Reais, que podem ser até perpétuas.

- Um ativo financeiro, como por exemplo as ações, não podem ter valores negativos, já em um projeto isso pode ocorrer.

- As opções reais são mais complexas que as financeiras. O preço de exercício pode ser incerto, e é comum a presença de opções compostas com incertezas técnicas, além das de mercado, e de interações estratégicas com outras opções.

No exercício das OR pode existir um determinado período de tempo para que elas ocorram, por exemplo o tempo de construção do projeto afeta a aparição de algumas opções. Pessoa (2011) fez uma síntese da relação entre OR e opções financeiras, como mostra a Tabela 3. 
Tabela 3 - Analogia entre Opções Reais e Financeiras

\begin{tabular}{l|l}
\hline \multicolumn{1}{c|}{ Opção financeira } & \multicolumn{1}{c}{ Opção real } \\
\hline Preço da ação & Valor do projeto \\
Preço de exercício da opção & Valor do investimento no projeto \\
Taxa de dividendos da ação & Fluxo de caixa gerado pelo projeto \\
& Taxa livre de risco \\
Taxa livre de risco & Volatilidade do valor do projeto \\
Volatilidade dos retornos da ação & Tempo de expiração da oportunidade \\
Tempo de expiração da opção & de investimento \\
\hline
\end{tabular}

Fonte: Pessoa(2011) apud Rigolon (1999)

\subsection{2.}

\section{Tipo de Opções Reais}

Dias (2014) fez uma classificação das opções reais conforme mostrado na Figura 8. Neste estudo será avaliada a opção de troca (switch option), onde o usineiro pode escolher entre produzir açúcar ou etanol dependendo do comportamento do preço de mercado das commodities.

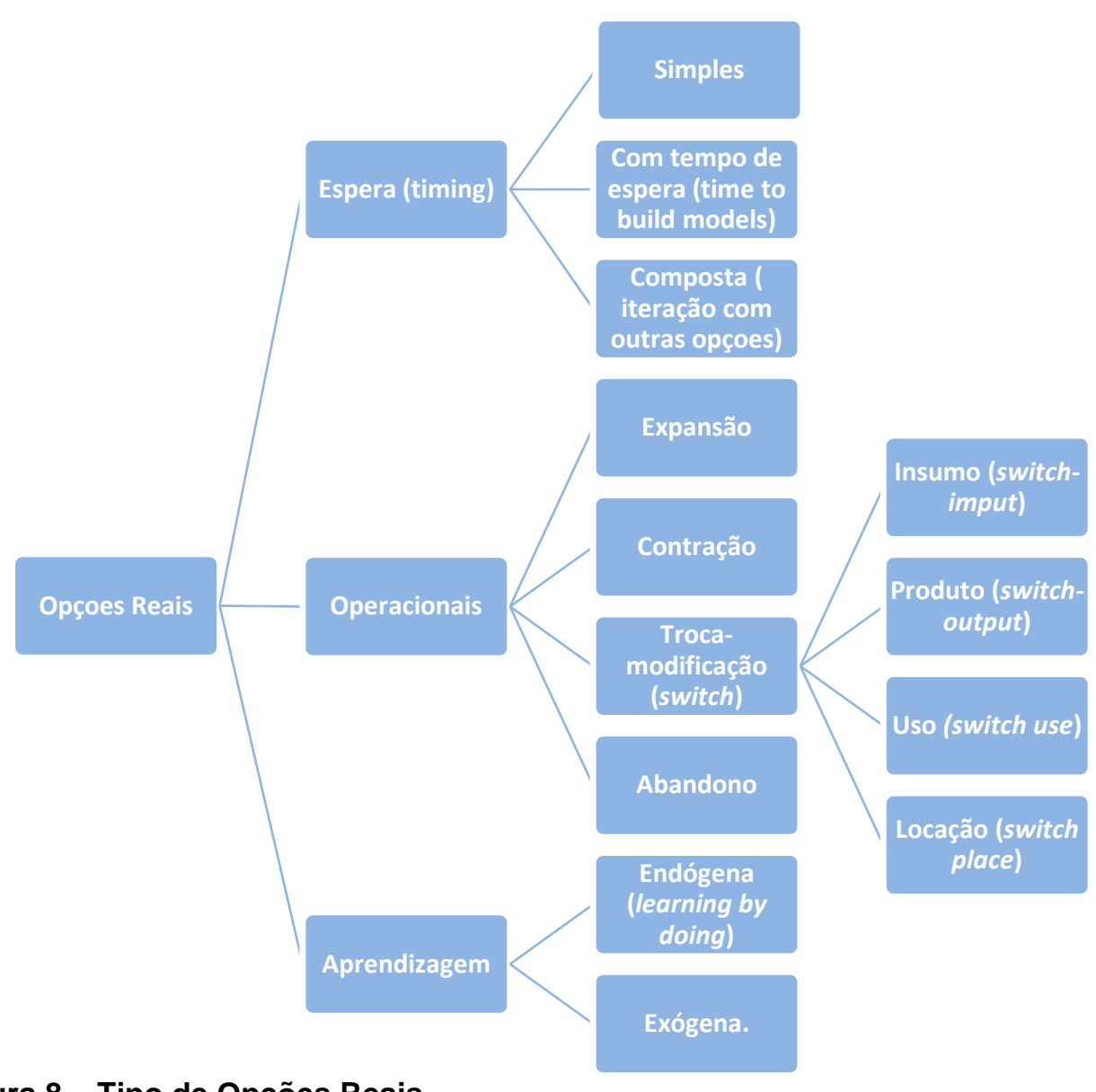

Figura 8 - Tipo de Opções Reais

Fonte: Dias (2014) 


\subsubsection{1.}

\section{Opção de troca}

A opção de troca procura estabelecer o valor que dá a flexibilidade de poder trocar um Mix de "output ou input", com o alvo de atingir o maior lucro de acordo com a flutuação dos preços. Acompanhando a Figura 8, esta opção pode ser de quatro tipos: Insumo (switch-input), Produto (switch-output), Uso (switch use) e Locação (switch place).

\section{A.}

\section{Opção de troca de insumo (switch input)}

A opção de troca de insumo (switch input) consiste em mudar a entrada (input) (exemplos: matéria prima, combustível) a ser processada, com o alvo de atender um só resultado (output). Pode-se considerar o exemplo do carro Flex Furl, onde os inputs disponíveis são os dois tipos de combustíveis, etanol e gasolina, que são capazes de gerar energia para mover o automóvel (output). Esta é uma opção real para o consumidor, quem pode aproveitar as oscilações dos preços desses combustíveis para se gerar menores custos. E ainda, para este exemplo não há custo de troca de insumos. A Figura 9, mostra o anteriormente dito.

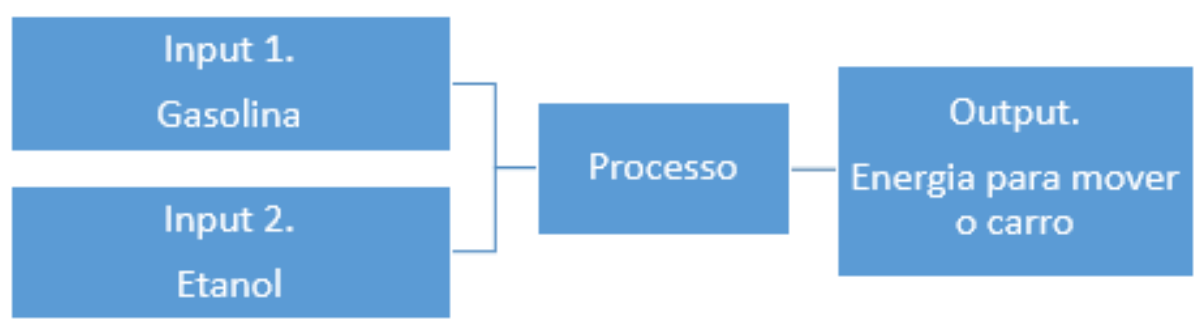

Figura 9 - Opção troca de insumo input-output exemplo do carro Flex-Fuel

B.

\section{Opção de troca de uso (switch use)}

Mede o valor que tem a múltipla aplicabilidade de um ativo, onde um mesmo ativo pode atuar em diferentes campos. Dias (2014) propõe um exemplo real de um navio (P.P. Moraes, atualmente chamado Petrobas-34) fabricado no final da década de 1950 para transporte de petróleo em viagens domesticas o qual, 
na década de 1960, foi convertido para viagens internacionais por causa da atração dos aumentos dos fretes de petróleo no mercado internacional.

\section{C.}

\section{Opção de troca de produto (switch output)}

Consiste em mudar a saída (output), a qual é o resultado do processamento de uma única entrada (input). Esta é o tipo de opção que avalia nesta dissertação, onde se tem como entrada a cana de açúcar e como saídas o açúcar cristal, o etanol hidratado, o etanol anidro e o etanol hidratado. Isso é ilustrado na Figura 10.

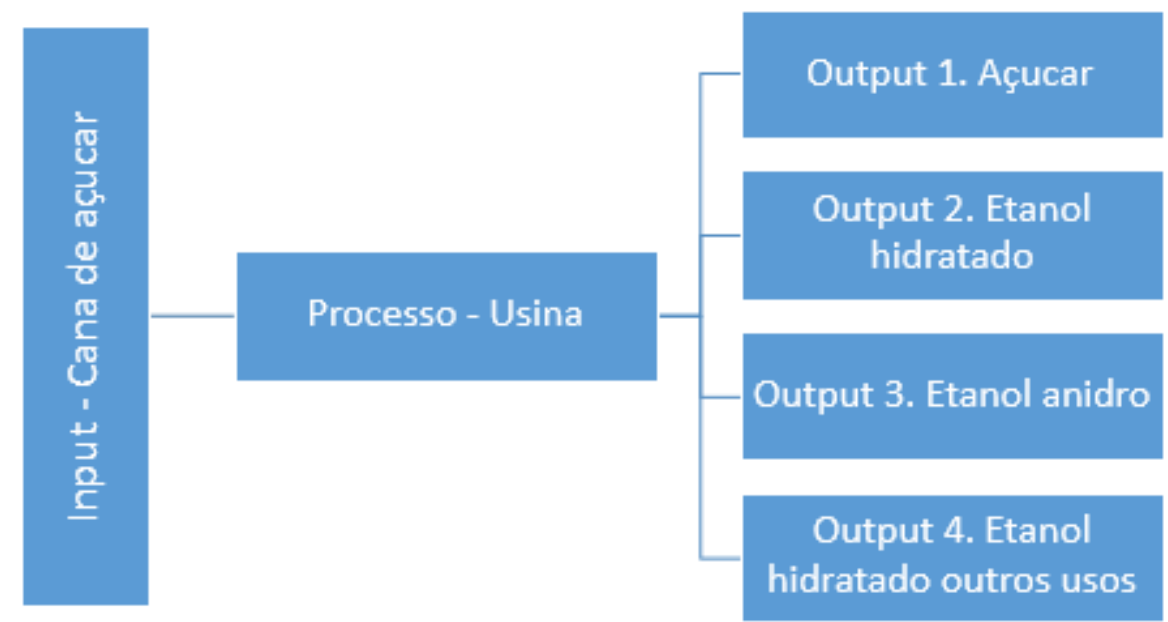

Figura 10 - Opção troca de produto input-output exemplo usina Flex

D.

\section{Opção de troca de locação (switch place)}

Mede o valor que dá a mobilidade de um ativo. Um exemplo pode ser as geradoras térmicas de eletricidade móveis, tais como geradores em barcaças, containers e caminhões, geralmente de pequeno/médio porte ( 100 MW) e em geral não muito eficientes, mas eficazes devido a sua flexibilidade, pois esses geradores móveis podem ir até o local onde existem problemas de escassez de energia devido a algum problema inesperado. 
3.

\section{PROCESSOS ESTOCASTICOS}

Os processos estocásticos são diferentes dos processos determinísticos, pois são regidos por fenômenos aleatórios, o que faz com que suas variáveis mudem de forma incerta ao longo do tempo, tendo como resultado uma dificuldade maior na sua modelagem.

\section{1.}

\section{Processo de Markov}

Os processos estocásticos se apresentam tanto no tempo discreto quanto no continuo. Os processos Markovianos são processos estocásticos em que o valor corrente é suficiente para descrever suas propriedades estatísticas de seus valores futuros, por essa razão são também chamados processos sem memória. Um processo estocástico $\{X(t)\}$ tem a propriedade de Markov se:

a. Tempo discreto:

$\operatorname{Prob}[\mathrm{X}(\mathrm{t}) \mid \mathrm{X}(\mathrm{t}-1), \mathrm{X}(\mathrm{t}-2), \mathrm{X}(\mathrm{t}-3), \ldots]=\operatorname{Prob}[\mathrm{X}(\mathrm{t}) \mid \mathrm{X}(\mathrm{t}-1)]$

\section{b. Tempo continuo:}

$\operatorname{Prob}\left[\mathrm{X}(\mathrm{t}) \in \mathrm{E} \mid \mathcal{F}_{\mathrm{s}}\right]=\operatorname{Prob}[\mathrm{X}(\mathrm{t}) \in \mathrm{E} \mid \mathrm{X}(\mathrm{s})], \mathrm{s}<t$

No primeiro caso, só é preciso ter a informação de $X(t-1)$; no segundo caso, não é necessária toda a informação acumulada até $s$ (filtração $\mathcal{F}_{\mathrm{s}}$ ), basta o último valor conhecido de $X$, i. é $X(s)$.

Este processo assume a eficiência fraca de mercado, a qual é representada apenas por informações disponibilizadas e de domínio público. Neste caso, estas informações rapidamente são incorporadas ao valor da variável, reforçando a perspectiva de dependência apenas do valor corrente da variável para qualquer previsão. 


\section{2.}

\section{Processo de Wiener}

Também conhecido como Movimento Browniano, é um tipo especifico de processo estocástico de Markov, que tem sido utilizado pela física para descrever o movimento de uma partícula sujeita a uma grande quantidade de pequenos choques moleculares. É um processo estocástico em tempo continuo que tem três importantes propriedades:

1. É um processo de Markov, pois o valor da variável corrente independe da trajetória dos preços no passado;

2. Seus incrementos são independentes, portanto a variação ocorrida num intervalo de tempo é independente da ocorrida em qualquer outro intervalo.

3. Os incrementos possuem distribuição normal com parâmetros que dependem somente do intervalo de tempo (incrementos estacionários).

Considerando que $z(t)$ represente um processo de Wiener, então, qualquer variação em $z, \Delta z$, correspondente ao intervalo de tempo $\Delta t$, deve satisfazer as seguintes condições:

1. A relação entre $\Delta \mathrm{z}$ e $\Delta \mathrm{t}$ deve é dada por: $\Delta \mathrm{z}=\varepsilon_{\mathrm{t}} \sqrt{\Delta \mathrm{t}}$, onde $\varepsilon_{\mathrm{t}} \sim \mathrm{N}(0,1)$.

2. A variável aleatória $\varepsilon(\mathrm{t})$ não possui correlação serial, ou seja, $\mathrm{E}\left[\varepsilon_{\mathrm{t}} \varepsilon_{\mathrm{s}}\right]=0$ para $\mathrm{t} \neq \mathrm{s}$, isso significa que os valores de $\Delta \mathrm{z}$ para dois intervalos de tempo diferentes são independentes, desta forma $\mathrm{z}(\mathrm{t})$ segue um processo de Markov com incrementos independentes.

Dada a condição 1 , se $\Delta z \sim N(0, \Delta t)$, então a variância de um processo de Wiener cresce linearmente com o horizonte de tempo. O processo de Wiener é um processo não-estacionário, e no longo prazo sua variância tende a infinito.

Com um $\Delta t$ tendendo a zero, pode-se representar o incremento do processo de Wiener: $d z=\varepsilon_{t} \sqrt{d t}$

Como $\varepsilon_{t} \sim N(0,1)$, então $E(d z)=0$ e $\operatorname{var}(d z)=E\left[d z^{2}\right]=d t$. Cabe notar, porém, que o processo de Wiener não tem derivada em relação ao tempo no sentido convencional. Assim, $\frac{\Delta \mathrm{z}}{\Delta \mathrm{t}}=\varepsilon_{t}(\Delta \mathrm{t})^{1 / 2}$ torna-se infinito quando $\Delta t$ se aproxima de zero. A importância do desvio-padrão dessa distribuição ser $\sqrt{d t}$ pode ser observada em intervalos de tempo pequenos, pois, neste caso, o desvio padrão será muito maior que o movimento do termo de tendência, isto é , para um 
$d t$ pequeno, $\sqrt{d t}$ será muito maior, o que gerara o movimento serrilhado do processo de Wiener.

\section{3.}

\section{Processo do Itô}

Um processo de Itô é um processo de Wiener generalizado definido pela (ou é a solução forte da) seguinte Equação Diferencial Estocástica (EDE), dado o valor inicial $V(t=0)$ (Dias, 2014).

$$
d x(t)=a(x, t) d t+b(x, t) d z
$$

Onde: $a(x, t) d t$ representa a parte determinística, e a parte estocástica $b(x, t) d z$, onde:

$$
\begin{aligned}
& x=\text { variável aleatória no instante } t \text {; } \\
& a=d r i f t \text { ou tendência instantânea do processo de Itô; } \\
& d t=\text { variação instantânea do tempo; } \\
& b=\text { volatilidade estimada de } d X \text { no instante } t \text {; } \\
& d z=\text { incremento de Wiener } \text { ( incremento aleatório com média zero e }
\end{aligned}
$$
variância $d t$ ).

$$
E(d x)=a(x, t) d t \text { e } \operatorname{Var}(d x)=[b(x, t)] d t \text {, como se demonstra a }
$$

continuação.

$$
\begin{aligned}
& E(d x)=E[a(x, t) d t+b(x, t) d z]=E[a(x, t) d t]+E[b(x, t) d z] \\
& =a(x, t) E(d t)+b(x, t) E(d z)=a(x, t) d t \\
& \operatorname{Vat}(d x)=E\left[(d x-E(d x))^{2}\right]=E\left[(d x-a(x, t) d t)^{2}\right] \\
& =E\left[(a(x, t) d t+b(x, t) d z-a(x, t) d t)^{2}\right] \\
& =E\left[(b(x, t) d z)^{2}\right]=b(x, t)^{2} d z^{2}=[b(x, t)]^{2} d t
\end{aligned}
$$

Os parâmetros $a(x, t)$ e $b(x, t)$, são também conhecidos como taxa de crescimento esperado instantâneo e taxa de variância instantânea do processo de Itô, respectivamente. 


\section{4.}

\section{Lema de Itô}

O lema de Itô pode ser entendido como uma versão para cálculo estocástico da expansão de Taylor. Dado que tanto os processos de Itô, quanto os processos de Wiener são processos estocásticos em tempo continuo, e na impossibilidade de se utilizar as regras ordinárias do cálculo, por não ter uma derivada convencional em relação ao tempo, se utiliza para resolve-as o lema de Itô.

Considere a variável $X$ que segue o processo de Itô dado por Equação 3.1

$$
d X=a(X, t) d t+b(X, t) d z
$$

Onde: $d z=\varepsilon \sqrt{d t}, \varepsilon \sim N(0,1)$

Assim, $d X=a(X, t) d t+b \varepsilon \sqrt{d t}$. Obtém-se a função $Y(x, t)$ através, do lema de Itô:

$$
d Y=\frac{\partial Y}{\partial X} d X+\frac{\partial Y}{\partial t} d t+\frac{1}{2} \frac{\partial^{2} Y}{\partial X^{2}} d X^{2}
$$

Onde:

$d X^{2}=(a(X, t) d t+b(X, t) d z)^{2}=[a(X, t)]^{2} d t^{2}+2 a(X, t) b(X, t) d t d z+$ $[b(X, t)]^{2} d z^{2}=b^{2}(X, t) d z^{2}=b^{2} d t$

Substituindo $d X$ e $d X^{2}$ na equação do Lema de Itô (Equação 3.2), obtém-se a diferencial da função $Y$ :

$$
\begin{gathered}
d Y=\frac{\partial Y}{\partial X}(a(X, t) d t+b(X, t) d z)+\frac{\partial Y}{\partial t} d t+\frac{1}{2} \frac{\partial^{2} Y}{\partial X^{2}} b^{2} d t \\
d Y=\left(a(X, t) \frac{\partial Y}{\partial X}+\frac{\partial Y}{\partial t}+\frac{1}{2} \frac{\partial^{2} Y}{\partial X^{2}} b^{2}(X, t)\right) d t \\
+b(X, t) \frac{\partial Y}{\partial X} d z
\end{gathered}
$$




\section{5}

\section{Movimento Browniano com drift}

O Movimento Browniano com drift (tendência) ou Movimento Aritmético Browniano (MAB) (Dias 2014), é o caso particular mais simples de processo de Itô, pois os termos $a$ e $b$ são constantes assim $a(x, t)=\alpha$ e $b(x, t)=\sigma$, então pela Equação 3.1:

$$
d x(t)=\alpha d t+\sigma d z
$$

No MAB, a constante " $\alpha$ " é o parâmetro de tendência (drift), e a constante “ $\sigma$ " é o parâmetro da variância, $d z$ é o incremento de Wiener. A parte determinística é representada pelo termo $\alpha d t$, e a parte estocástica por $\sigma d z$. Notese que $E(d x)=\alpha d t$ e $\operatorname{Var}(d x)=\sigma^{2} d z$, conforme é mostrado abaixo:

$$
\begin{gathered}
E(d X)=E(\alpha d t+\sigma d z)=E(\alpha d t)+E(\sigma d z)=\alpha E(d t)+\sigma E(d z)=\alpha d t \\
\begin{array}{r}
\operatorname{Var}(d X)=E\left[(d x-E(d x))^{2}\right]=E\left[(d x-\alpha d t)^{2}\right] \\
=E\left[(\alpha d t+\sigma d z-\alpha d t)^{2}\right]=E\left[(\sigma d z)^{2}\right]=\sigma^{2} d z^{2}=\sigma^{2} d t
\end{array}
\end{gathered}
$$

Este processo é apropriado para variáveis econômicas cujo comportamento é crescente numa taxa linear, em que a incerteza se incrementa com o tempo. Pessoa (2011) destaca as seguintes caraterísticas:

1. Devido à distribuição normal, $x$ pode ser tanto positivo quanto negativo;

2. Se $t+d t>t$ então $x_{t+d t}$ é um valor futuro do processo relativo ao tempo t e sua distribuição segue $\mathrm{x}_{\mathrm{t}+\mathrm{dt}} \sim \mathrm{N}\left(\mathrm{x}_{\mathrm{t}}+\alpha \mathrm{dt}\right.$, $\left.\sigma \mathrm{dz}\right)$;

3. A variância da previsão $x_{t+d t}$ tende a infinito se $t+d t$ também tende.

\section{6.}

\section{Movimento Geométrico Browniano (MGB)}

Um caso especial da Equação 3.1 (processo de Itô) é o Movimento Geométrico Browniano (MGB). Neste processo $a(X, t)=\alpha X$ e $b(x, t)=\sigma X$, 
onde $\alpha$ e $\sigma$ são constantes. Portanto, se $X$ segue um MGB, então ela obedece à seguinte equação diferencial estocástica (EDE), dado $v(0)^{15}$

$$
d X(t)=\alpha X d t+\sigma X d z
$$

Onde: $X=$ variável aleatória no instante t;

$\alpha=$ drift (tendência);

$d t=$ variação instantânea do tempo;

$\sigma=$ volatilidade;

$d z=$ incremento de Wiener (incremento aleatório com média zero e variância $d t$ ).

Os únicos termos estocásticos nessa equação são $d X$ e $d z$, já que $X$ é conhecido no instante $t$. Cabe ressaltar que enquanto no MAB a variável estocástica segue uma distribuição normal, no MGB segue uma distribuição lognormal. Já a taxa de variação da variável estocástica, $d x / x$, claramente tem distribuição normal. Uma variável $x$ que segue o MGB e possui uma distribuição log-normal tem as seguintes características:

$$
\begin{aligned}
& E[x(t)]=x_{0} e^{\alpha t} \\
& \operatorname{Var}[x(t)]=x_{0}^{2} e^{2 \alpha t}\left(e^{\alpha^{2} t}-1\right)
\end{aligned}
$$

Devido à sua simplicidade e fácil compreensão, o MGB é amplamente utilizado para modelagem de ativos financeiros e reais: preço de ações, commodities financeiras, índices de mercado, como para terrenos, demanda de novos produtos, etc.

Pessoa (2011) cita algumas características desse movimento que merecem destaque:

1. Se x começa sendo positivo, ele sempre será positivo, ou seja, não varia de positivo a negativo.

2. $\mathrm{x}$ tem uma barreira absorvente em zero, ou seja, se $\mathrm{x}$ chega a zero (um evento com probabilidade zero), então x permanece nesse valor.

3. A variância da previsão de $x_{u}$ tende a infinito quando $u$ tende a infinito.

\footnotetext{
${ }^{15}$ Para que uma EDE possa ter solução única é necessário que se especifique a condição inicial, aqui $\mathrm{x}(\mathrm{t}=0)$. Caso contrário poderia ter infinitas soluções.
} 
Bastian-Pinto (2009) menciona que a pesar do MGB ser mais simples de implementar na modelagem de preços de commodities, ele retorna valores sobrestimados ao ser comparado com a modelagem feita por médio de um Movimento de Reversão à Média. O autor conclui que o MRM retrata mais fielmente a evolução de preços das commodities açúcar e etanol.

\subsection{1.}

\section{Discretização do MGB}

A equação discreta para um MGB é essencial para realizar a simulação do processo estocástico. Consiste em procurar uma equação que tenha $x_{t}$ em função de $x_{t-1}$. A equação é mostrada a seguir:

$$
X_{t}=X_{t-1} \exp \left[\left(\alpha-\frac{\sigma^{2}}{2}\right) \Delta t+\sigma N(0 ; 1) \sqrt{\Delta t}\right]
$$

Esta é uma discretização útil para uma simulação exata. Para uma simulação neutra ao risco, basta diminuir o prêmio de risco $\pi$ do drift $\alpha$.

$$
X_{t}=X_{t-1} \exp \left[\left(\alpha-\pi-\frac{\sigma^{2}}{2}\right) \Delta t+\sigma N(0 ; 1) \sqrt{\Delta t}\right]
$$

\subsection{2.}

\section{Estimativa dos parâmetros}

Os parâmetros da Equação 3.5, se determinam utilizando a sua equação discreta (Equação 3.8), e considerando que $X_{t}=\operatorname{Ln}\left(x_{t}\right)$ (Nascimento, 2012):

$$
\ln \left(x_{t}\right)-\ln \left(x_{t-1}\right)=\left(\alpha-\frac{\sigma^{2}}{2}\right) \Delta t+\sigma N(0 ; 1) \sqrt{\Delta t}
$$

Então, a volatilidade $\sigma$ e o drift $\alpha$ são dados por:

$$
\begin{aligned}
& \operatorname{Var}\left[\ln \left(x_{t}\right)-\ln \left(x_{t-1}\right)\right]=\operatorname{Var}[\sigma N(0 ; 1) \sqrt{\Delta t}]=\sigma^{2} \Delta t \\
& \sigma=\sqrt{\frac{\operatorname{Var}\left[\ln \left(x_{t}\right)-\ln \left(x_{t-1}\right)\right]}{\Delta t}}
\end{aligned}
$$




$$
\begin{aligned}
& E\left[\ln \left(x_{t}\right)-\ln \left(x_{t-1}\right)\right]=E\left|\left(\alpha-\frac{\sigma^{2}}{2}\right) \Delta t\right|=\alpha \Delta t-\frac{\sigma^{2}}{2} \Delta t \\
& \alpha=\frac{E\left[\ln \left(x_{t}\right)-\ln \left(x_{t-1}\right)\right]}{\Delta t}+\frac{\sigma^{2}}{2}
\end{aligned}
$$

\section{7.}

\section{Processo de Reversão à Média}

O processo de Reversão à Média (MRM) é um processo contínuo, caso particular de um processo de Itô, com uma característica principal, o sentido e intensidade do componente de tendência variam com o tempo (pois dependem do preço corrente), enquanto que no MGB a tendência é fixa. Num MRM a tendência num instante $t$ pode ser a de subir, se o preço corrente $P(t)$ estiver abaixo do nível de equilíbrio $P$, e em outro instante $s$ pode ser a de queda, se $P(s)$ estiver acima de $P$, enquanto que no MGB todo choque estocástico é um choque permanente na trajetória de longo prazo desses preços. No MRM cada choque estocástico é apenas um desvio transitório do nível de equilíbrio de longo prazo $P$.

Os mecanismos modelados por este processo normalmente são mecanismos de mercado, ou seja mecanismos de oferta e demanda. Se o preço está alto em relação a um preço de equilíbrio, tanto as forças de oferta e demanda entram a puxar para baixo aquele preço. Utilizando a mesma lógica, se espera que acontecendo um preço baixo, estas mesmas forças puxem para cima, dando assim a este modelo uma visão microeconômica.

É importante notar que a intensidade do termo de tendência é uma função crescente da diferença $(\bar{P}-P)$, portanto quanto mais distante esteja o preço do nível de equilíbrio $\bar{P}$, maior será a intensidade do termo de tendência que faz os preços voltarem ou reverterem à média de longo prazo.

O modelo mais simples e mais popular de um processo MRM é o modelo de Ornstein-Uhlenbeck O-U, também conhecido como MRM aritmético. É dado por:

$$
d X(t)=\eta(\bar{X}-X(t)) d t+\sigma d z(t)
$$

Onde: $\eta$ é a velocidade de reversão 
$\bar{X}$ é o nível de equilíbrio de longo prazo ou média de longo prazo, $d z$ é o incremento de Wiener, $\sigma$ a volatilidade.

Como $X$ pode assumir valores negativos, resulta mais apropriado modelar o logaritmo dos preços, e não os preços em si. Desta forma: $X=\ln (x) \Rightarrow x=e^{X}$, o que mantem os preços das commodities $x$ sempre positivos por mais que o valor de $X$ possa ser negativo, pois não faria sentido uma série de preços de açúcar ou etanol negativos.

O MRM implica que tanto $d x$ como $x$ tem distribuição normal com média e variância ( Dixit e Pindyck 1994 p.74).

$$
\begin{aligned}
& E(X(t))=\bar{X}+\left(X_{0}-\bar{X}\right) e^{-\eta t} \\
& \operatorname{Var}(X)=\frac{\left(1-e^{-2 \eta t}\right) \sigma^{2}}{2 \eta}
\end{aligned}
$$

Pode-se observar através destas equações que quando $t \rightarrow \infty$ o valor esperado converge para a média de longo prazo $\bar{X}$. Para o caso da variância, ela cresce com o tempo $t$, mas de forma assintótica para o valor finito $\sigma^{2} / 2 \eta$ (quando $t \rightarrow \infty$ ), ao contrario do MGB onde a variância cresce de forma ilimitada com o horizonte de previsão $(t)$.

Com relação à velocidade de reversão, $\eta$, Dias (2014) ressalta que se a velocidade de reversão for muito forte, o termo estocástico fica muito menor que o termo de tendência e a variância decresce, assim, $\eta \rightarrow \infty$ então $e^{-\eta t} \rightarrow 0 \mathrm{e}$ $\sigma^{2} / 2 \eta \rightarrow 0$, assim o valor esperado da variável $X$ convergirá para a média de longo prazo $\bar{X}$, e sua variância para zero, $\operatorname{Var}(X) \rightarrow 0$. Já com $\eta$ tendendo a zero, a Equação 3.11 se transformará em $d X(t)=\sigma d z$, o que equivale a um MGB simples, e $E(X(t)) \rightarrow 0$ e sua variância $\operatorname{Var}(X) \rightarrow \sigma^{2} t$, com o qual se pode concluir que um MRM extremadamente lento tende a se transformar em um Movimento Browniano.

Além disso, aparece outro conceito importante deste processo ligado ao comportamento da velocidade de reversão $\eta$, este é o half-life, ou seja da meiavida da reversão $H$, que nos dá a medida da lentidão do processo. É o tempo em 
que a variável estocástica leva para percorrer a metade do caminho entre o seu valor corrente e a média de longo prazo. A relação, entre $\eta$ e $H$ para o logaritmo do preço $x$ é dada por $H=\ln 2 / \eta$. A relação deixa ver que para este conceito só é relevante a velocidade de reversão, deixando de lado a média de longo prazo e o valor corrente.

O conceito de meia vida é usado amplamente, mas é definido para a parte determinística do MRM. Considerando a Equação 3.11 se tem:

$$
d X(t)=\eta(\bar{X}-X(t)) d t \Rightarrow d X(t) /(\bar{X}-X(t))=\eta d t
$$

Integrando desde $X_{0}\left(\mathrm{em} t_{0}\right)$ até ao valor de $X$ no instante $t_{1}$, i.é, $X_{1} t_{1}$, e com $\Delta t=t_{1}-t_{0}$, Dias(2014) demostra que:

$$
\left.\int_{x_{0}}^{x_{1}} \frac{d x}{\bar{x}-x}=\int_{t_{0}}^{t_{1}} \eta d t \Rightarrow-\operatorname{Ln}(\bar{x}-x)\right]_{x_{0}}^{x_{1}}=\eta \Delta t \Rightarrow \operatorname{Ln}\left[\frac{x_{1}-\bar{x}}{x_{0}-\bar{x}}\right]=-\eta \Delta t
$$

Pela definição de meia-vida, pode-se escrever: $\Delta t=H \Rightarrow X_{1}-\bar{X}=$ $0,5\left(X_{0}-\bar{X}\right)$. Logo:

$$
\operatorname{Ln}[0,5]=-\eta H \Rightarrow-\operatorname{Ln}[2]=-\eta H \Rightarrow H=\frac{\operatorname{Ln}[2]}{\eta}
$$

\subsection{1.}

\section{Discretização do Modelo de Reversão à Média}

Para poder simular o processo é preciso ter uma equação em tempo discreto, para o qual se soma a parcela determinística da Equação 3.12 com a estocástica da Equação 3.13, a qual é multiplicada pela distribuição normal com média 0.

$$
X_{t}=X_{t-1} e^{-\eta \Delta t}+\bar{X}\left(1-e^{-\eta \Delta t}\right)+\sigma \sqrt{\frac{1-e^{-2 \eta \Delta t}}{2 \eta} N(0,1)}
$$

\subsection{2.}

\section{Estimativa dos parâmetros}

É preciso conhecer os parâmetros da Equação 3.11, ou seja, os valores da média de longo prazo $\bar{X}$, volatilidade $\sigma$ e da velocidade de reversão $\eta$. O MRM pode ser visto como a versão em tempo contínuo do processo em tempo discreto 
denominado em econometria como processo auto regressivo de ordem $1, A R(1)$. Assim, a Equação 3.11 é o limite quando $\Delta t \rightarrow 0$ do seguinte processo $A R(1)$.

$$
X_{t}-x_{t-1}=x_{t-1}\left(e^{-\eta \Delta t}-1\right)+\bar{x}\left(1-e^{-\eta \Delta t}\right)+\varepsilon_{t}
$$

Onde: $\varepsilon_{t} \sim N\left(0, \sigma_{\varepsilon}\right)$ e lembrando que o $X_{t}=\operatorname{Ln}\left(x_{t}\right)$ e $\bar{X}=\operatorname{Ln}(\bar{x})$ e substituindo na Equação 3.15:

$$
\ln \left(x_{t}\right)-\ln \left(x_{t-1}\right)=\ln (\bar{x})\left(1-e^{-\eta \Delta t}\right)+\ln \left(x_{t-1}\right)\left(e^{-\eta \Delta t}-1\right)+\varepsilon_{t} \quad(E q .3 .16)
$$

Rescrevendo essa equação:

$$
\ln \left(\frac{x_{t}}{x_{t-1}}\right)=a+(b-1) \ln \left(x_{t-1}\right)+\varepsilon_{t}
$$

Comparando a Equação 3.16 com a Equação 3.17, se pode obter os parâmetros para a estimação do modelo, para o caso da velocidade de reversão:

$$
b-1=e^{-\eta \Delta t}-1
$$

Então,

$$
\eta=\frac{-\ln (b)}{\Delta t}
$$

Para a estimativa do nível de equilíbrio $\bar{x}: a=\bar{x}\left(1-e^{-\eta \Delta t}\right)$. E como $1-b=1-e^{-\eta \Delta t}$, então a média de longo prazo da variável estocástica é dada por:

$$
\bar{x}=\left(\frac{a}{1-b}\right)
$$

Dias (2014) estima o preço de equilíbrio, que depende de $\bar{x}$ como:

$$
\bar{P}=\operatorname{Exp}\left[\bar{x}+\frac{\sigma^{2}}{(2 \eta)}\right]
$$

A determinação da volatilidade é obtida igualando a variância dos erros da regressão, $\sigma_{\varepsilon}^{2}$, à Equação 3.13: 


$$
\sigma_{\varepsilon}^{2}=\left(1-e^{-2 \eta \Delta t}\right) \frac{\sigma^{2}}{2 \eta}
$$

Substituindo na equação anterior o $\eta$ dado na Equação 3.18, e tendo em conta que $b^{2}=e^{-2 \eta \Delta t}$ :

$$
\sigma_{\varepsilon}^{2}=-\left(1-b^{2}\right)\left(\frac{\sigma^{2} \Delta t}{2 \ln (b)}\right)
$$

De onde tem-se:

$$
\sigma=\sigma_{\varepsilon} \sqrt{\frac{2 \ln (b)}{\left(b^{2}-1\right) \Delta t}}
$$

Onde: $\Delta t$ é definido como $\Delta t=\frac{1}{N}$ e $N$ é a quantidade de dados que tem na amostra num ano, $\Delta t=\frac{1}{12}$ para dados mensais.

Já com estas expressões se deduz que sendo $H=\frac{\ln (2)}{\eta}$ entao $H$ :

$$
H=\frac{\ln (2)}{\ln (b)} \Delta t
$$

\section{8}

\section{Determinação do processo}

Partindo da Equação 3.17, a qual é uma equação de regressão linear geral, pode-se fazer uma análise do que acontece com o comportamento do parâmetro $b$, e como ele mostra o tipo de movimento que vai descrever melhor a variável, bem seja um MGB ou um MRM. Caso $b=1$ (MGB), então a reta da regressão é horizontal, já que na Equação 3.17 o coeficiente angular $b-1$ é igual a zero. A intuição é que a taxa de crescimento no MGB independe do nível dos preços, ela é sempre igual a $\alpha$; para o caso do MRM a taxa de retorno depende do nível dos preços. Assim, no MRM a reta da regressão deve ter inclinação negativa, pois se o nível de preços fosse alto, o retorno esperado para o próximo período é baixo ou até negativo, e se o nível de preços corrente fosse baixo, o retorno esperado para o próximo período é alto, isso quer dizer que para um MRM o coeficiente angular $b-1<0 \Rightarrow b<1$. 
O teste padrão para identificar se os preços se comportam como um MGB ou como um MRM é o Teste da Raiz Unitária, sendo o mais popular o Teste de Dickey-Fuller (1981). Neste, testa-se a hipótese de a inclinação da reta da regressão ser zero. Assim $H_{0}: b-1=0$ e $H_{1}: b-1 \neq 0$, então se os dados mostrarem que não se pode rejeitar a hipótese $H_{0}$, a série terá raiz unitária e seguirá um caminho aleatório, podendo ser modelada por um MGB. Uma regressão linear por mínimos quadrados é realizada sobre a Equação 3.17, e logo a seguir é aplicado o Teste de Disckey-Fuller que gera a estatística $\tau$. Se $\tau<$ valor critico $\Rightarrow H_{0}$ é rejeitado, no caso da regressao da Equação 3.17 (com constante e sem tendencia temporal), a estatística de teste é a razão $\tau$ da estimativa de $b$ por minimos quadrados, que deve ser comparada com os valores criticos do teste de Dickey-Fuller. Usando a notação $P_{t}=\operatorname{Ln} p_{t}$, Razão $t$, determinada $\tau^{*}$, é:

$$
\text { Estatistica } D F: \tau^{*}=\frac{(\hat{b}-1)}{\sqrt{\operatorname{Var}[\hat{b}]}}
$$

Onde o método dos mínimos quadrados dá as estimativas de $b$ e da variância do estimador $b$, Dias (2014):

$$
\begin{aligned}
& \hat{b}=\frac{\sum_{t=1}^{N}\left(p_{t-1}-\bar{p}_{t-1}\right)\left(p_{t}-\bar{p}_{t}\right)}{\sum_{t=1}^{N}\left(p_{t-1}-\bar{p}_{t-1}\right)^{2}} \\
& \mathrm{e} \\
& \operatorname{Var}[\hat{b}]=\frac{\sum_{t=1}^{N} \varepsilon_{t}^{2}}{(N-2) \sum_{t=1}^{N}\left(p_{t-1}-\bar{p}_{t-1}\right)^{2}}
\end{aligned}
$$

Onde: $x_{0}=0$

$\bar{x}$ é a média amostral

$N$ é o tamanho da amostra (quantidade de dados).

Se a estatística do $\tau^{*}$ for maior que o valor crítico da Tabela 4, a hipótese nula $H_{0}$ não é rejeitada, sugerindo raiz unitária ou MGB, se $\tau^{*}$ for menor do que o valor critico, a hipotese nula $H_{0}$ é rejeitada.

Tem se encontrado que ao realizar este teste sobre o preço de commodities não financeiras, a hipótese nula da raiz unitária dificilmente é rejeitada, Dixit e Pindyck (1994) e Pindyck (1999) só conseguiram comprovar que os preços do 
petróleo não seguem o MGB para uma serie de dados de 120 anos. Já Dias (2005a) faz a regressão dos preços nominais do petróleo do tipo Brent num período de 34 anos, sem conseguir rejeitar $H_{0}$. No entanto, Bastian-Pinto (2009) e Dias (2014) defendem que, mesmo não sendo rejeitada a hipótese nula, quando obtido um $b$ que esteja entre 0 e 1 , há indícios de reversão à média. Além disso, fatores estilizados também devem ser considerados na escolha do modelo. Dias (2014) comenta que o Teste de Raiz Unitária tem um poder fraco por precisar de séries muito longas para detectar a reversão.

Tabela 4 - Valores críticos para o Teste da Raiz Unitária de Dick-Fuller $\left(\tau^{*}\right)$

\begin{tabular}{c|c|c|c}
\hline Amostra (n de dados) & $\begin{array}{c}\mathbf{1 \%} \\
\text { significância }\end{array}$ & $\begin{array}{c}\mathbf{5 \%} \\
\text { significância }\end{array}$ & $\begin{array}{c}\mathbf{1 0 \%} \\
\text { significância }\end{array}$ \\
\hline 25 & $-3,75$ & $-3,00$ & $-2,62$ \\
50 & $-3,58$ & $-2,93$ & $-2,60$ \\
100 & $-3,51$ & $-2,89$ & $-2,58$ \\
250 & $-3,46$ & $-2,88$ & $-2,57$ \\
500 & $-3,44$ & $-2,87$ & $-2,57$ \\
$>500$ & $-3,43$ & $-2,86$ & $-2,57$ \\
\hline
\end{tabular}

Fonte: Dias (2014)

Nos anos 80, surgiu um novo teste como alternativa ao Teste da Raiz Unitária para identificação ou não de processos estacionários, em particular identificar MRM. Esse teste é chamado Razão da Variância, que identifica em que extensão os choques estocásticos são temporários, desvios temporários do nível de equilíbrio, como no MRM, ou permanentes, como no caso do MGB. Pindyck(1999) utiliza o Teste da Razão da Variância como uma alternativa à sua pesquisa. O teste é descrito assim:

$$
R_{k}=\frac{1}{k} \cdot \frac{\operatorname{var}\left(x_{t+k}-x_{t}\right)}{\operatorname{var}\left(p_{t+1}-p_{t}\right)}
$$

O termo var representa a variância das series na diferença entre os preços, com retardos de $k$ períodos nas series de preços $p$.

Se $x_{t}$ segue um caminho aleatório, ou seja, não é estacionária, então a variância do numerador deverá crescer linearmente com $k$, de forma que $R_{k}$ tende a 1 para $\mathrm{k}$ grande. Por outro lado, se o $x_{t}$ for autoregressiva, ou seja, um processo estacionário, a variância do numerador irá crescer até certo limite quando $k$ 
aumenta, e assim $R_{k}$ tende a cair com o aumento de $k$ (e tende a zero para $\mathrm{k}$ tendendo a infinito). Caso a razão aumente com $k$, então nem a hipótese de MGB $\left(R_{k} \rightarrow 1\right)$ nem MRM $\left(R_{k} \rightarrow 0\right)$ são razoáveis. Pindyck(1999) encontrou para o preço do petróleo e do carvão um $R_{k}$ com $k$ convergindo para valores entre $0,1 \mathrm{e}$ 0,2 , para $k$ grande. 
4.

\section{MÉTODO BINOMIAL}

Cox, Ross e Rubinstein (1979) foram os pioneiros na avaliação do preço de uma opção que converge de forma fraca para um MGB, quando o tempo diminui, com a utilização de uma abordagem discreta por meio de árvores recombinantes, onde em cada nó se encontram os possíveis comportamentos dos fatores estocásticos. Os autores mostraram que o valor de uma opção do tipo europeu no modelo binomial converge para o valor dado pela fórmula de Black e Scholes, com o qual conseguiram generalizar o modelo de Black e Scholes(1973). Na abordagem realizada por Cox, Ross e Rubinstein(1979), os saltos de subida (up) e os de descida (down) são inversos, formando uma árvore recombinante (lattice) e fazendo com que em cada amostra $N$ se obtenham $N+1$ nós. Note-se que se não for recombinante, a árvore teria $2^{N}$ nós.

No entanto, Boyle (1988) foi o primeiro a utilizar a abordagem de Cox, Ross e Rubinstein(1979) em um modelo trinomial para avaliação de opções com um ativo-objeto. Ao utilizar processos estocásticos de dois fatores, Boyle(1988) introduz um novo conceito, o de árvores bivariáveis, com o qual Nelson e Ramaswamy (1990) obtém um modelo para processos estocásticos que seguem tanto um MGB quanto um MRM discreto.

Para modelar o preço do petróleo e calcular a opção de abandono de um poço de petróleo, Hahn (2005) utilizou um modelo com dois fatores. BastianPinto et. al. (2009), trabalharam com o preço de duas commodities, açúcar e etanol, utilizando um MRM para avaliar uma opção de troca de input, desenvolvendo uma árvore quadrinomial utilizando a aproximação proposta por Nelson e Ramaswamy (1990).

Gastaldi (2012) avaliou, pela metodologia proposta por Nelson e Ramaswamy(1990), a possibilidade de antecipação ou postergação do corte de uma floresta de eucalipto, frente a incertezas acerca do preço de mercado da madeira.

Hahn e Dyer (2011) trabalharam com processos estocásticos de dois fatores e árvores binomiais bivariáveis para modelar em tempo discreto, utilizando um 
formato de árvores bidimensional para os mesmos problemas analisados por Schwartz e Smith(2000).

No Brasil, Samanez e Costa (2013) avaliaram opções do tipo swing no mercado de gás natural, usando o modelo da árvore binomial bivariável e determinando o valor dos parâmetros por meio de Filtros de Kalman.

\section{1.}

\section{Árvore Binomial Recombinante}

Nelson e Ramaswamy (1990) propõem um método geral para o desenvolvimento das árvores binomiais recombinantes. O problema é encontrar uma sequência binomial que convirja para a seguinte equação diferencial estocástica:

$$
d X(t)=\alpha(x, t) d t+\sigma(x, t) d z
$$

Onde $X_{t}$ é o logaritmo neperiano do preço $x_{t}$ do ativo no instante $t$, ou seja, $X(t)=\operatorname{Ln} x_{t}, \alpha(x, t)$ e $\sigma(x, t)$ são a taxa de crescimento do processo (drift) e o desvio-padrão, respectivamente, e $d z$ é o incremento de Wiener. Para resolver este problema os autores propuseram uma sequência binomial simples de duração $\Delta t$ com $n$ períodos e horizonte de tempo $T=n \Delta t$ :

$$
\begin{aligned}
& X_{t}^{+}=Y+\sqrt{\Delta t} \sigma(X, t) \text { Movimento de subida (up) } \\
& X_{t}^{-}=Y-\sqrt{\Delta t} \sigma(X, t) \text { Movimento de descida (down) } \\
& p_{t}=\frac{1}{2}+\frac{1}{2} \sqrt{\Delta t} \alpha(x, t) / \sigma(X, t) \text { Probabilidade de up } \\
& 1-p_{t} \text { Probabilidade de down }
\end{aligned}
$$

Com este conjunto de equações se consegue determinar os up e down, que são iguais para cada rama, e a probabilidade $p_{t}$ em cada nó, e portanto gerar a árvore recombinante (lattice). No entanto, os valores para algumas probabilidades $p_{t}$ em cada nó podem ser negativas, razão pela qual os autores fazem uma censura, forçando os valores a se enquadrarem no intervalo $0 \leq p_{t} \leq 1$.

Substituindo $\alpha(x, t)$ e $\sigma(X, t)$ pelos fatores do processo de fator único de Ornstein-Uhlenbeck|: $\eta\left(\bar{X}-X_{t}\right)$ e $\sigma$, se tem que: 


$$
d X(t)=\eta\left(\bar{X}-X_{t}\right) d t+\sigma d z_{t}
$$

Restringindo as probabilidades de $p_{t}$ tem-se:

$X_{t}^{+}=X+\sqrt{\Delta t} \sigma-$ Movimento de subida (up)

$X_{t}^{-}=X-\sqrt{\Delta t} \sigma-$ Movimento de descida (down)

$$
\left\{\begin{array}{lc}
q_{t}=\frac{1}{2}+\frac{1}{2} \sqrt{\Delta t} \eta \frac{(\bar{X}-X)}{\sigma} & \text { Se: } 0 \leq q_{t} \leq 1 \\
q_{t}=0 & \text { Se: } q_{t} \leq 0 \quad \text { Probabilidades up } \\
q_{t}=1 & \text { Se: } q_{t} \geq 1
\end{array}\right.
$$

$1-q_{t}$ - Probabilidade de descida down

Os autores resumem para as probabilidades:

$$
q_{t}=\max \left\{0, \min \left[1, \frac{1}{2}+\frac{1}{2} \sqrt{\Delta t} \eta \frac{\left(\bar{X}-X_{t}\right)}{\sigma}\right]\right\}
$$

A probabilidade $q_{t}$ irá se alterar no tempo, dependente de $X_{t}$. Esta probabilidade censurada produz um modelo que converge fracamente para um processo de reversão à média.

Em um intervalo de tempo $\Delta t$, a árvore vem dada como mostra a Figura 11, onde o valor anterior vem sendo incrementado por $\Delta X$.

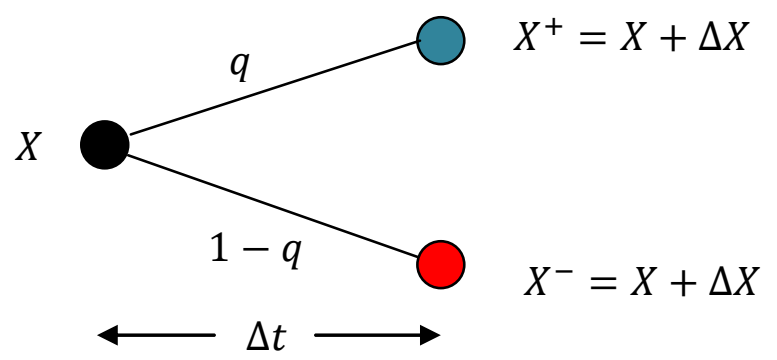

Figura 11 - árvore binomial para um intervalo de tempo $\Delta t$ Fonte: Hahn e Dyer (2011)

Os s incrementos $\Delta X$ são: $\Delta X^{+}=\sigma \sqrt{\Delta t}$ e $\Delta X^{-}=-\sigma \sqrt{\Delta t}$, lembrando que $X$ representa logaritmo neperiano do preço, então $\Delta x^{+}=e^{\sigma \sqrt{\Delta t}}$ e $\Delta x^{+}=e^{-\sigma \sqrt{\Delta t}}$ pelo qual: 


$$
\begin{aligned}
& X^{+}=X+\sigma \sqrt{\Delta t} \Rightarrow X^{+}=\operatorname{Ln}\left(x^{+}\right)=\operatorname{Ln}(X+\sigma \sqrt{\Delta t}) \Rightarrow \\
& \left(x^{+}\right)=x e^{\sigma \sqrt{\Delta t}} \\
& X^{-}=X+\sigma \sqrt{\Delta t} \Rightarrow X^{-}=\operatorname{Ln}\left(x^{-}\right)=\operatorname{Ln}(X+\sigma \sqrt{\Delta t}) \Rightarrow \\
& \left(x^{-}\right)=x e^{-\sigma \sqrt{\Delta t}}
\end{aligned}
$$

O modelo final para uma variável é mostrado na Figura 12.

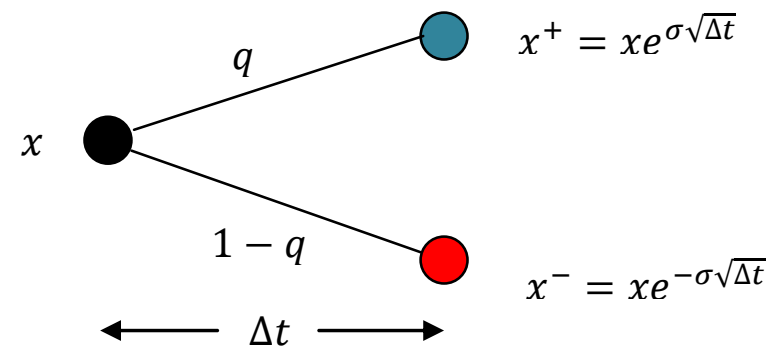

Figura 12 - Nó de ramificação binomial para os preços $(X=\operatorname{Ln}(x))$

Para poder avaliar opções, normalmente se usa a forma neutra ao risco do processo para poder descontar com a taxa livre de risco $r$, porque caso contrário teria que se procurar a taxa de desconto ajustada ao risco $\mu$ para a opção, o qual resulta difícil de determinar. Para um processo ajustado ao risco, tem-se que $\mu=\alpha+\delta$, onde $\delta$ é o a taxa de dividendos caso o ativo-objeto seja uma ação, o a taxa de conveniência, caso seja uma commodity. Já no caso da forma neutra ao risco, se troca o $\mu$ por $r$, sendo a taxa de conveniência dada por: $\alpha=r-\delta$. Para o MRM: $d X(t)=\eta\left(\bar{X}-X_{t}\right) d t+\sigma d z_{t}$, e $\alpha=\eta\left(\bar{X}-X_{t}\right)$. Para o MRM neutro aos risco: $\alpha=r-\delta=r-\mu+\eta\left(\bar{X}-X_{t}\right) \Rightarrow \alpha=\eta\left(\bar{X}-\frac{\mu-r}{\eta}-X_{t}\right)$, sendo o prêmio de risco $\pi=\mu-r$. O termo $\frac{\mu-\boldsymbol{r}}{\eta}$ é um prêmio de risco normalizado que penaliza ao logaritmo do preço. Consequentemente, no MRM neutro ao risco, temos que:

$$
d X(t)=\eta\left(\bar{X}-\frac{\pi}{\eta}-X_{t}\right) d t+\sigma d z_{t}
$$

E a probabilidade de Martingale ajustada ao risco: 


$$
q_{t}=\max \left\{0, \min \left[1, \frac{1}{2}+\frac{1}{2} \sqrt{\Delta t} \eta \frac{\left(\bar{X}-\frac{\pi}{\eta}-X_{t}\right)}{\sigma}\right]\right\}
$$

\section{2.}

\section{Modelagem bivariável do processo de Reversão à Média}

$\mathrm{Na}$ modelagem bivariável, se procura combinar duas variáveis incertas correlacionadas que acompanham processos auto-regressivos numa só arvore. Schwartz e Smith (2000) decompõem em dois fatores o logaritmo neperiano do preço, aplicando um MGB para o longo prazo e um MRM para o curto prazo. Hahn e Dyer (2011) desenvolveram um método para a construção de uma árvore binomial bivariável aplicável ao modelo de dois fatores de Schwartz e Smith (2000).

Seguindo Hahn e Dyer (2011), a combinação das duas variáveis levam a uma árvore quadrinomial, como se mostra na Figura 13.

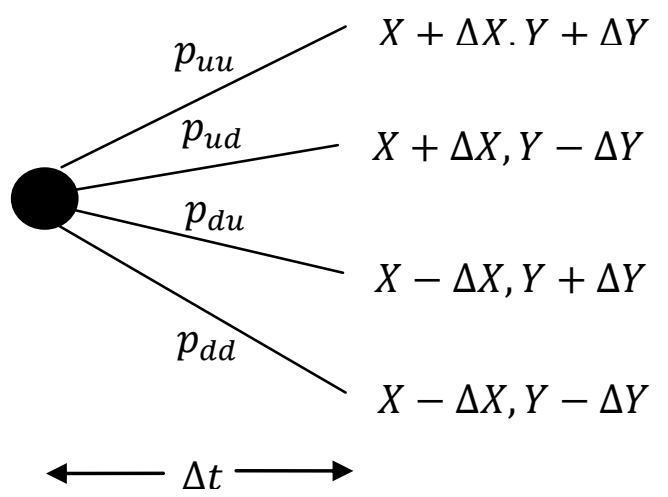

Figura 13 - Árvore bivariável (quadrinomial)

Fonte: Hahn e Dyer (2011)

No caso das commodities tratadas neste estudo, é assumido que o logaritmo do preço do açúcar $(X)$ e o logaritmo do preço do etanol $(Y)$ seguem um MRM. Assim, $\quad d X(t)=\eta\left(\bar{X}-X_{t}\right) d t+\sigma d z_{X}, \quad$ e $\quad d Y(t)=\eta\left(\bar{Y}-Y_{t}\right) d t+\sigma d z_{Y} . \quad$ A relação entre os incrementos dos dois processos é dado por: $d z_{X} d z_{Y}=\rho_{X Y} d t$, onde $\rho$ é um parâmetro de correlação (constante). 
Hand e Dyer (2011) utilizam o mesmo método básico utilizado por Boyle (1988), para determinar as probabilidades conjuntas dos processos:

$$
\left\{\begin{array}{l}
p_{u u}=\frac{\Delta_{X} \Delta_{Y}+\Delta_{Y} v_{X} \Delta t+\Delta_{X} v_{Y} \Delta t+p \sigma_{X} \sigma_{Y} \Delta t}{4 \Delta_{X} \Delta_{Y}} \\
p_{u d}=\frac{\Delta_{X} \Delta_{Y}+\Delta_{Y} v_{X} \Delta t-\Delta_{X} v_{Y} \Delta t-p \sigma_{X} \sigma_{Y} \Delta t}{4 \Delta_{X} \Delta_{Y}} \\
p_{d u}=\frac{\Delta_{X} \Delta_{Y}-\Delta_{Y} v_{X} \Delta t+\Delta_{X} v_{Y} \Delta t-p \sigma_{X} \sigma_{Y} \Delta t}{4 \Delta_{X} \Delta_{Y}} \\
p_{d d}=\frac{\Delta_{X} \Delta_{Y}-\Delta_{Y} v_{X} \Delta t-\Delta_{X} v_{Y} \Delta t+p \sigma_{X} \sigma_{Y} \Delta t}{4 \Delta_{X} \Delta_{Y}}
\end{array}\right.
$$

Onde os incrementos são $\Delta_{X}=\sigma_{X} \sqrt{\Delta t}$ e $\Delta_{Y}=\sigma_{Y} \sqrt{\Delta t}$. Naturalmente a soma de todas as probabilidades conjuntas tem que ser igual a 1 . Assim, $p_{u u}+p_{u d}=1$ e $p_{d u}+p_{d d}=1$ e o drift de cada processo é dado por $v_{X}=\eta_{X}\left(\bar{X}-X_{t}\right)$ e $v_{Y}=\eta_{Y}\left(\bar{Y}-Y_{t}\right)$.

A abordagem de Hahn e Dyer (2011) combina duas árvores recombinantes, baseados em Nelson e Ramaswamy (1990), em que as probabilidades dos preços em cada nó da árvore são censuradas, quando a reversão conduz a valores maiores a um e menores a zero. Desafortunadamente, dado que se tem dois fatores, e portanto quatro nós, a censura não pode ser feita diretamente, como no caso de um só fator. Devido a essa impossibilidade, Hahn e Dyer (2011) propõem aplicar as regras Bayesianas para decompor as probabilidades conjuntas no produto das probabilidades marginal e condicional:

$$
P(X \cap Y)=P(X) * P(Y \mid X)
$$

Probabilidades marginais para $\mathrm{X}$ :

$$
\begin{aligned}
& p_{u}=\frac{1}{2}+\frac{1}{2} \frac{v_{x} \Delta_{t}}{\Delta_{x}} \\
& p_{d}=\frac{1}{2}-\frac{1}{2} \frac{v_{x} \Delta_{t}}{\Delta_{x}}
\end{aligned}
$$

As equações conjuntas (Equação 4.10) são divididas pelas probabilidades marginais de $X$ para se obter as probabilidades condicionais. As equações 4.12 mostram as verdadeiras equações, corrigidas pelo autor desta dissertação, pois 
encontrou-se erros de sinais nas equações apresentadas no trabalho original de Hahn e Dyer (2011):.

$$
\left\{\begin{array}{l}
p_{u \mid u}=\frac{\Delta_{X}\left(\Delta_{Y}+\Delta t v_{Y}\right)+\Delta t\left(\Delta_{Y} v_{X}+p \sigma_{X} \sigma_{Y}\right)}{2 \Delta_{Y}\left(\Delta_{X}+\Delta t v_{X}\right)} \\
p_{d \mid u}=\frac{\Delta_{X}\left(\Delta_{Y}-\Delta t v_{Y}\right)+\Delta t\left(\Delta_{Y} v_{X}-p \sigma_{X} \sigma_{Y}\right)}{2 \Delta_{Y}\left(\Delta_{X}+\Delta t v_{X}\right)} \\
p_{u \mid d}=\frac{\Delta_{X}\left(\Delta_{Y}+\Delta t v_{Y}\right)-\Delta t\left(\Delta_{Y} v_{X}+p \sigma_{X} \sigma_{Y}\right)}{2 \Delta_{Y}\left(\Delta_{X}-\Delta t v_{X}\right)} \\
p_{d \mid d}=\frac{\Delta_{X}\left(\Delta_{Y}-\Delta t v_{Y}\right)-\Delta t\left(\Delta_{Y} v_{X}-p \sigma_{X} \sigma_{Y}\right)}{2 \Delta_{Y}\left(\Delta_{X}-\Delta t v_{X}\right)}
\end{array}\right.
$$

A árvore quadrinomial com probabilidades conjuntas, é agora dividida em duas etapas de probabilidades, marginais e condicionais no mesmo $\Delta_{t}$, para as variáveis $X$ e $Y$, respetivamente. A Figura 14 mostra a árvore quadrinomial com probabilidades conjuntas. Tal como foi mencionado, e seguindo Nelson e Ramaswamy (1999), nesta abordagem as probabilidades também são censuradas para não chegar a se obter valores negativos nem maiores a 1.

Commodity $X$

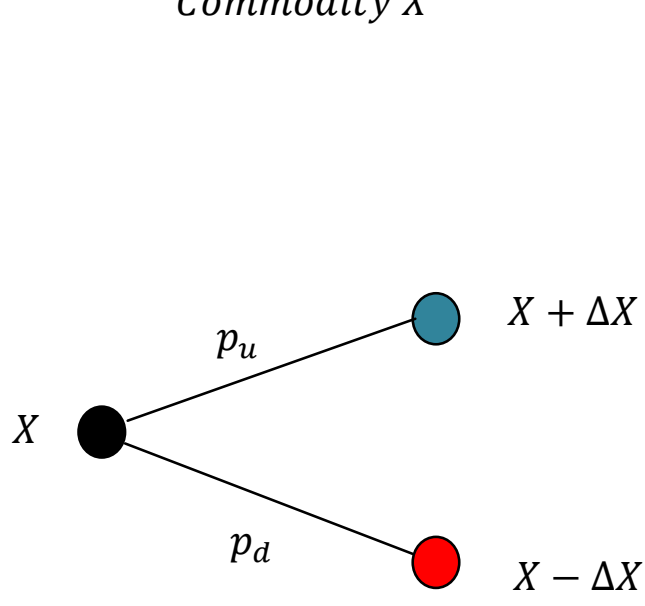

\section{Commodity $Y$}
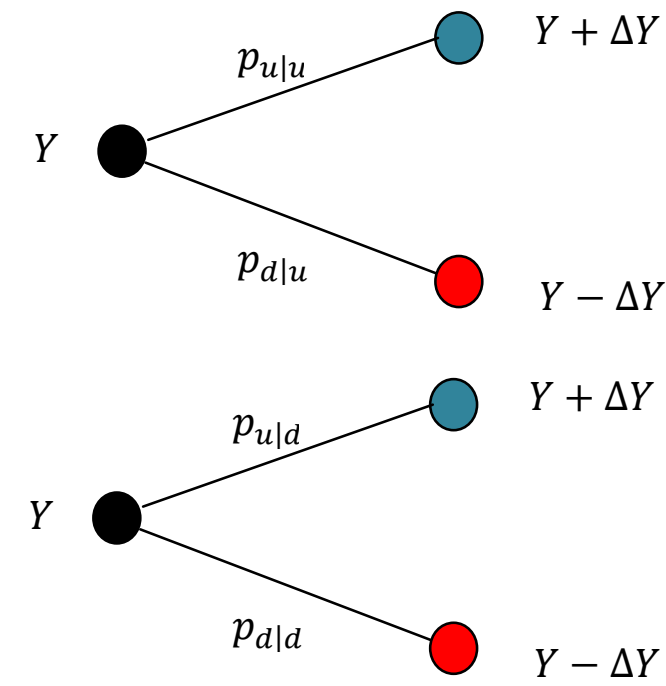

$\Delta t$

Figura 14 - Divisão, marginal condicional do quadrinomial

Fonte: Hahn e Dyer (2011) 
Nesta nova formulação deve-se cumprir que: $p_{u \mid u}+p_{d \mid u}=1$ e $p_{u \mid d}+$ $p_{d \mid d}=1$. Para cada uma das probabilidades marginais e condicionais, a censura tem que ser na medida necessária. 
5.

\section{Avaliação da opção de flexibilidade no setor sucro-alcooleiro}

Nesta seção será avaliado o valor da flexibilidade que tem os processadores de cana de açúcar de produzir etanol ou açúcar, no caso de açúcar com etanol como subproduto.

No presente trabalho serão estudadas duas regiões. Na Figura 1 pode-se observar o mapa da produção da cana de açúcar, e também uma ilustração da distribuição dela no país, mostrando que as regiões sudeste e nordeste são as maiores produtoras.

Na região Nordeste, o Estado de Alagoas é o maior produtor de etanol, e o terceiro do Brasil, e Pernambuco o segundo maior produtor da região, pelo qual estes dois representarão esta região. Para a região Sudeste o estado de maior produção é São Paulo portanto é o escolhido para a sua representação.

Os dados foram obtidos do Centro de Estudos Avançados em Economia $(\mathrm{CEPEA})^{16}$ que é parte do Departamento de Economia, Administração e Sociologia da ESALQ-USP. As séries históricas foram levantadas em formato mensal começando em maio de 2003 a julho de 2014, contendo 134 observações. As quais foram deflacionadas pelo Índice Geral de Preços - Disponibilidade Interna IGP DI, fornecido pela Fundação Getúlio Vargas e disponibilizado em bases mensais no site da Ipeadata ${ }^{17}$, tendo como referência julho de 2014.

Com relação às commodities, o etanol tem duas composições distintas, etanol anidro e etanol hidratado, conforme definido por Gonçalves, et al. (2006). Para representar o nível de preço do produto foi considerada uma participação de $70 \%$ do etanol anidro e o restante do etanol hidratado, dado que ambos se produzem em uma usina aproximadamente nessa proporção. A Moeda por unidade de medida para a Açúcar é R $\$ /$ Saca de $50 \mathrm{Kg}$, e para o Etanol é R $\$ /$ Litro. Os preços históricos e os preços históricos deflacionados são representados nas Figuras 15, 16, 17 e 18.

\footnotetext{
${ }^{16}$ Cepea: http://cepea.esalq.usp.br/

${ }^{17}$ Ipeadata: http://www.ipeadata.gov.br/
} 


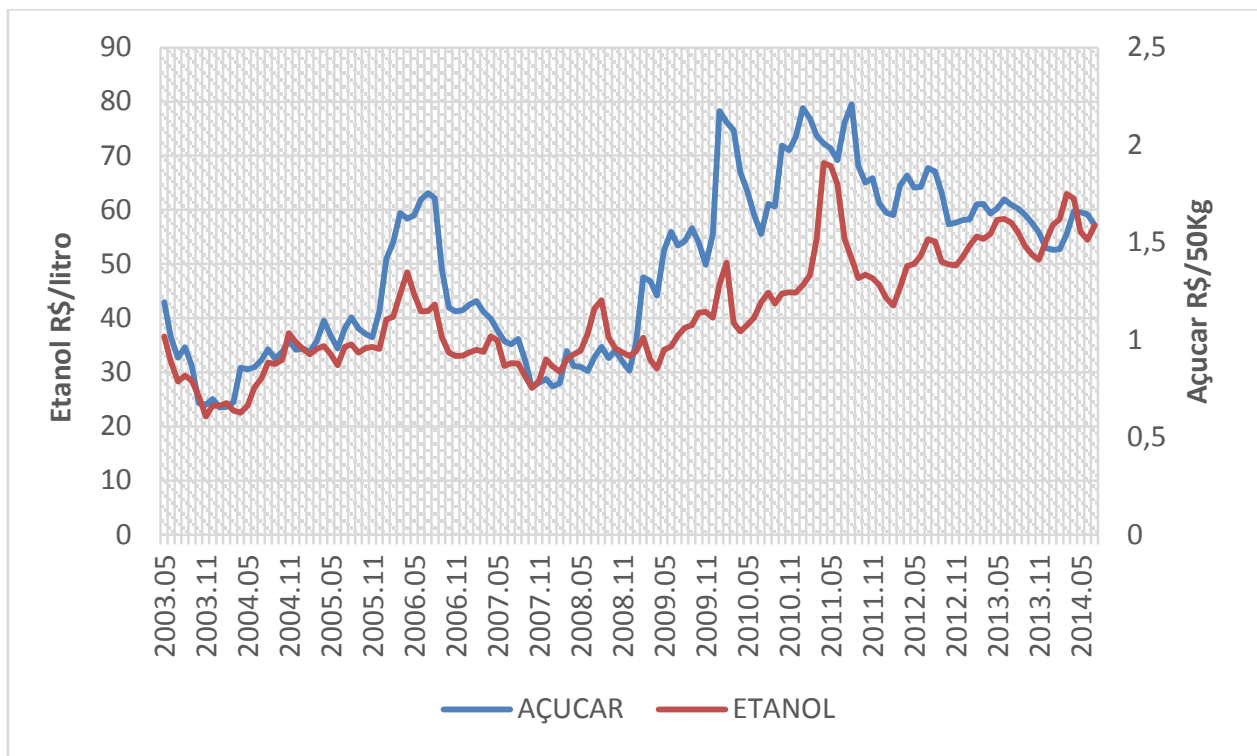

Figura 15 - Preços do etanol e do açúcar para a região Nordeste

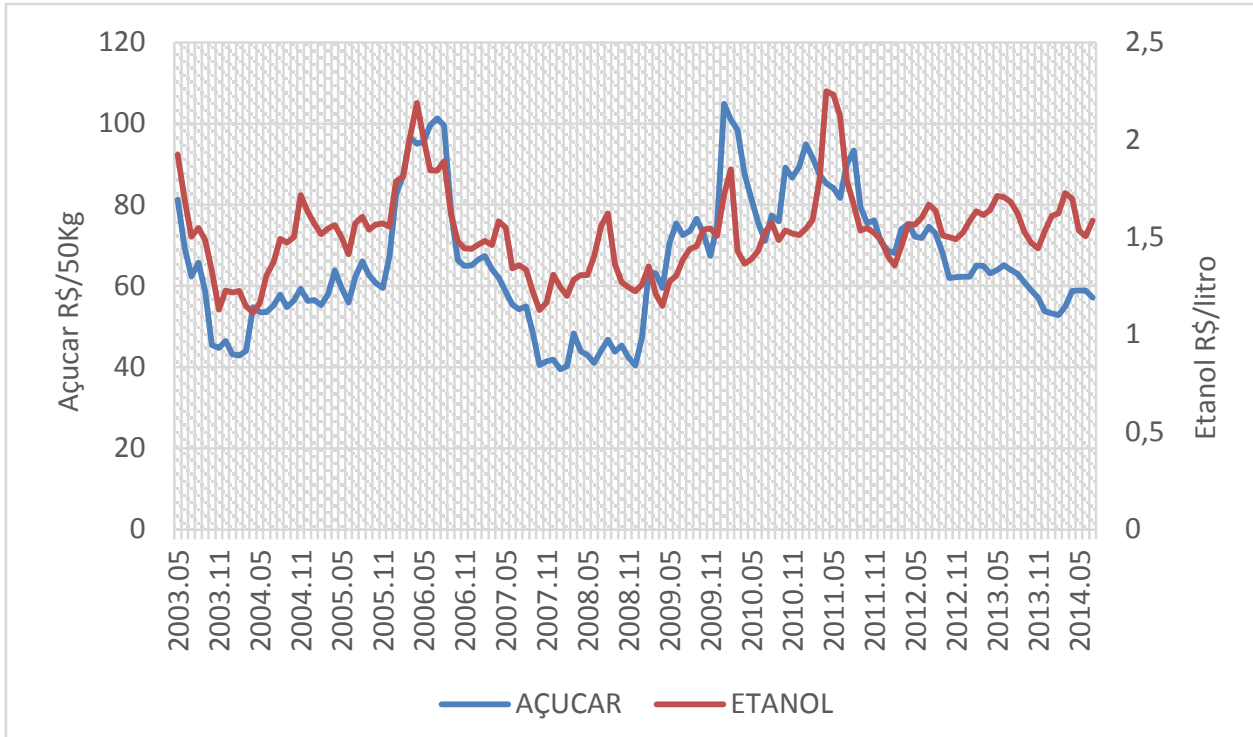

Figura 16 - Preços do etanol e do açúcar deflacionados para a região NE pelo IGPDI, Base: JUL 2014

Pode-se notar que na Figura 15, as séries dos preços nominais do açúcar e do etanol, possuem um comportamento próximo, subindo e descendo em proporções semelhantes com uma correlação positiva de 0,7447 , ou seja: com o preço do etanol subindo, os usineiros procuram produzir mais etanol, com isso a quantidade de açúcar processada se reduz, fazendo o preço subir. Igualmente mostra que, o comportamento dos preços tem tendência de crescimento, o que sugere serem descritas por um MGB. Porém, na Figura 16, os preços 
deflacionados do açúcar e do etanol na região Nordeste tem um fator de correlação de 0,653 , sendo menor em relação à correlação dos preços nominais e observa-se na figura maior proximidade nos dados. A tendência do crescimento desaparece para os preços deflacionados com um comportamento similar ao MRM.

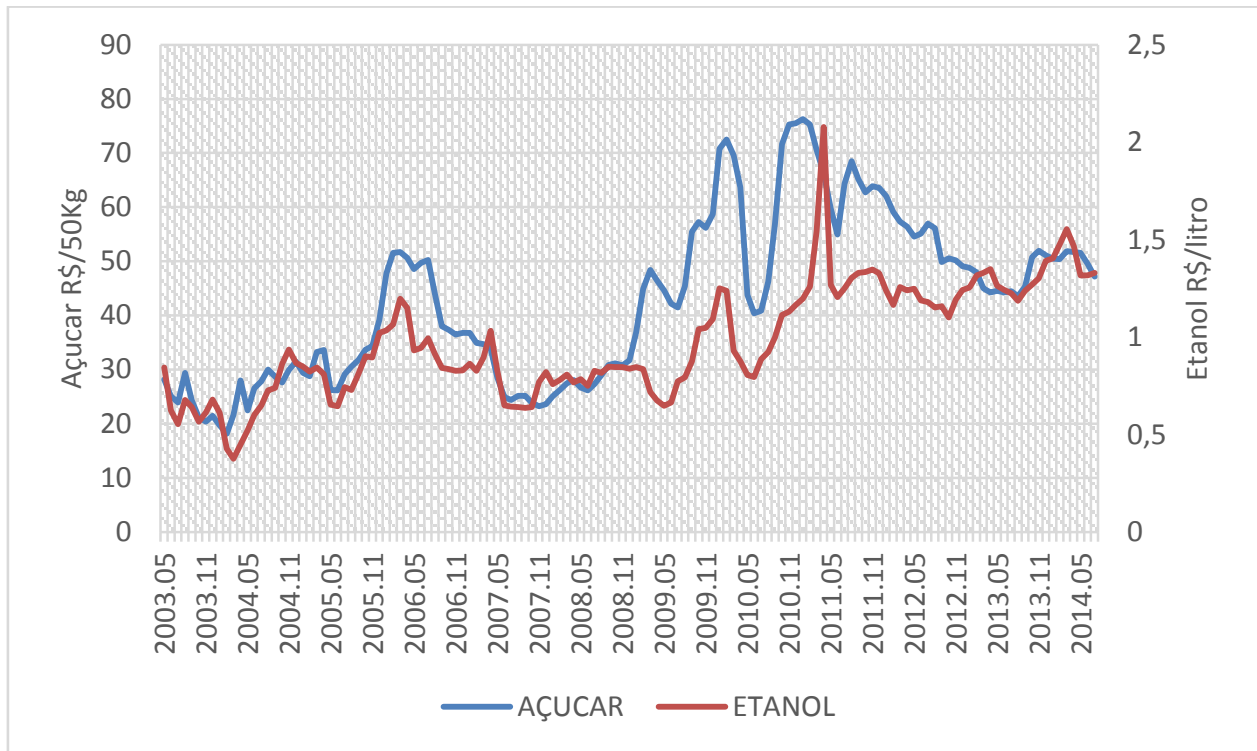

Figura 17 - Preços do etanol e do açúcar para a região Sudeste

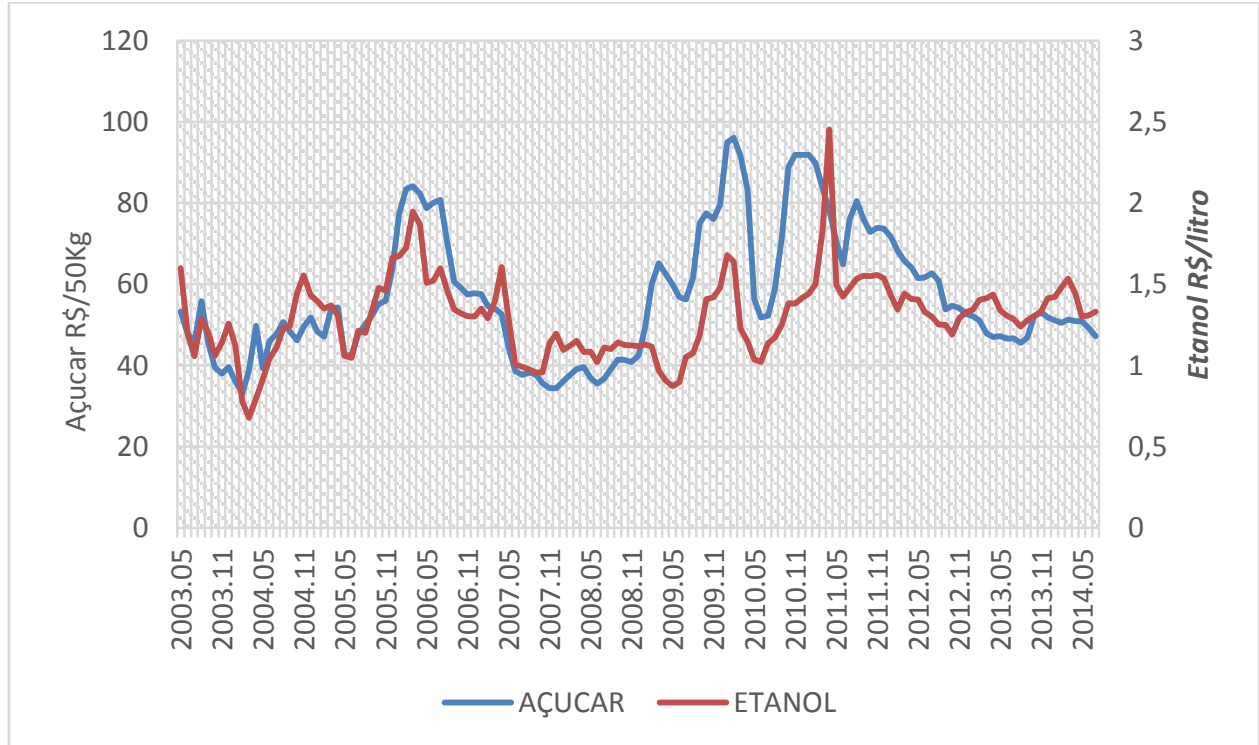

Figura 18 - Preços do etanol e do açúcar deflacionados para a região SE pelo IGPDI, Base: JUL 2014

Para os preços nominais da região Sudeste (Figura 17) nota-se uma tendência a crescer no tempo como um MGB. As duas commodities acompanhamse nos movimentos de descida e subida com uma correlação positiva de 0,7664. 
Os preços deflacionados desta região (Figura 18) perdem a tendência de crescimento, apresentando uma correlação positiva 0,612 .

\section{1.}

Determinação dos parâmetros dos processos por meio da regressão linear

Já com os preços deflacionados para as duas regiões, Sudeste e Nordeste, o passo seguinte é fazer uma regressão linear do logaritmo neperiano dos preços. Assim: $\left(\ln \left(x_{t}\right)-\ln \left(x_{t-1}\right)\right)=a+(b-1) \ln \left(x_{t-1}\right)+\varepsilon_{t}$. Os resultados das regressões para as séries de preços deflacionados estão listadas na Tabela 5.

Tabela 5 - Parâmetros da regressão dos preços deflacionados do etanol e açúcar para a região Nordeste e Sudeste

\begin{tabular}{l|c|c|c|c}
\hline \multirow{2}{*}{ Parâmetro } & \multicolumn{2}{c|}{ Nordeste } & \multicolumn{2}{c}{ Sudeste } \\
\cline { 2 - 5 } \multicolumn{1}{c|}{ Etanol } & Açúcar & Etanol & Açúcar \\
\hline$a-1$ & 0,05502005 & 0,2648551 & 0,03883416 & 0,23650794 \\
$b$ & $-0,1385877$ & $-0,0643308$ & $-0,16558986$ & $-0,0590724$ \\
$\sigma_{\varepsilon}$ Erro padrão & 0,8614123 & 0,9356691 & 0,83441014 & 0,9409276 \\
da estimativa & 0,06875673 & 0,0837948 & 0,10257082 & 0,09327734 \\
& & & & \\
\hline
\end{tabular}

As retas plotadas das regressões e suas equações correspondentes para as séries de dados usadas podem ser observadas nas Figuras 19, 20, 21 e 22.

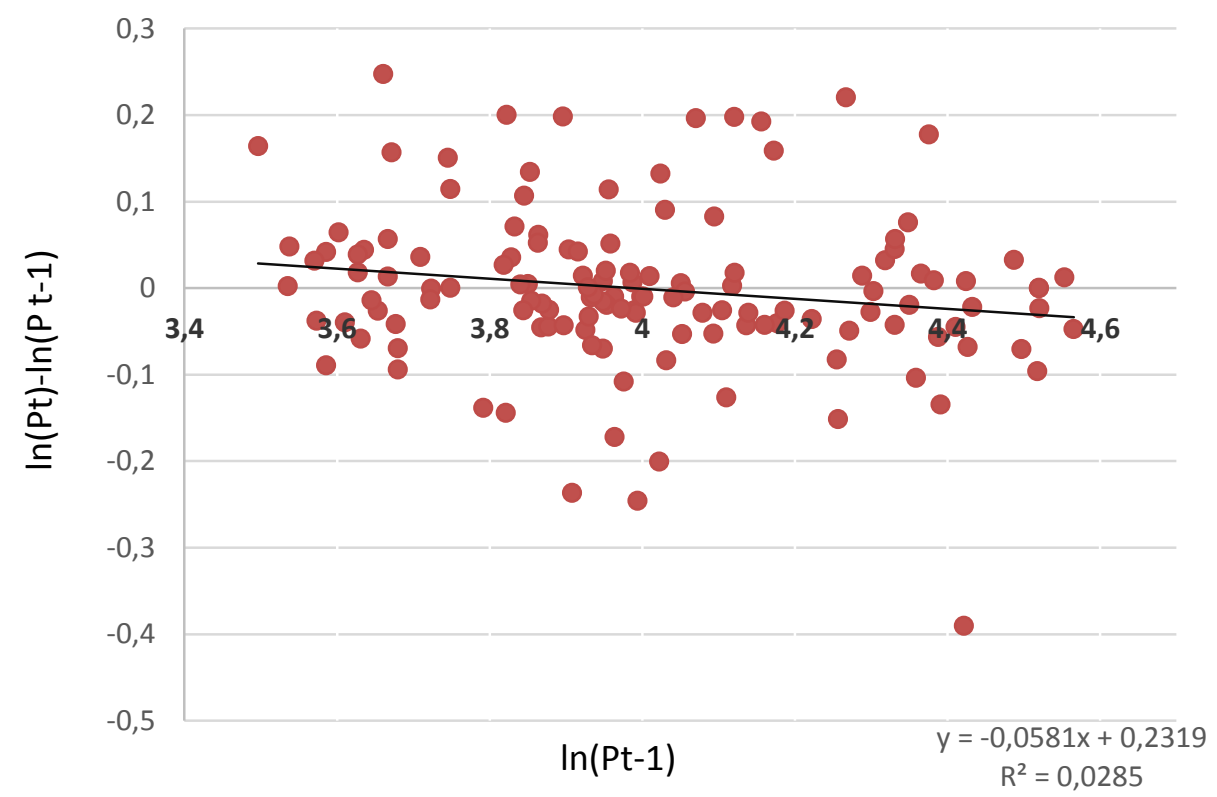

Figura 19 - Regressão para o açúcar na região Sudeste 


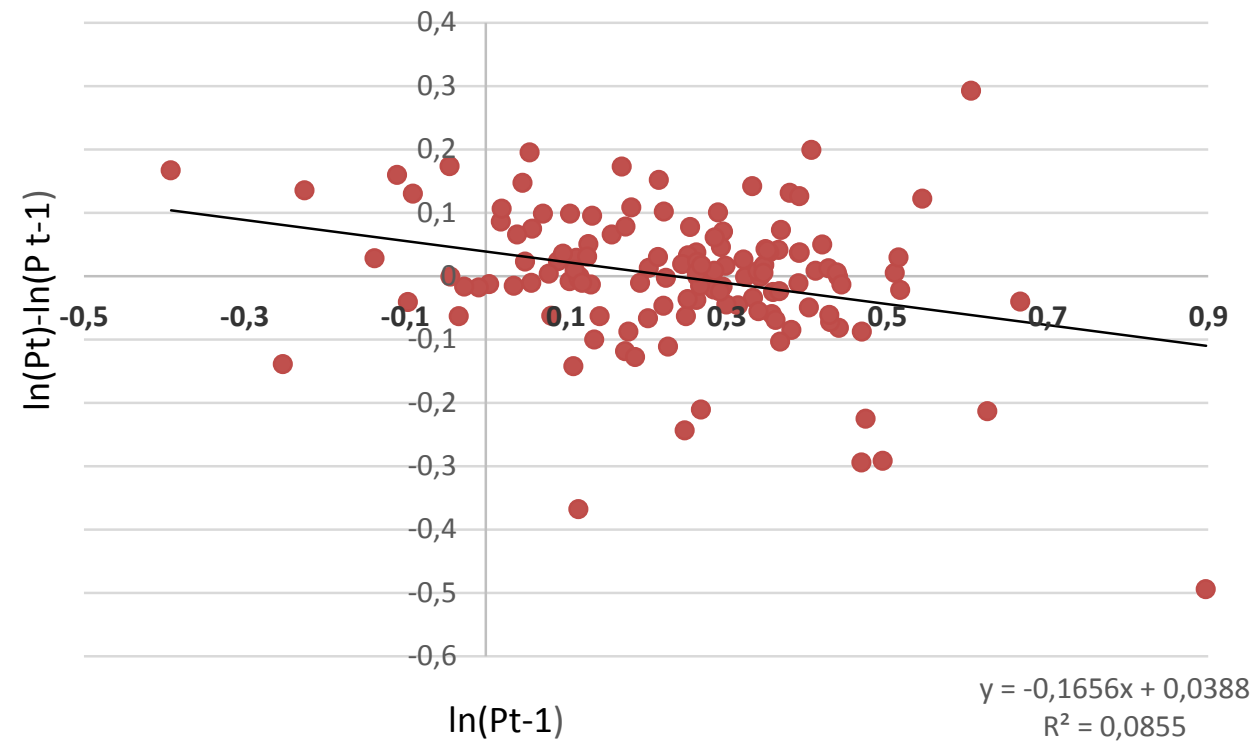

Figura 20 - Regressão para o etanol na região Sudeste

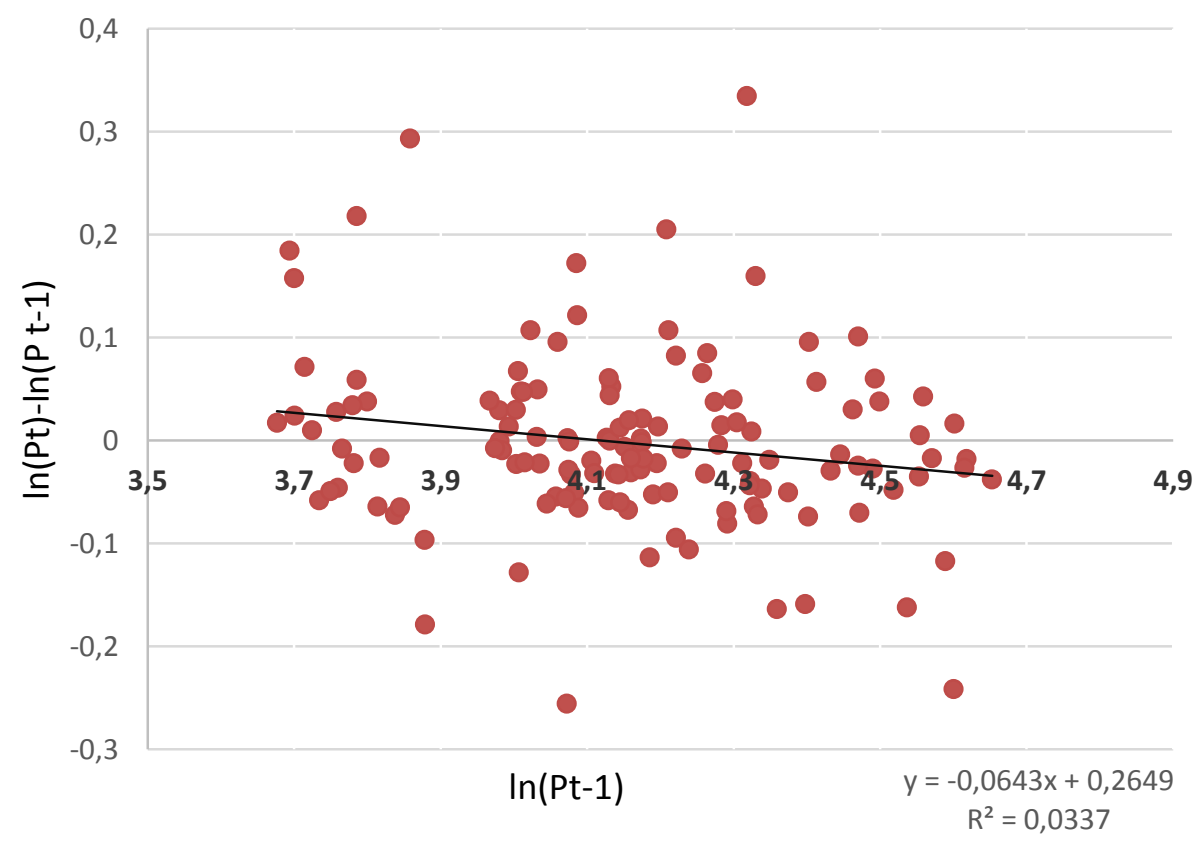

Figura 21 - Regressão para o açúcar na região Nordeste 


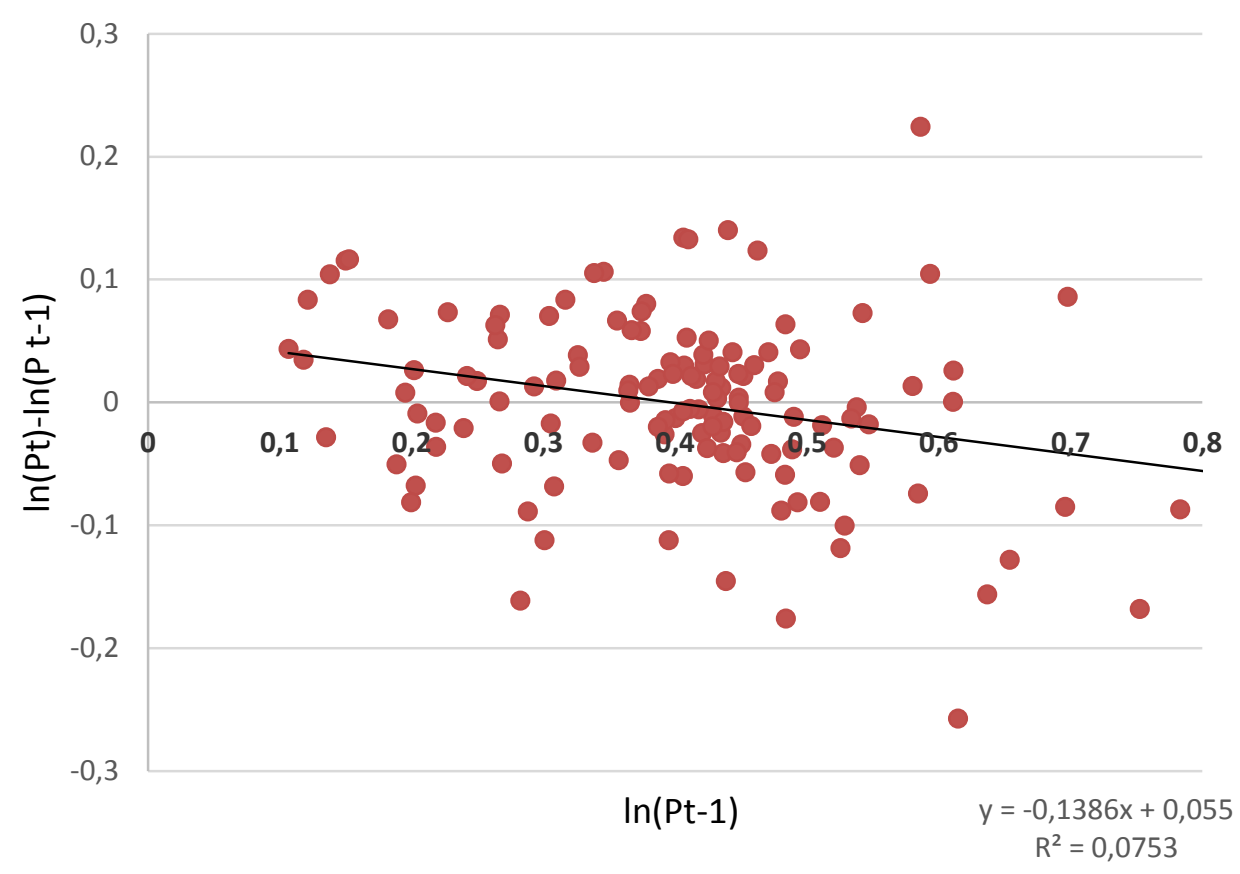

Figura 22 - Regressão para o etanol região Nordeste

Pode-se observar nas Figuras 19, 20, 21 e 22, que a linha de tendência mostra uma inclinação negativa, que lembrando o tratado no capitulo 3 , poderia se considerar os indícios do processo auto regressivo ( $b$ entre 0 e 1 ).

\section{2.}

\section{Determinação do processo}

O teste estatístico mais comum para verificar estacionariedade é o Teste da Raiz Unitária de Dickey-Fuller (1981). Geralmente é utilizado para verificar a adequabilidade do MGB na série dos preços. Neste teste, a presença de uma ou mais raízes unitárias indica a não estacionariedade, ou seja, os valores tendem a aumentar com o transcorrer do tempo, assumindo diferentes padrões. As hipóteses para o caso são:

$H_{0}: b-1=0$, existe $\mathrm{n}$ raízes unitárias, MGB

$H_{1}: b-1 \neq 0$, não existem raízes unitárias MRM

Se a estatística do teste, $\tau^{*}$, (baseada nos resíduos da regressão e que não tem distribuição $t$ ) for maior que o valor crítico da Tabela 4, a hipótese nula $H_{0}$ 
não é rejeitada, sugerindo raiz unitária ou MGB, e se $\tau^{*}$ for menor do que o valor critico, a hipótese nula $H_{0}$ é rejeitada.

Seguindo a teoria do capitulo 3 para a determinação do processo, os resultados obtidos podem ser observados na Tabela 6 .

Tabela 6 - Teste da Raiz Unitária de Dickey e Fuller

\begin{tabular}{l|c|c|c|c}
\cline { 2 - 5 } & \multicolumn{2}{|c|}{ Nordeste } & \multicolumn{2}{c}{ Sudeste } \\
\cline { 2 - 5 } & Etanol & Açúcar & Etanol & Açúcar \\
\hline Observações & 134 & 134 & 134 & 134 \\
$\tau^{*}$ para $(b-1)$ & $-3,277$ & $-2,14594517$ & $-3,513$ & $-2,00010441$ \\
Valor critico 5\% & $-2,88$ & $-2,88$ & $-2,88$ & $-2,88$ \\
\hline
\end{tabular}

Os valores encontrados para o caso do açúcar nas regiões estudadas, apresentam valores $\tau^{*}$ menores ao valor critico de $5 \%$ o qual indica a presença de raiz unitária, MGB, por outro lado para o caso do etanol os valores $\tau^{*}$ são menores do que o valor critico, o qual rejeita a hipóteses nula, o que indica a presença de um processo estacionário.

Os valores obtidos para os coeficientes $b$ mostrados na Tabela 5, inferiores a 1, podem ser o indício da presença de algum nível de reversão à média.

Para poder identificar a presença de um processo estacionário nos dados, em particular identificar MRM, o Teste da Razão da Variância descrito no capítulo 3 foi aplicado. A Figura 23 mostra o teste para os preços deflacionados do etanol e do açúcar na região Nordeste e Sudeste, e a Figura 24 mostra o teste para o logaritmo neperiano dos preços das duas commodities nas duas regiões citadas. O teste foi programado no Matlab, com retardos $k$ de 1 a 134 . 


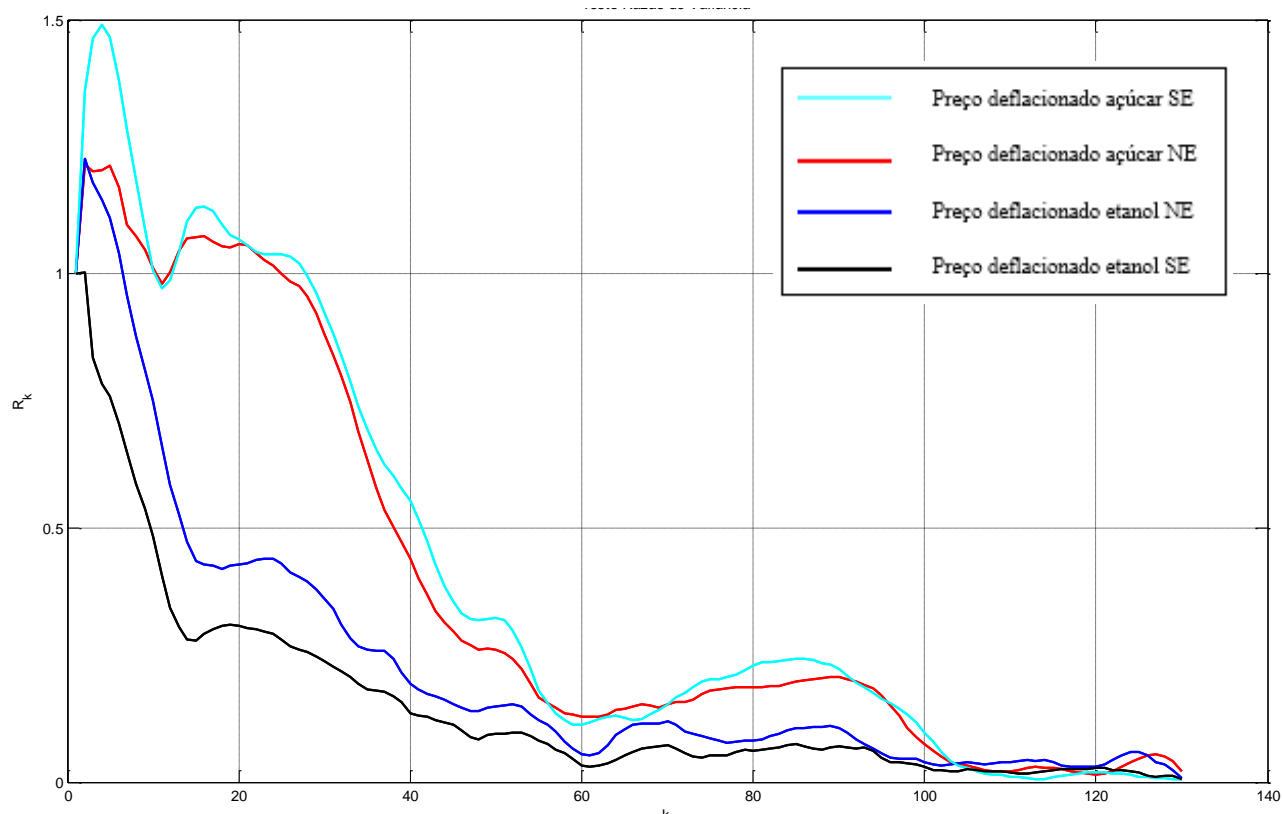

Figura 23 - Teste de Razão da Variância dos preços deflacionados do açúcar e do etanol nas regiones do Nordeste e Sudeste

Pode-se notar que em todas as series inicialmente há um amento da razão da variância $R_{k}$, com o aumento dos retardos $k$. Este fato é consistente tanto com o MGB quanto com o MRM. Além disso, $\mathrm{R}_{\mathrm{k}}$ cresce no início e quando atinge um máximo começa a cair, em torno de $k=17$. $\mathrm{R}_{\mathrm{k}}$ comporta-se novamente crescente ao aumento dos retardos, mas quando $k=19$ se mostra novamente inverso aos retardos.

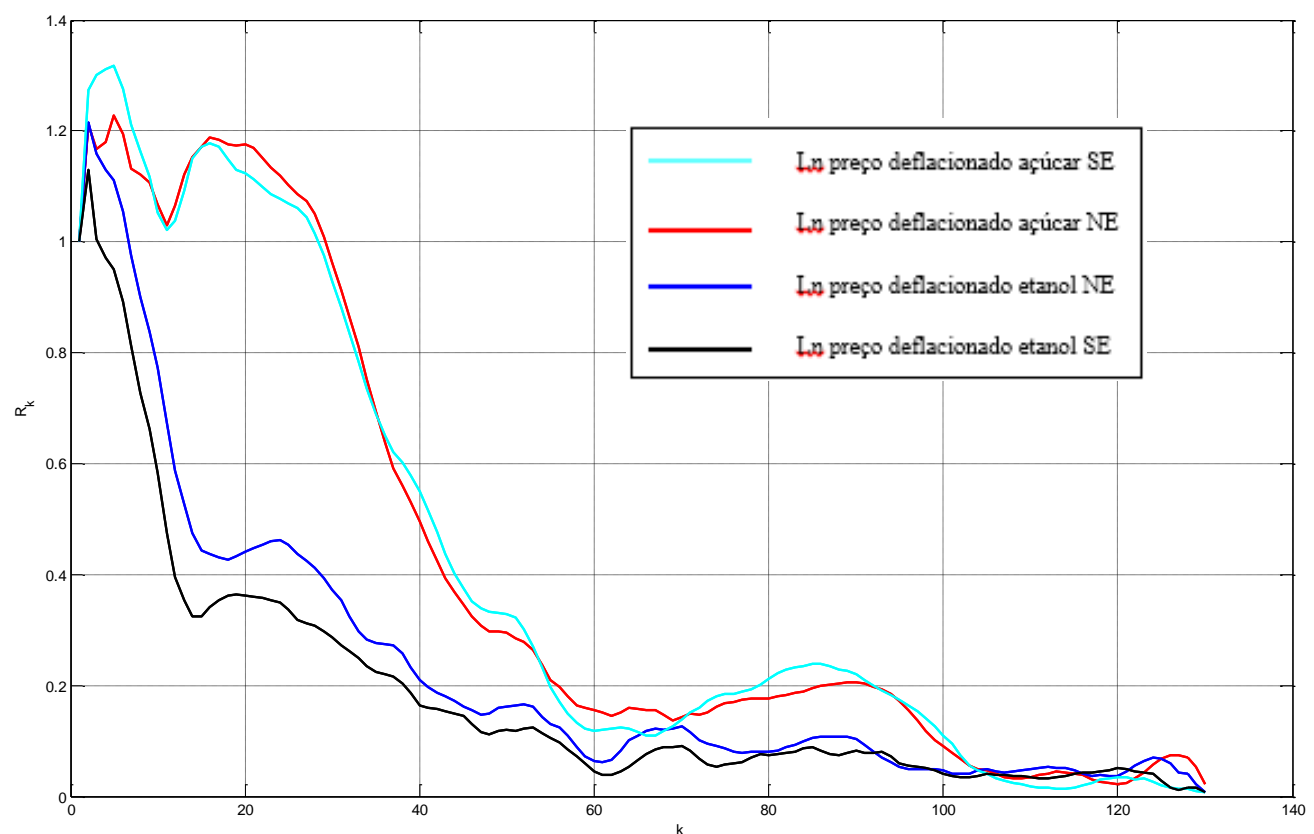

Figura 24 - Teste Razão da Variância dos In (preços) deflacionados do açúcar e do etanol nas regiões do Nordeste e Sudeste 
Para valores de $k$ superiores a 60, as séries começam a cair mais lentamente, tendendo a uma estabilidade a longo prazo, que para $k=134$, mostra-se assintótico com valores ao redor de 0,01 . Sendo assim, pode ser inferido que as séries têm certa tendência à estabilidade com o aumento dos retardos, e que todas as séries de etanol e açúcar tendem a uma reversão à média.

\section{3.}

\section{Parâmetros estocásticos para o etanol e o açúcar}

Uma vez que foram estimados os valores dos coeficientes das regressões, e feitos os testes para determinar o comportamento dos dados. A seguir são calculados os parâmetros do MRM, tanto para o açúcar quanto para o etanol. Com os valores dos coeficientes, mostrados na Tabela 5, são calculados os valores dos parâmetros do MRM que se apresentam na Tabela 7. Os resumos das equações de cálculo desses parâmetros, são apresentados na Tabela 8 .

Tabela 7 - Parâmetros estocásticos do etanol e do açúcar para as regiões do Nordeste e Sudeste

\begin{tabular}{l|c|c|c|c}
\cline { 2 - 5 } \multicolumn{1}{c|}{} & \multicolumn{2}{c|}{ Nordeste } & \multicolumn{2}{c}{ Sudeste } \\
\hline \multicolumn{1}{c}{ Parâmetro } & Etanol & Açúcar & Etanol & Açúcar \\
\hline Preço inicial (julho 2014) & 1,585835 & 57,185 & 1,33046 & 47,1785 \\
Média de longo prazo & 1,51487225 & 64,9400055 & 1,30885845 & 59,1207416 \\
Volatilidade & 0,25615065 & 0,29997619 & 0,38791796 & 0,33300789 \\
Velocidade de reversão & 1,79018431 & 0,79792061 & 2,17236272 & 0,73066893 \\
H meia vida(anos) & 0,387193194 & 0,86869191 & 0,31907525 & 0,9486474 \\
$\mathrm{P}(\mathrm{H})$ & 1,550353625 & 61,0625028 & 1,31965923 & 53,1496208 \\
\hline
\end{tabular}

Tabela 8 - Resumo das equações para determinar os parâmetros num MRM

\begin{tabular}{c|c}
\hline Parâmetros estocásticos & Equação \\
\hline $\bar{x}$ & $\left(\frac{a}{1-b}\right)$ \\
$\bar{P}$ & $\operatorname{Exp}\left[\bar{x}+\frac{\sigma^{2}}{(2 \eta)}\right]$ \\
$\sigma$ & $\sigma_{\varepsilon} \sqrt{\frac{2 \ln (b)}{\left(b^{2}-1\right) \Delta t}}$ \\
& $\frac{-\ln (b)}{\Delta t}$ \\
$\eta$ & \\
\hline
\end{tabular}




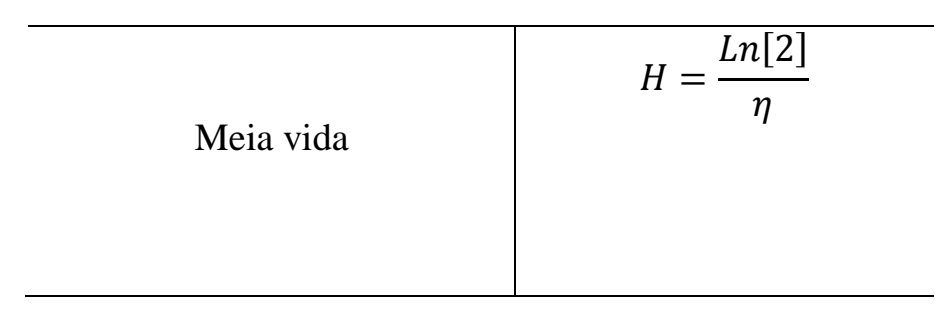

Para cada região tem-se duas equações diferenciais estocásticas:

$$
\begin{aligned}
& \text { Regiao Nordeste }\left\{\begin{array}{l}
d X_{n}(t)=\eta_{a n}\left(\overline{X_{n}}-X_{n t}\right) d t+\sigma_{a n} d z_{t n a} \\
d Y_{n}(t)=\eta_{e n}\left(\overline{Y_{n}}-Y_{n t}\right) d t+\sigma_{e n} d z_{t n e}
\end{array}\right. \\
& \text { Regiao Sudeste }\left\{\begin{array}{l}
d X_{s}(t)=\eta_{a s}\left(\overline{X_{s}}-X_{s t}\right) d t+\sigma_{a s} d z_{t s a} \\
d Y_{s}(t)=\eta_{e s}\left(\overline{Y_{s}}-Y_{s t}\right) d t+\sigma_{e s} d z_{t s e}
\end{array}\right.
\end{aligned}
$$

Onde: $d z_{\text {tna }}, d z_{\text {tne }}$ são os processos padrão de Wiener da região Nordeste para o açúcar e o etanol, respectivamente, e $d z_{t s a}$ e $d z_{t s e}$, para a região Sudeste. Os processos são correlacionados da seguinte forma:

$$
\begin{aligned}
& d z_{\text {tna }} d z_{\text {tne }}=\rho_{n} d t \\
& d z_{\text {tsa }} d z_{\text {tse }}=\rho_{s} d t
\end{aligned}
$$

Conforme os resultados das regressões, as correlações dos log-retornos das séries utilizadas foram os seguintes:

$$
\begin{aligned}
& \rho_{n}=0,44435401 \\
& \rho_{s}=0,40727737
\end{aligned}
$$

\section{4 .}

\section{Metodologia de avaliação}

A companhia Nacional de Abastecimento (CONAB), no programa de cooperação com o Ministério da Agricultura Pecuária e Abastecimento (MAPA), no seu informe: "Acompanhamento da safra brasileira de cana de açúcar"18 apresenta o levantamento de dados da produção do açúcar e do álcool para os anos 2014 e 2015 em todas as unidades de produção sucroalcooleira dos estados

18

http://www.conab.gov.br/OlalaCMS/uploads/arquivos/14_08 $28 \quad 08 \quad 52 \quad 35$ boletim_cana_port ugues - 2o lev - 2014-15.pdf 
produtores. Com base nesse relatório, a Tabela 9 mostra o resumo da produção para as regiões Nordeste e Sudeste.

Tabela 9 - Produção e destinação de cana de açúcar nas regiões do Nordeste e Sudeste

\begin{tabular}{l|r|r|r}
\cline { 2 - 4 } & \multicolumn{3}{|c}{$\begin{array}{c}\text { Indústria Sucroalcooleira } \\
\text { (1000 Ton.) }\end{array}$} \\
\hline Região/UF & \multicolumn{1}{c|}{ Total } & \multicolumn{1}{c}{ Açúcar } & \multicolumn{1}{c}{ Etanol } \\
\hline Nordeste & $\mathbf{5 5 6 0 2}$ & $\mathbf{3 0 9 6 3}$ & $\mathbf{2 4 6 3 8}$ \\
PE & 14.447 & 10.107 & 4.339 \\
AL & 23.173 & 16.402 & 6.771 \\
Total PE e AL & 37.621 & 26.509 & 11.111 \\
Sudeste & $\mathbf{4 2 1 . 9 2 6}$ & $\mathbf{2 1 4 . 9 9 3}$ & $\mathbf{2 0 6 . 9 3 3}$ \\
SP & 356.283 & 187.369 & 168.914 \\
Relação nordeste (\%) & $\mathbf{6 7 , 6 6}$ & & \\
Relação sudeste (\%) & $\mathbf{8 4 , 4 4}$ & & \\
\hline
\end{tabular}

Fonte: $C O N \overline{A B}$ - MAPA safra 2014/15

Para esta dissertação, a região Nordeste está representada pelos estados de Pernambuco (PE) e Alagoas (AL), que constituem o 67,66\% da produção da região. E a região Sudeste, pelo Estado de São Paulo (SP) com o 84,44\% da produção da região. De acordo com o informe da CONAB 2012 "Perfil do Setor do Açúcar e do Álcool no Brasil”"19 Safra 2011/2012, na Tabela 10 são apresentadas o número de usinas nas regiões do Nordeste e Sudeste.

Fonte: Safra 2011/12

Tabela 10 - Número de usinas nas regiões do Nordeste e Sudeste

\begin{tabular}{c|c}
\hline Região & Usinas \\
\hline Centro-sul & $\mathbf{3 1 8}$ \\
SP & 169 \\
Nordeste & $\mathbf{8 4}$ \\
PE & 22 \\
AL & 24 \\
Total & $\mathbf{4 6}$ \\
\hline
\end{tabular}

Com base nas Tabelas 9 e 10, determina-se a quantidade de produção por região, assim:

$$
Q=\frac{\text { Total produção (região) }}{\text { Número de usinas (região) }}
$$

19

http://www.conab.gov.br/OlalaCMS/uploads/arquivos/13 $10 \quad 02 \quad 11 \quad 28 \quad 41$ perfil sucro 2012. pdf 


$$
\begin{aligned}
& Q_{N}=\frac{37.621 .000}{46}=817.848 \text { ton./ano } \\
& Q_{S}=\frac{356.283 .000}{169}=2.108 .193 \text { ton./ano }
\end{aligned}
$$

Neto et. al. (2002) apresentam os índices de produção do açúcar e do etanol no Brasil, conforme a Tabela 11.

Tabela 11 - Índices de produção do açúcar e do etanol no Brasil

\begin{tabular}{l|c|c}
\hline \multicolumn{1}{c|}{ Região } & $\begin{array}{c}\text { Açúcar } \\
\left(\mathrm{Kg}_{\text {Açúcar }} / \text { ton. Cana }\right.\end{array}$ & $\left.\begin{array}{c}\text { Etanol } \\
\left(1_{\text {Etanolr }} / \text { ton.Cana }\right.\end{array}\right)$ \\
\hline Nordeste & 92,8 & 65,7 \\
Centro-Sul & 90,6 & 75,2 \\
SP & 93,4 & 76,9 \\
Brasil & 91,5 & 72,5 \\
\hline
\end{tabular}

Fonte: Neto et. al. (2002)

As proporções de produção, $\alpha$ (açúcar), e $\beta$ (etanol), é determinada para cada commodity e região, com base na Tabela 9, e apresentada a continuação na Tabela 12.

\section{Tabela 12 - Proporção da produção do açúcar e do etanol para a região Nordeste e Sudeste

\begin{tabular}{l|c|c}
\cline { 2 - 3 } & Nordeste & Sudeste \\
\hline $\boldsymbol{\alpha}$ açúcar & 0,705 & 0,526 \\
$\boldsymbol{\beta}$ etanol & 0,295 & 0,474 \\
\hline
\end{tabular}

Considerando os índices de produção do açúcar e do etanol no Brasil mostrados na Tabela 11, e as quantidades para cada região $\left(Q_{N}\right.$ e $\left.Q_{S}\right)$, as equações seguintes nos permitem determinar a recita bruta do etanol e do açúcar de uma usina padrão, para as regiões Nordeste e Sudeste.

$$
R B=\text { Eficiência } * Q * \text { Preço commodity }
$$


Região Sudeste:

$$
\begin{gathered}
R B_{\text {Etanol }, S E}=76,9\left(\frac{L}{t}\right) * 2.108 .193\left(\frac{t}{\text { ano }}\right) * P_{\text {Etanol }, S E}\left(\frac{\$ R}{L}\right) \\
=162.120 .041 * P_{\text {Etanol }, S E} \\
R B_{A c ̧ u ́, S E}=93,4\left(\frac{K g}{t}\right) * 2.108 .193\left(\frac{t}{\text { ano }}\right) * P_{A c ̧ u ́, S E}\left(\frac{\$ R}{50 K g}\right) \\
=3.938 .105 * P_{A c ̧ u ́, S E}
\end{gathered}
$$

Região Nordeste:

$$
\begin{aligned}
& R B_{\text {Etanol }, N E}= 65,7\left(\frac{L}{t}\right) * 817.848\left(\frac{t}{\text { ano }}\right) * P_{\text {Etanol }, N E}\left(\frac{\$ R}{L}\right) \\
&=53.732 .613 * P_{\text {Etanol }, N E} \\
& R B_{A c ̧ u ́, N E}=92,8\left(\frac{K g}{t}\right) * 817.848\left(\frac{t}{\text { ano }}\right) * P_{A c ̧ u ́, N E}\left(\frac{\$ R}{50 K g}\right) \\
&=1.517 .926 * P_{A c ̧ u ́, N E}
\end{aligned}
$$

O fluxo de caixa pode ser representado da seguinte forma:

$$
F C=R B[(1-I C M S)-C V T-C F T] *(1-I R)
$$

Onde, RB representa a receita bruta, para realizar a análise dos dados desta dissertação foi necessário simular alguns dados com o intuito de completar a série estudada, as demonstrações contábeis das usinas de açúcar e álcool pesquisadas resumem-se ao mínimo obrigatório para publicação. A publicação das demonstrações é feita para atender à legislação societária e não para informar aos usuários da contabilidade. As notas explicativas das empresas trazem poucas divulgações voluntárias de informações adicionais. Com isso, algumas análises ficam prejudicadas o custo variável total CVT (20\% da RB), o custo fixo total CFT (10\% da RB) são exemplos de dados simulados. O imposto de renda de 19\% segundo Bastian et. al. (2009). Os fluxos de caixa para as duas commodities e 2 regiões são os seguintes: 
Região Sudeste (em R \$1.000):

$$
\begin{aligned}
F C_{\text {Etanol,SE }}= & 162.120 P_{\text {Etanol,SE }}\left[\left(1-I C M S_{\text {Etanol }, S E}\right)-0,2-0,1\right] * \\
(1-0,19) & \\
F C_{E t a n o l, S E}= & 162.120 P_{E t a n o l, S E}\left(0,7-I C M S_{E t a n o l, S E}\right) *(1-0,19) \\
F C_{A c ̧ u ́, S E}=\{[ & \left.3.938 * P_{A c ̧ u ́, S E}\left(\left(1-I C M S_{A c ̧ u ́, S E}\right)-O, 2-0,1\right)\right] 0,526 \\
& \left.+\left[162.120 P_{E t a n o l, S E}\left(0,7-I C M S_{E t a n o l, S E}\right)\right] 0,474\right\}(1 \\
& -0,19)
\end{aligned}
$$

Região Nordeste (em R \$1.000):

$$
\begin{aligned}
F C_{\text {Etanol }, N E} & \\
& =53.732 P_{\text {Etanol,NE }}\left[\left(1-I C M S_{\text {Etanol }, N E}\right)-0,2-0,1\right] \\
& *(1-0,19) \\
F C_{\text {Etanol }, N E}= & 53.732 P_{\text {Etanol }, N E}\left(0,7-I C M S_{E t a n o l, N E}\right) *(1-0,19) \\
F C_{A c ̧ u ́, N E}=\{[ & \left.1.517 * P_{\text {Açú,NE }}\left(\left(1-I C M S_{A c ̧ u ́, N E}\right)-0,2-0,1\right)\right] 0,705 \\
& \left.+\left[53.732 P_{\text {Etanol,NE }}\left(0,7-I C M S_{\text {Etanol }, N E}\right)\right] 0,295\right\}(1 \\
& -0,19)
\end{aligned}
$$

Conforme o site da CEPEA, a Tabela 13 mostra as alíquotas de ICMS para as commodities nas regiões do Nordeste e Sudeste.

\section{Tabela 13 - ICMS para a região Nordeste e Sudeste}

Fonte: CEPEA 2014

\begin{tabular}{l|c|c}
\hline \multicolumn{1}{c|}{ ICMS } & Nordeste & Sudeste \\
\hline Etanol & $25 \%$ & $12 \%$ \\
Açúcar & $12 \%$ & $7 \%$ \\
\hline
\end{tabular}

Para a análise desenvolvida nesta dissertação foi considerada a taxa de juros livre de risco $(r)$ real de 7,25\%. Foi determinada a partir da rentabilidade média das Letras do Tesouro Nacional (LTN) com vencimento em 2011,2012, 2013, 
2014, descontada à inflação média esperada para o próximo biênio (estimada em $5,3 \%)$. O horizonte de tempo é de cinco anos, tomando amostras semestrais, pelo qual $T=5, n=10$ e $\Delta t=0.5$. O prêmio de risco $\pi$ deflacionado para o setor sucroalcooleiro foi calculado por meio do Capital Asset Pricing Model (CAPM), a partir dos valores das empresas do setor com ações negociadas na BM\&FBOVESPA (aproximado em $6 \%$ a.a.)

\subsection{1.}

\section{Avaliação das árvores recombinantes}

De acordo com a abordagem das árvores recombinantes (Nelson e Ramaswamy, 1990) apresentada no capitulo 4, nesta seção é apresentado o algoritmo desenvolvido com base na teoria, e programado no Matlab. A Tabela 14 mostra o resumo dos parâmetros a serem utilizados nas computações.

A árvore consta de $n=10$ amostras, com $n+1$ nós em cada uma. A amostra zero $(t=0)$ começa com um valor inicial, o qual é multiplicado pelo correspondente incremento determinístico (up e down) para poder se chegar até a seguinte amostra $(t=0,5)$, gerando assim dois nós. Esses novos nós, são novamente multiplicados pelo up e down, mantendo-se a correspondente ordem de subida e descida, e permitindo gerar assim a nova amostra 2 com 3 nós. Este procedimento se repete até chegar à amostra 10 ( $t=5$ anos), que tem 11 nós. Como exemplo ilustrativo, a Figura 25 apresenta a expansão do preço do etanol para a região Nordeste.

Tabela 14 - Resumo dos parâmetros do trabalho

\begin{tabular}{|c|c|c|c|c|}
\hline & \multicolumn{2}{|c|}{ Nordeste } & \multicolumn{2}{|c|}{ SUDESTE } \\
\hline Parâmetro & Etanol & Açúcar & Etanol & Açúcar \\
\hline Preço inicial (julho 2014) & 1,585835 & 57,185 & 1,33046 & 47,1785 \\
\hline Volatilidade & 0,25615065 & 0,29997619 & 0,38791796 & 0,33300789 \\
\hline Velocidade de reversão & 1,79018431 & 0,79792061 & 2,17236272 & 0,73066893 \\
\hline Média de longo prazo & 1,51487225 & 64,9400055 & 1,30885845 & 59,1207416 \\
\hline $\begin{array}{l}\text { Média de longo prazo } \\
\text { ajustada }\end{array}$ & 1,464941061 & 60,2358928 & 1,27320284 & 54,4599346 \\
\hline$U p$ & 1,198566023 & 1,2362903 & 1,31560866 & 1,26550612 \\
\hline $\begin{array}{l}\text { Correlação } \\
\Delta t\end{array}$ & \multicolumn{2}{|c|}{0,44435401} & \multicolumn{2}{|c|}{0,40727737} \\
\hline & \multicolumn{2}{|c|}{0,5} & \multicolumn{2}{|c|}{0,5} \\
\hline
\end{tabular}




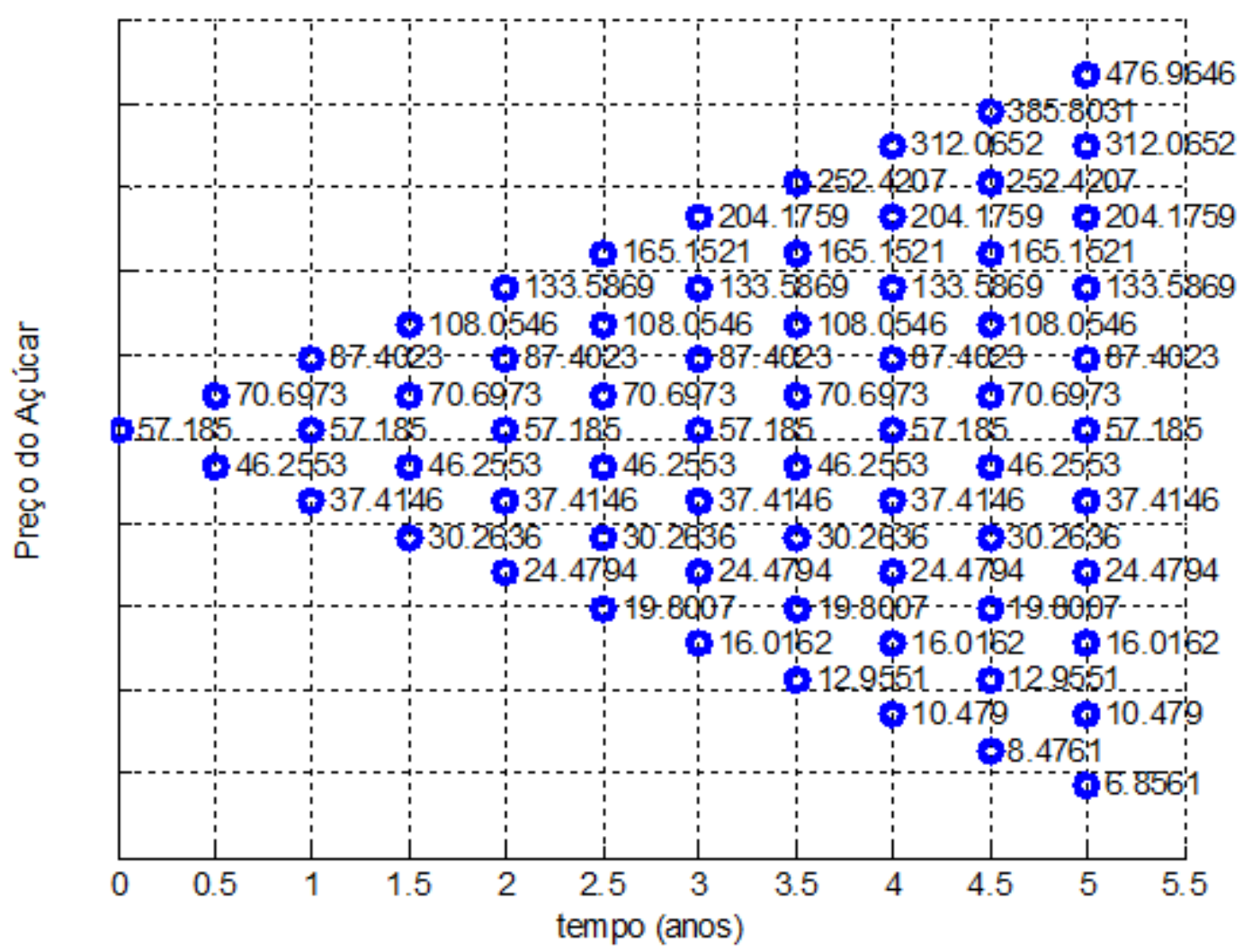

Figura 25 - Árvore recombinante do preço do açucar na região Nordeste

Utilizando a abordagem censurada de Nelson e Ramaswamy (1990) para as probabilidades, dada pela formulação $\mathrm{q}_{\mathrm{t}}=\max \left\{0, \min \left[1, \frac{1}{2}+\frac{1}{2} \sqrt{\Delta t} \eta \frac{\left(\bar{x}-\frac{\pi}{\eta}-x_{t}\right)}{\sigma}\right]\right\}$, a Figura 26 mostra, com fins ilustrativos, o valor de $q_{t}$ para o açúcar na região Nordeste 


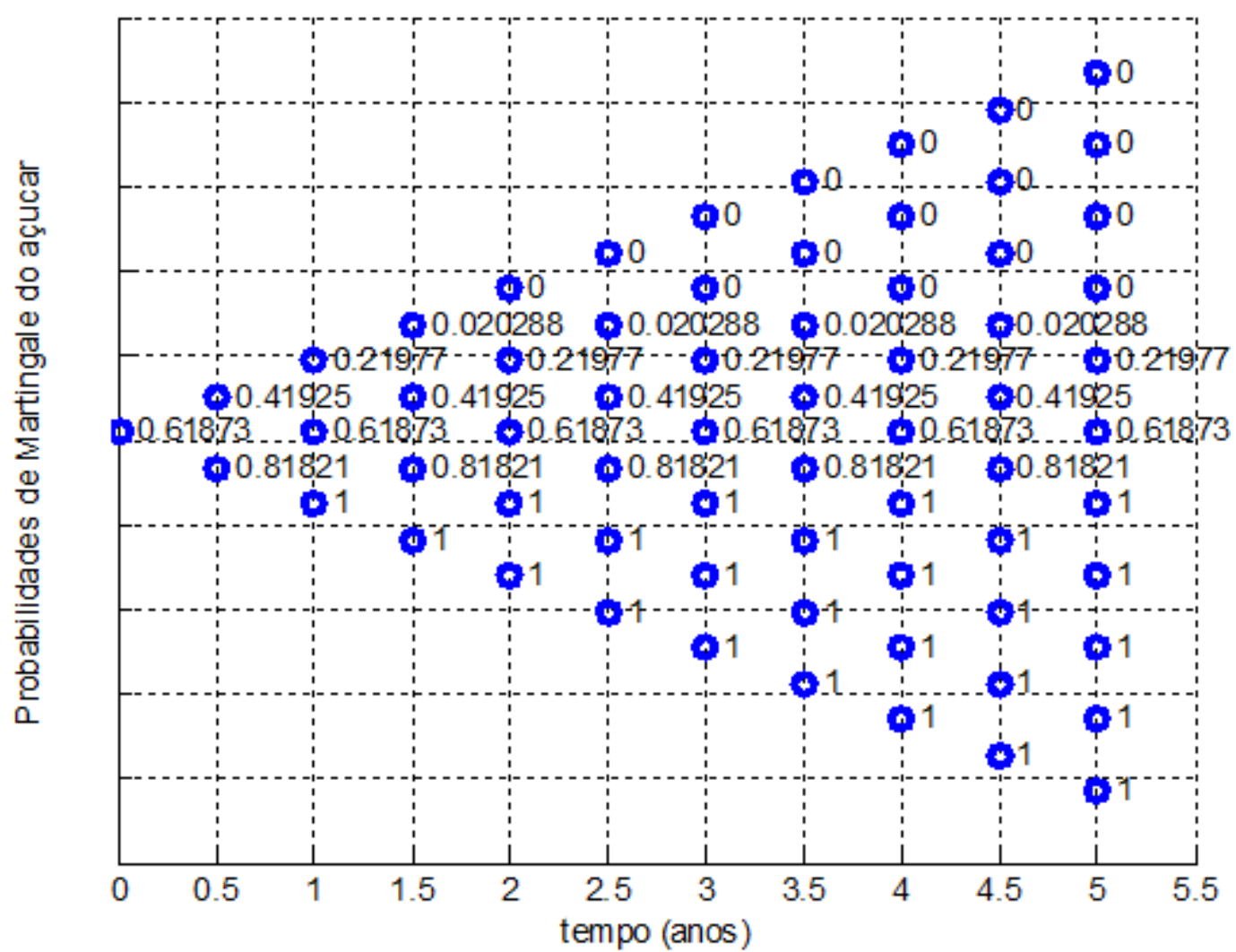

Figura 26 - Probabilidades de Martingale censuradas do açúcar na região Nordeste

Estes valores gerados representam as probabilidades de Martingale censuradas $\left(q_{t}\right)$ em cada ponto. A probabilidade Martingale de descida $\left(1-q_{t}\right)$ não é mostrada na figura. Pode ser visto na figura como o método penaliza fortemente aqueles valores que estão afastados da média de longo prazo, para cima ou para baixo, deixando-os com uma probabilidade de ocorrência igual a zero.

Cada um dos preços censurados $\left(\mathrm{q}_{\mathrm{t}}\right)$ da árvore recombinante gera um valor de fluxo de caixa em cada ponto. Esses fluxos são descontados à taxa livre de risco, iniciando com os fluxos finais (em $\mathrm{t}=10$ são 11 fluxos de caixa), com as probabilidades de Martingale censuradas das amostras anteriores (de $t=4,5)$. A esse valor acrescenta- se o fluxo existente no ponto $\mathrm{t}=4,5$. $\mathrm{O}$ mesmo processo de retroindução (backwards) é seguido até chegar no ponto $t=0$. Nesse ponto, os fluxos de $t=0$ são acrescentados aos de $t=1$. Na Figura 27 como ilustração, podem ser vistos os valores presentes (VP), ponto a ponto no tempo, para o caso do açúcar na região Nordeste. A taxa livre de risco é usada no desconto dos fluxos de caixa, dado que no cálculo de $q_{t}$ utiliza-se a média de longo prazo ajustada ao $\operatorname{risco}\left(\bar{X}-\frac{\pi}{\eta}\right)$. 


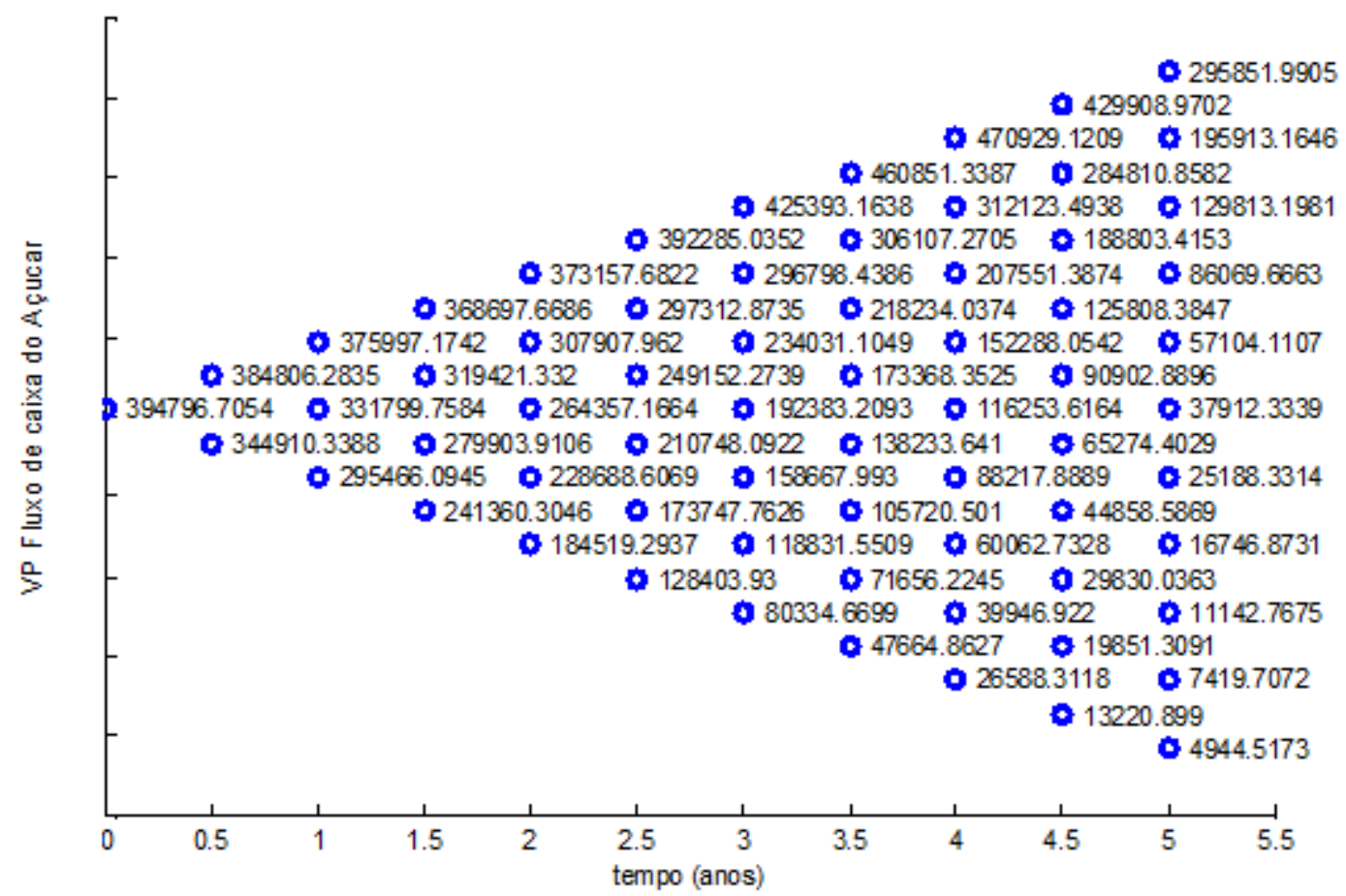

Figura 27 - Valor presente dos fluxos do açúcar na região Nordeste

Na Figura 27 pode ser notado que o VP (no ponto $t=0$ ) dos fluxos de caixa para o açúcar na região Nordeste é de 394.796. As três arvores restantes (etanol NE e açúcar e etanol SE) são apresentadas nos anexos desta dissertação.

Para as duas commodities e duas regiões analisadas, a Tabela 15 apresenta nos valores presentes (VP), como resultado da abordagem seguida nesta pesquisa.

Tabela 15 - Valores presentes (VP) dos fluxos de caixa das árvores recombinantes

\begin{tabular}{l|c|c}
\cline { 2 - 3 } \multicolumn{1}{c}{} & \multicolumn{2}{c}{ Commodity } \\
\hline Região & Etanol & Açúcar \\
\hline Nordeste (em R\$ 1000) & 272.283 & 394.796 \\
Sudeste (em R\$ 1000) & 930.427 & 1.093 .256 \\
\hline Diferença & 658.144 & 698.460 \\
\hline$\%$ & 241,71 & 176,92 \\
\hline
\end{tabular}

Nota-se que para a região Sudeste se tem um VP maior nas duas commodities. Para o caso do etanol, a diferença entre as duas regiões é de $\mathrm{R} \$ 658.144 .000$, o que representa uma diferença de $242 \%$ favorável à região Sudeste. Já o caso da indústria do açúcar, a diferencia de VP é de $\mathrm{R} \$$ 698.460.000. representando uma diferença percentual de $177 \%$. 


\subsection{2.}

\section{Avaliação das árvores bivariáveis}

Partindo das árvores recombinantes do etanol $(x)$ e do açúcar $(y)$, se programou em Matlab uma árvore quadrinomial onde em cada amostra se tem $4^{n}$ nós, cada um com uma matriz de preços $2 x 1 \quad[X, Y]$. Cada nova árvore quadrinomial gera mais uma, até se chegar ao ponto $n=10$, onde se terão $4^{10}=$ 1.048.576 nós para essa amostra ( $t=5$ anos, 10 semestres). A seguir é construída uma matriz fluxo de caixa $2 x 1\left[\mathrm{FC}_{\mathrm{X}}, \mathrm{FC}_{\mathrm{Y}}\right]$ calculada a partir das matrizes de preços em todos os tempos para cada nó. Em cada matriz fluxo de caixa será escolhida a maior, a mesma que será descontada com as probabilidades conjuntas, que são o resultado da multiplicação das probabilidades marginais censuradas $\left(\max \left(0, \min \left(1, P_{\text {marginal }}\right)\right.\right.$ pelas probabilidades condicionais censuradas $\left(\max \left(0, \min \left(1, P_{\text {condicionais }}\right)\right.\right.$ do período anterior $n=9$. Esse processo é seguido até se chegar a $t=0$.

As Figuras 28 e 29 mostram um fragmento do processo, desde $n=2$ com $4^{2}=16$ nós, até $t=1$ ano com $4^{1}=4$ nós. Nelas se consegue distinguir probabilidades de valor zero, resultado de terem sido censuradas por serem negativas. Tal como foi descrito anteriormente, a censura não se faz diretamente sobre as probabilidades conjuntas, senão sobre as probabilidades marginais e condicionais, que ao serem multiplicadas, resultam nas probabilidades conjuntas.

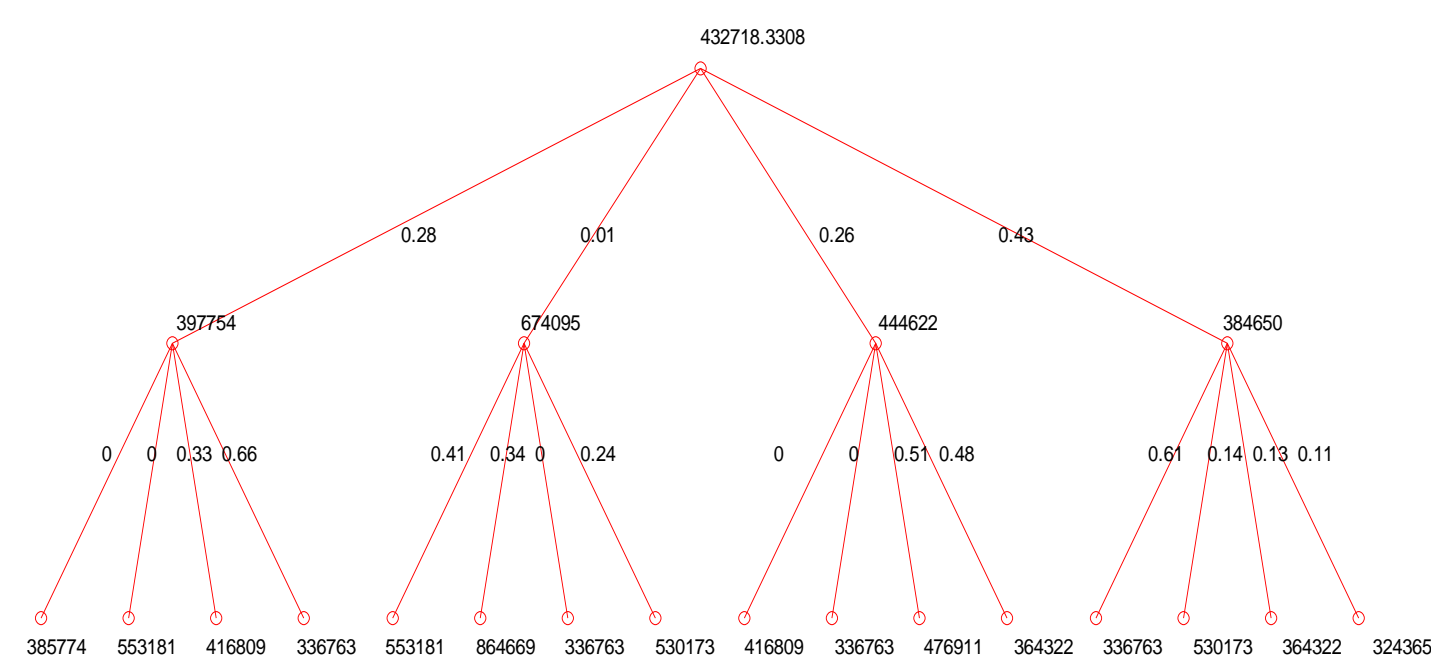

Figura 28 - Valor presente (VP) dos fluxos de caixa para a árvore quadrinomial bivariável para região Nordeste 


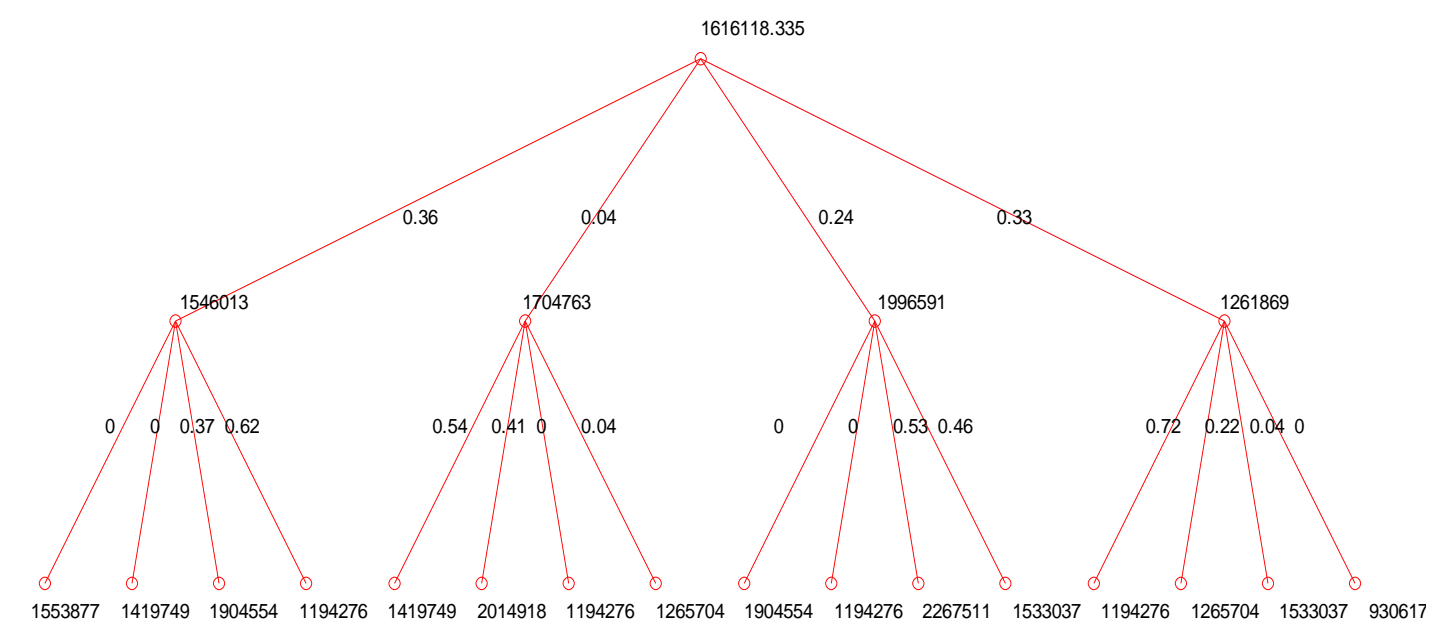

Figura 29 - Valor presente (VP) dos fluxos de caixa para a árvore quadrinomial bivariável para região Sudeste

Na Tabela 16, são apresentados, para as duas regiões estudadas, os resultados dos valores presentes (VP) dos fluxos de caixa para usinas que produzem etanol ou açúcar exclusivamente, além do valor presente (VP) dos fluxos de caixa para usinas flexíveis.

Tabela 16 - Resultados dos valores presentes dos fluxos de caixa (VP), das árvores binômias e bivariáveis e o valor da opção de troca

\begin{tabular}{c|c|c|c|c|c|c|c}
\cline { 2 - 8 } & Etanol & Açúcar & Usina Flex & $\begin{array}{c}\text { \%tanol } \\
\text { Eçúcar }\end{array}$ & $\begin{array}{c}\text { Valor } \\
\text { opção } \\
\text { para o } \\
\text { etanol }\end{array}$ & $\begin{array}{c}\text { Valor } \\
\text { opção } \\
\text { para o } \\
\text { açúcar }\end{array}$ \\
\hline $\begin{array}{c}\text { Nordeste } \\
\text { (em } \$ R \\
1000)\end{array}$ & 272.283 & 394.796 & 432.718 & $\mathbf{5 8 , 9 2}$ & $\mathbf{9 , 6 0}$ & 160.435 & 37.922 \\
\hline $\begin{array}{c}\text { Sudeste } \\
\text { (em } \$ R \\
1000)\end{array}$ & 930.427 & 1.093 .256 & 1.616 .118 & $\mathbf{7 3 , 7 0}$ & $\mathbf{4 7 , 8 2}$ & 685.691 & 522.862 \\
\hline Diferença & $\mathbf{6 5 8 . 1 4 4}$ & $\mathbf{6 9 8 . 4 6 0}$ & $\mathbf{1 . 1 8 3 . 4 0 0}$ & & & $\mathbf{5 2 5 . 2 5 6}$ & $\mathbf{4 8 4 . 9 4 0}$ \\
\hline $\begin{array}{c}\text { \% entre } \\
\text { regióes }\end{array}$ & $\mathbf{2 4 1 , 7 1}$ & $\mathbf{1 7 5 , 9 2}$ & $\mathbf{2 7 3 , 4 8}$ & & & $\mathbf{3 2 7 , 3 9}$ & $\mathbf{1 2 7 8 , 7 8}$ \\
\hline Fon
\end{tabular}

Fonte: o autor

Evidencia-se, por exemplo para o caso do Nordeste, que a usina flex, com um VP de R \$ 432.718.000, é muito mais apropriada comparada a uma usina que produz exclusivamente açúcar, que tem um VP de $\mathrm{R} \$ 394.796 .000$. A diferença é de e $9,6 \%$. Já para o caso comparativo de uma usina cuja produção é dedicada 
exclusivamente ao etanol, a diferença em relação à usina flex é de 58,9\%, favorável à flex.

Para o caso da região Sudeste, a diferença a favor da flex é de $73.6 \%$ e $47,8 \%$, respectivamente, se comparada com uma usina que produz exclusivamente etanol, e uma que produz açúcar (as usinas que produzem açúcar tem como subproduto algum residual de produção de etanol).

No caso do valor da opção de flexibilidade, nota-se que esse valor na região Sudeste é mais expressivo, se comparado à região Nordeste. Isso é de se esperar, pois as vantagens comparativas nos fatores determinantes são maiores nessa região. Para ambas as regiões, a tabela mostra que a flexibilidade agrega um valor expressivo. Se observa que no caso do etanol, para a região Nordeste a opção tem um valor de $\mathrm{R} \$ 160.435 .000$, e para a região Sudeste $\mathrm{R} \$ 685.691 .000$, ou seja um $327 \%$ maior no Sudeste. O mesmo acontece para o caso do açúcar, onde para a região Nordeste a opção de flexibilidade tem um valor de $\mathrm{R} \$ 37.922 .000$, enquanto que na região Sudeste essa opção vale $\mathrm{R}$ \$ 522.862.000 para uma usina como a usada como estudo de caso nesta dissertação, portanto, a opção de troca na região Sudeste tem um valor do $1.278 \%$ maior do que na região Nordeste. 


\section{6.}

\section{Conclusões}

Da crescente preocupação com questões como o desenvolvimento de tecnologias alternativas ao uso de combustíveis fósseis, menos poluentes e que adotassem mecanismos limpos de produção é que surgem os biocombustíveis, como o Etanol. O potencial de produção e o aumento na demanda por Etanol fazem da cana-de-açúcar uma das mais importantes culturas no cenário atual da agroindústria nacional. A cana-de-açúcar não é tratada apenas como mais um produto agrícola nacional, mas como a mais importante fonte de biomassa energética em razão do potencial do mercado sucroalcooleiro no Brasil.

Pelos aspetos descritos e resultados gerados no desenvolvimento desta dissertação, pode-se concluir, principalmente, que o valor da opção de troca no setor sucroalcooleiro esta ligado a fatores determinantes, tais como: a produção da cana do açúcar por região, destacando-se a região Sudeste que produz 421.926.000 toneladas de cana de açúcar contra 55.602.000 toneladas na região Nordeste (a produção de toneladas de cana de açúcar da região nordeste representa o $38 \%$ da região sudeste). O índice de eficiência do etanol na região sudeste é de 75,2 L/ton, enquanto que na região nordeste é 65,7 L/ ton. Se conclui, também, que o imposto ICMS gera uma variação importante na indústria sucroalcooleira, encontrando que a região Sudeste possui incentivos fiscais maiores (ICMS de 12\% para o etanol e 7\% para a açúcar), enquanto que para o caso da região Nordeste as taxas são maiores (ICMS 25\% para o etanol e 12\% para o açúcar).

Encontrou-se no estudo que as usinas de dedicação exclusiva na região Sudeste, têm maior valor presente de fluxo de caixa que aquelas localizadas na região Nordeste, para o caso da indústria do açúcar para as duas regiões registrase uma diferença de 698.460.000 e de \$R, 658.144.000 para a indústria do etanol.

A utilização de um MRM é árvores quadrinomiais com probabilidades censuradas, nos permitiu determinar o valor embutido nas usinas com opção de flexibilidade produtiva.

Conclui-se, pelos valores encontrados, que o fator preço de mercado das commodities, aliado ao fator fiscal, são os determinantes maiores no valor da opção de troca embutida numa usina flex. 
Para futuros trabalhos pode-se considerar modelar cada preço por meio de dois fatores, por um MGB para o curto prazo, e por um MRM para o longo prazo. 


\section{7.}

\section{Referências Bibliográficas}

BASTIAN, P. C. L. Modelagem de Opcões Reais com Processos de Reversão à Média em Tempo Discreto: Uma Aplicação na Indústria Brasileira de Etanol. Rio de Janeiro, RJ, 2009. Tese de Doutorado. PUC-Rio

BASTIAN-PINTO, C. L.; BRANDÃO, L. E. T.; HAHN, W. J. Flexibility as a source of value in the production of alternative fuels: The ethanol case. Energy Economics. v.31, n. 3, p.p. 411-422, May 2009.

BLACK, F.; SCHOLES M. The Pricing of Options and Corporate Liabilities. Journal of Political Economy, n. 81, p.p. 637 - 654, May-Jun, 1973.

BOYLE, P. A. A Lattice Framework for Option Pricing with Two State Variables. Journal of Financial and Quantitative Analysis, n. 23, n. 1, p.p. 1 - 12, 1988.

COPELAND, T.; ANTIKAROV, V. "Real Options - A Practitioner's Guide". New York: Texere LLC Publishing, 2001, 372 pp.

CORREA NETO, V.; RAMON, D. Análise de Opções Tecnológicas para Projetos de Co-Geração no Setor Sucroalcooleiro. SETAP: Brasília, 2002.

COX, J, C.; ROSS, S. A.; RUBINSTEIN, M. Option pricing: A simplified approach. Journal of Financial Economics, n. 7, p.p. 229-263, September, 1979.

DIAS, Marco Antonio Guimarães. Análise de Investimentos com Opções Reais - Teoria e Prática com Aplicações em Petróleo e em outros Setores. Volume 1: Conceitos Basicos e Opções Reais em Tempo Discreto. Rio de Janeiro: Editora Interciência, 2014. 330 p.

DIAS, Marco Antonio Guimarães. Análise de Investimentos com Opções Reais - Teoria e Prática com Aplicações em Petróleo e em outros Setores. Volume 2: Processos Estocásticos e Opções Reais em Tempo Continuo. Rio de Janeiro: Editora Interciência, 2014. 500 p.

DIAS, M. A. G. Opções Reais Híbridas com Aplicações em Petróleo. Tese de Doutorado, PUC-Rio, Rio de Janeiro, RJ, Janeiro, 2005.

DICKEY, D., FULLER, W. Likelihood ratio statistics for autoregressive time series with a unit root. Econometrica. n. 49, p.p. 1057-1072, 1981.

DIXIT, A., PINDYCK, R. Investment under uncertainty. Princeton University Press: Princeton, NJ, 1994.

GASTALDI, H. L. G. Opções reais em investimentos florestais. São Paulo, SP, 2012. Dissertação de Mestrado. Insper Instituto de Ensino e Pesquisa. 
GONCALVES, D., NETO, J., BRASIL, H. The option of switching an investment project into an agribusiness project. in annals: 10 International Conference on Real Options. New York, 2006.

HAHN, W. J.; DYER, J.S. Discrete Time Approach Modeling Two-Factor MeanReverting Stochastic Processes. Decision Analysis, v. 8, n. 3, p.p. 220-232, September, 2011.

HAHN, W. J. A Discrete-Time Approach for Valuing Real Options with Underlying Mean-Reverting Stochastic Processes. PhD Dissertation, The University of Texas, Austin, May, 2005.

KULATILAKA, N. The Value of Flexibility: The Case of a Dual-Fuel Industrial Steam Boiler. Financial Management, v. 33, n. 3, p.p. 271 - 280, Autumn, 1993.

LIMA, N. C., et al. Caracterização da demanda do combustível etanol hidratado no mercado brasileiro. FAPA - Gestão Contemporânea [online], 2013, vol. 13, p. 25-44. Disponível em: http://seer4.fapa.com.br/index.php/arquivo/article/view/168/118.

MELO, F. H. de; FONSECA, E.G. da. Proálcool, energia e transportes. São Paulo: Pioneira, FIPE, 1981.

MORAES, M. A. F. D. de. A desregulamentação do setor sucroenergético do Brasil. Americana: Caminho Editorial, 2000.

NASCIMIENTO, C. C. do. O valor da opção do carro Flex por região geográfica do Brasil: uma aplicação do TOR com MRM. Rio de Janeiro, RJ, 2012. Dissertação de Mestrado. PUC-Rio

NELSON, D. B.; RAMASWAMY, K. Simple Binomial Processes as Diffusion Approximations in Financial Models. The Review of Financial Studies, v. 3, n. 3, p.p. 393-430, 1990.

PESSOA, P. F. P. Opções de Conversão com Movimento de Reversão à Média com Saltos de Poisson: o Caso do Setor Sucroalcooleiro Brasileiro. Rio de Janeiro, RJ, 2011. Dissertação de Mestrado. PUC-Rio

PINDYCK, R. S. The Long-Run Evolution of Energy Prices. The Energy Journal, 20, p.p. 1-27. 1999.

TRIGEORGIS, L. Real Options: managerial flexibility and strategy in resource allocation. Cambridge, MA: MIT Press, 1996. 427 p.

SAMANEZ, C.P.; FERREIRA, L. R.; NASCIMIENTO, C. C. Avaliação da opção de troca de combustível no carro brasileiro flex: um estudo por região geográfica usando teoria de opções reais e simulação estocástica. Production. v.24, n. 3. 2013. 
SAMANEZ, C.P.; COSTA, L. A. Avaliação das opções de swing em contratos de gás natural usando um modelo de dois fatores. Production. v.24, n. 4, p.p. 760775. 2013.

SANTOS, A. M. M. M.; BURITY, P. BNDES: 50 anos - Histórias setoriais: o complexo automotivo. 2002. Disponível em: http://www.bndes.gov.br

SANTOS, M. H. de C. Política e políticas de uma energia alternativa: o caso do Próalcool. Rio de Janeiro: Notrya, 1993.

SCHWARTZ, E. S.; SMITH, J. E. Short-term Variations and Long-term Dynamics in Commodity Prices. Management Science, v. 7, n. 46, p.p. 893-911, Jul, 2000.

SCANDIFFIO, M. I. G. Análise prospectiva do álcool combustível no Brasil: cenários de 2004 a 2024. Tese (Doutorado em Planejamento de Sistemas Energéticos) - Faculdade de Engenharia Mecânica, Universidade Estadual de Campinas, Campinas, 2005. 
8.

\section{ANEXOS}

\section{1.}

\section{Demonstração das propriedades estatísticas do MRM}

Considere um processo de Ornstein-Uhlenbeck que é descrito pela seguinte equação diferencial estocástica:

$$
d Y(t)=\eta(\bar{Y}(t)) d t+\sigma d z(t)
$$

A solução pode ser obtida como segue. Mas primeiro deve-se notar que:

$d\left(e^{\eta} Y(t)\right)=Y(t) \eta e^{\eta} d t+e^{\eta} d Y(t)$

$e^{\eta} d Y(t)=d\left(e^{\eta} Y(t)\right)-Y(t) \eta e^{\eta} d t$

Multiplicando ambos os lados da Equação 8.1 por $e^{\eta}$, tem-se:

$e^{\eta t} d Y(t)=e^{\eta t} \eta\left(\bar{Y}-Y(t) d t+e^{\eta t} \sigma d z(t)\right.$

Igualando a Equação 8.2:

$d\left(e^{\eta t} Y(t)=\eta e^{\eta t} \bar{Y} d t+e^{\eta t} \sigma d z(t)\right.$

Essa equação pode ser resolvida como segue:

$$
\begin{aligned}
& e^{\eta t} Y(t)=Y_{0}+\int_{0}^{1} \eta e^{\eta s} \bar{Y} d s+\int_{0}^{1} e^{\eta s} \sigma d z_{s} \\
& Y(t)=Y_{0} e^{-\eta t}+\int_{0}^{1} \eta e^{-\eta(t-s)} \bar{Y} d s+\int_{0}^{1} e^{-\eta(t-s)} \sigma d z
\end{aligned}
$$

A primeira integral se torna $\bar{Y}\left(1-e^{-\eta t}\right)$ e como $z$, segue o Movimento Browniano, a segunda integral é normalmente distribuída com média zero e variância $E\left[\left(\int_{0}^{1} e^{-\eta(t-s)} \sigma d z\right)^{2}\right]$.

Pela isomeria de itô: 
$E\left[\left(\int_{0}^{1} e^{-\eta(t-s)} \sigma d z\right)^{2}\right]=\int_{0}^{1}\left(e^{-\eta(t-s)} \sigma\right)^{2} d s=\int_{0}^{1} e^{-2 \eta(t-s)} \sigma^{2} d s=\left(1-e^{-2 \eta t}\right) \frac{\sigma^{2}}{2 \eta}$

Logo, $Y_{t}$ é normalmente distribuído com:

$$
\begin{aligned}
& E\left[Y_{t} \mid Y_{0}\right]=\bar{Y}+\left(Y_{0}-\bar{Y}\right) e^{-\eta t} \\
& \operatorname{Var}\left[Y_{t} \mid Y_{0}\right]=\left(1-e^{-2 \eta t}\right) \frac{\sigma^{2}}{2 \eta}
\end{aligned}
$$

\section{2.}

\section{Dedução das probabilidades condicionais $\mathbf{P}_{\mathbf{u} \mid \mathbf{d}}$ e $\mathbf{P}_{\mathbf{d} \mid \mathbf{d}}$}

$$
P_{u \mid d}=\frac{P_{d u}}{P_{d}}=\frac{\frac{\Delta_{X} \Delta_{Y}-\Delta_{Y} v_{X} \Delta t+\Delta_{X} v_{Y} \Delta t-p \sigma_{X} \sigma_{Y} \Delta t}{4 \Delta_{X} \Delta_{Y}}}{1-P_{u}}
$$

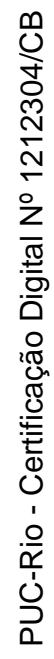

$$
\begin{gathered}
P_{u \mid d}=\frac{\frac{\Delta_{X} \Delta_{Y}-\Delta_{Y} v_{X} \Delta t+\Delta_{X} v_{Y} \Delta t-p \sigma_{X} \sigma_{Y} \Delta t}{4 \Delta_{X} \Delta_{Y}}}{1-\left(\frac{1}{2}+\frac{1}{2} \frac{v_{X} \Delta t}{\Delta_{X}}\right)}=\frac{\frac{\Delta_{X}\left(\Delta_{Y}+\Delta t v_{Y}\right)-\Delta t\left(\Delta_{Y} v_{X}+p \sigma_{X} \sigma_{Y}\right)}{4 \Delta_{X} \Delta_{Y}}}{\frac{1}{2}\left(1-\frac{v_{X} \Delta t}{\Delta_{X}}\right)} \\
P_{u \mid d}=\frac{\frac{\Delta_{X}\left(\Delta_{Y}+\Delta t v_{Y}\right)-\Delta t\left(\Delta_{Y} v_{X}+p \sigma_{X} \sigma_{Y}\right)}{4 \Delta_{X} \Delta_{Y}}}{\frac{1}{2 \Delta_{X}}\left(\Delta_{X}-v_{X} \Delta t\right)}=\frac{\frac{\Delta_{X}\left(\Delta_{Y}+\Delta t v_{Y}\right)-\Delta t\left(\Delta_{Y} v_{X}+p \sigma_{X} \sigma_{Y}\right)}{2 \Delta_{Y}\left(\Delta_{X}-v_{X} \Delta t\right)}}{P_{d \mid d}}=\frac{\frac{P_{d d}}{P_{d}}=\frac{\Delta_{X} \Delta_{Y}-\Delta_{Y} v_{X} \Delta t-\Delta_{X} v_{Y} \Delta t+p \sigma_{X} \sigma_{Y} \Delta t}{4 \Delta_{X} \Delta_{Y}}}{P_{d}} \\
P_{u \mid d}=\frac{\frac{\Delta_{X} \Delta_{Y}-\Delta_{Y} v_{X} \Delta t-\Delta_{X} v_{Y} \Delta t+p \sigma_{X} \sigma_{Y} \Delta t}{4 \Delta_{X} \Delta_{Y}}}{\frac{1}{2}-\frac{1}{2} \frac{v_{X} \Delta t}{\Delta_{X}}}=\frac{\frac{\Delta_{X}\left(\Delta_{Y}-\Delta t v_{Y}\right)-\Delta t\left(\Delta_{Y} v_{X}-p \sigma_{X} \sigma_{Y}\right)}{4 \Delta_{X} \Delta_{Y}}}{\frac{1}{2}\left(1-\frac{v_{X} \Delta t}{\Delta_{X}}\right)} \\
P_{u \mid d}=\frac{\frac{\Delta_{X}\left(\Delta_{Y}-\Delta t v_{Y}\right)-\Delta t\left(\Delta_{Y} v_{X}-p \sigma_{X} \sigma_{Y}\right)}{2 \Delta_{Y}\left(\Delta_{X}-v_{X} \Delta t\right)}}{\frac{1}{2 \Delta_{X}}\left(\Delta_{X}-v_{X} \Delta t\right)}
\end{gathered}
$$




\section{3.}

\section{Valor presente (VP) dos fluxos de caixa das árvores recombinantes} para as commodities na região Nordestes e Sudeste.

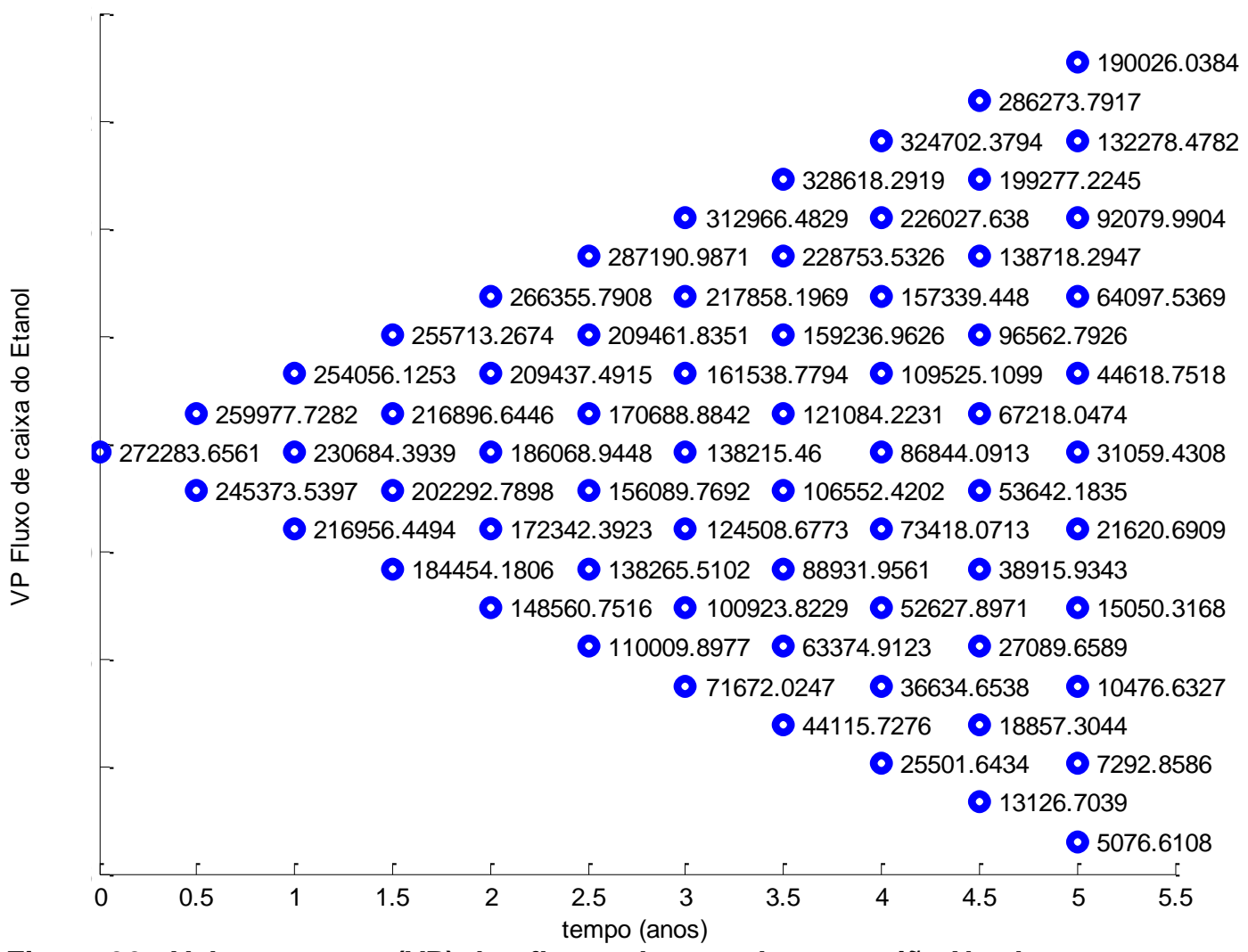

Figura 30 - Valor presente (VP) dos fluxos do etanol para região Nordeste

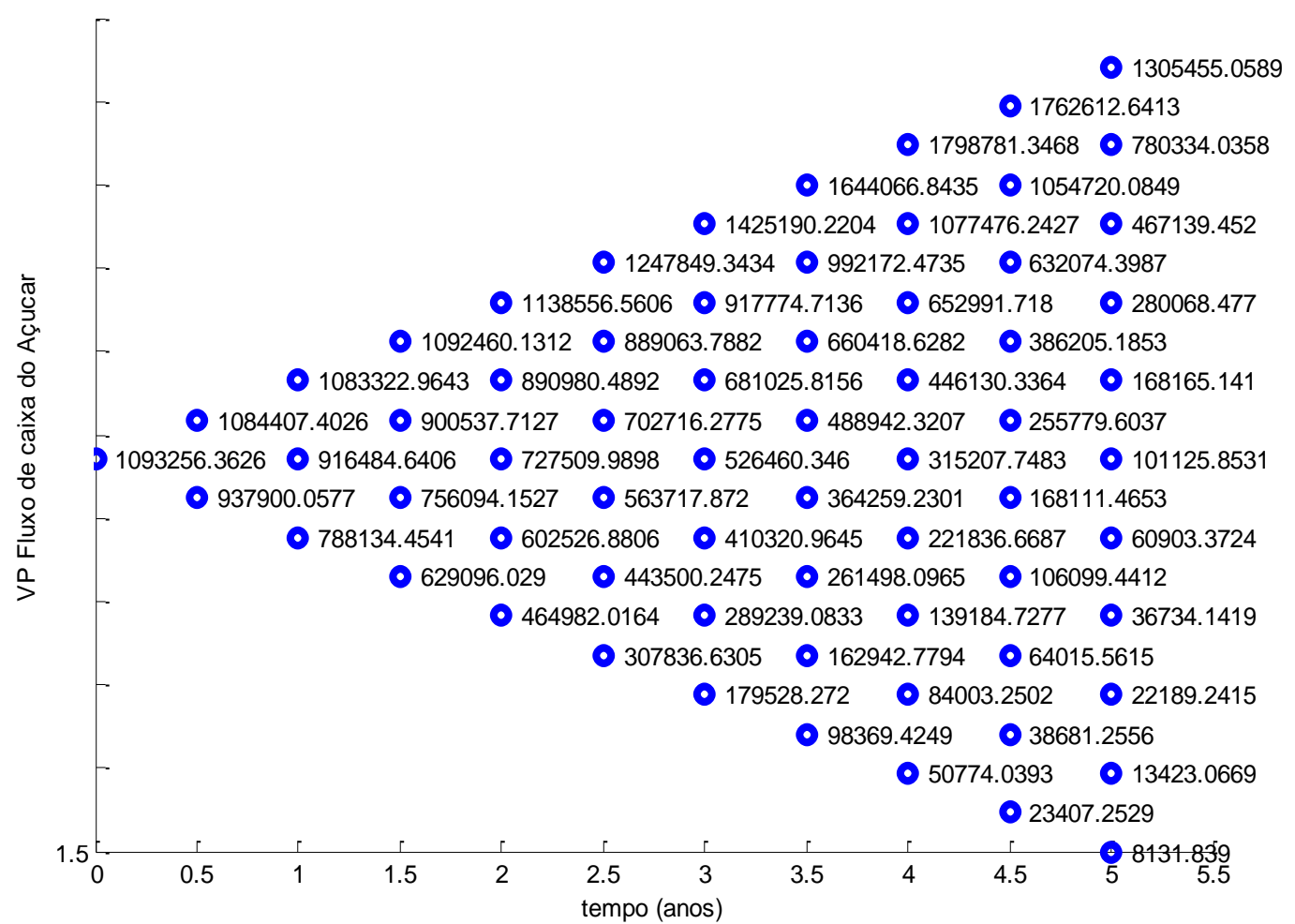

Figura 31 - Valor presente (VP) dos fluxos do açúcar para região Sudeste 


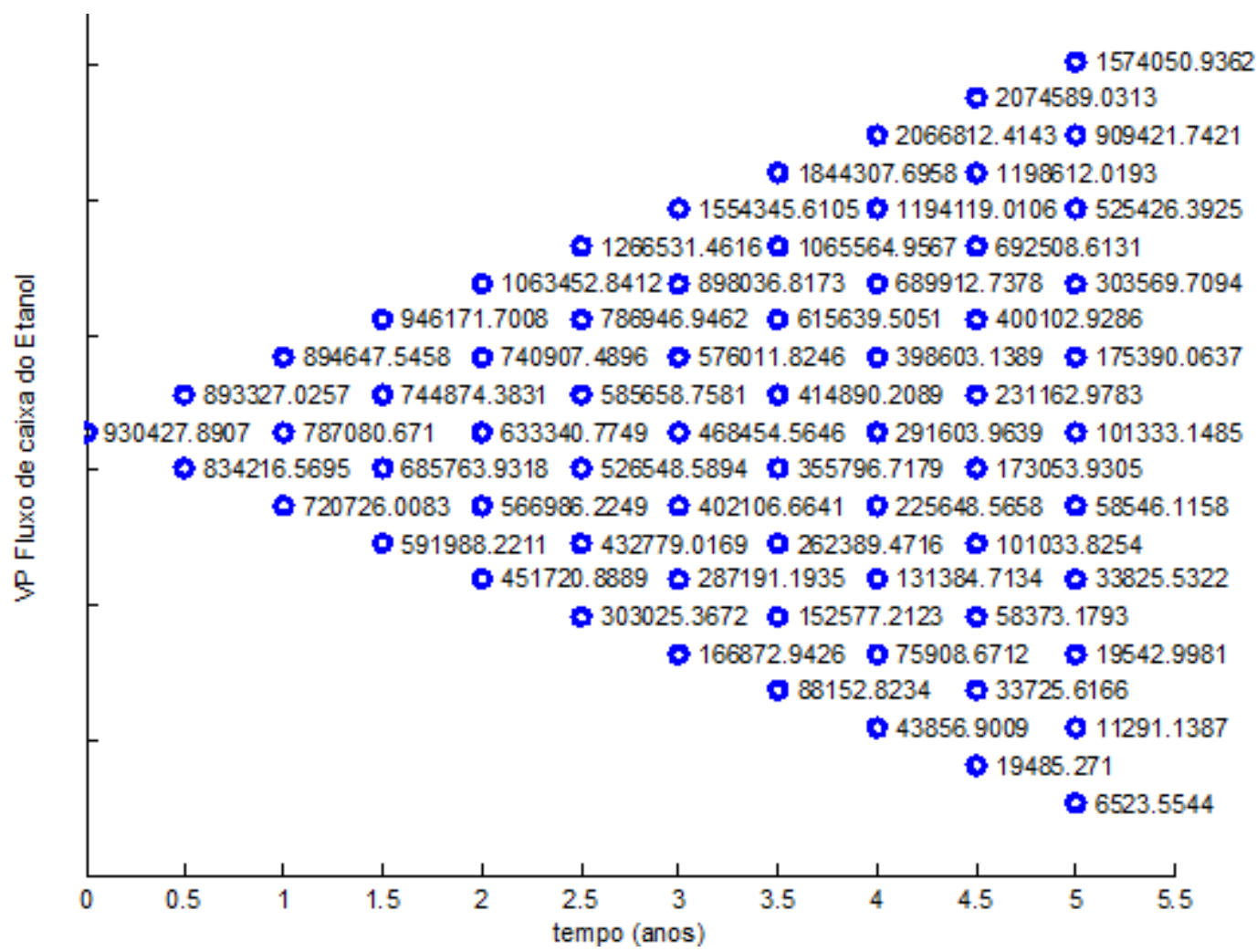

Figura 32 - Valor presente (VP) dos fluxos do etanol para região Sudeste 